\title{
Wildlife Management Plan for the Oak Ridge Reservation
}

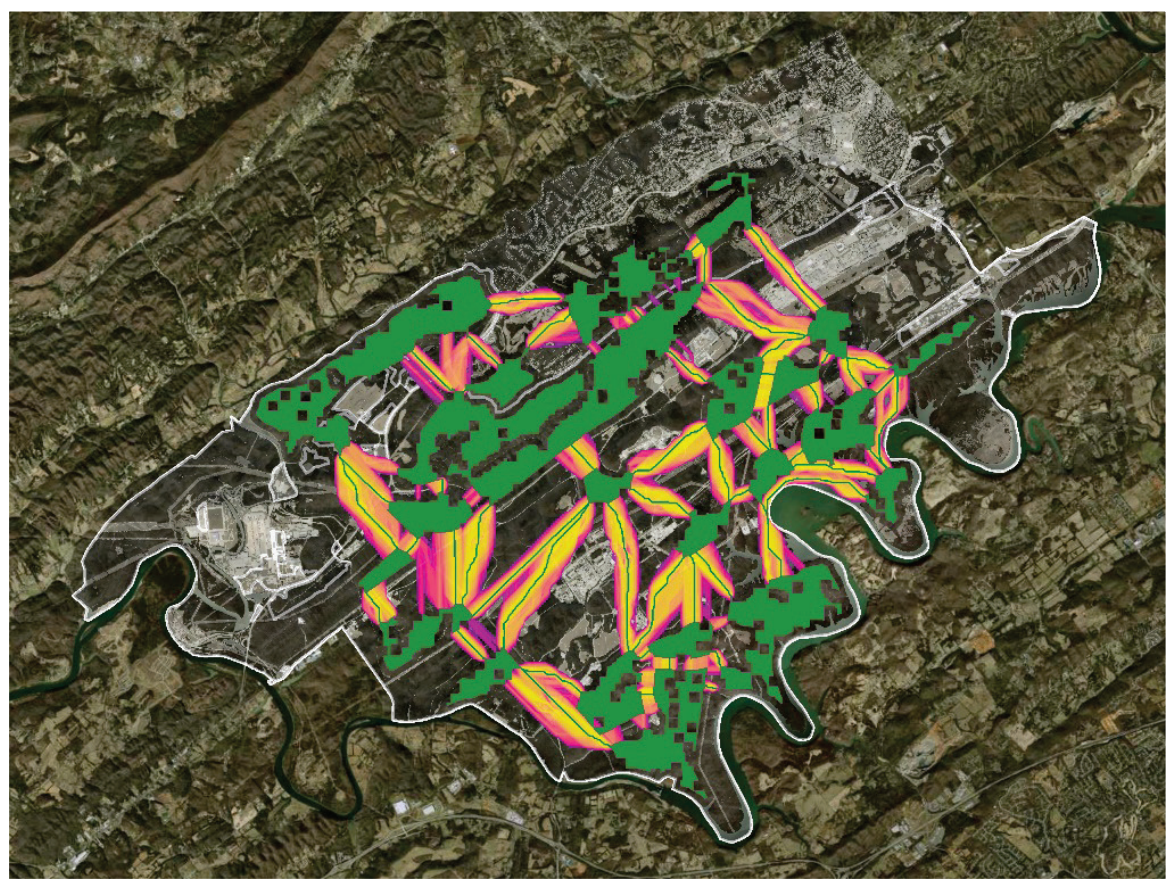

Evin Carter Neil R. Giffen Kitty McCracken Sarah E. Darling Aubrey Deck Greg Byrd

October 2019

Approved for public release.

Distribution is unlimited. 


\section{DOCUMENT AVAILABILITY}

Reports produced after January 1, 1996, are generally available free via US Department of Energy (DOE) SciTech Connect.

Website www.osti.gov

Reports produced before January 1, 1996, may be purchased by members of the public from the following source:

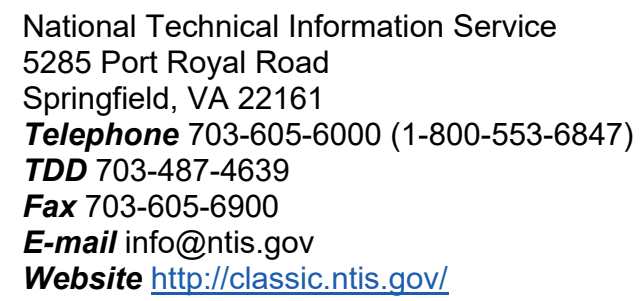

Reports are available to DOE employees, DOE contractors, Energy Technology Data Exchange representatives, and International Nuclear Information System representatives from the following source:

Office of Scientific and Technical Information

PO Box 62

Oak Ridge, TN 37831

Telephone 865-576-8401

Fax 865-576-5728

E-mail reports@osti.gov

Website http://www.osti.gov/contact.html

This report was prepared as an account of work sponsored by an agency of the United States Government. Neither the United States Government nor any agency thereof, nor any of their employees, makes any warranty, express or implied, or assumes any legal liability or responsibility for the accuracy, completeness, or usefulness of any information, apparatus, product, or process disclosed, or represents that its use would not infringe privately owned rights. Reference herein to any specific commercial product, process, or service by trade name, trademark, manufacturer, or otherwise, does not necessarily constitute or imply its endorsement, recommendation, or favoring by the United States Government or any agency thereof. The views and opinions of authors expressed herein do not necessarily state or reflect those of the United States Government or any agency thereof. 
Natural Resources Management Program

\title{
WILDLIFE MANAGEMENT PLAN FOR THE OAK RIDGE RESERVATION
}

\author{
Evin Carter ${ }^{1}$ \\ Neil R. Giffen ${ }^{2}$ \\ Kitty McCracken ${ }^{1}$ \\ Sarah E. Darling ${ }^{2}$ \\ Aubrey Deck ${ }^{3}$ \\ Greg Byrd ${ }^{2}$
}

\footnotetext{
${ }^{1}$ Environmental Sciences Division, Oak Ridge National Laboratory

${ }^{2}$ Facilities and Operations Directorate, Oak Ridge National Laboratory

${ }^{3}$ Tennessee Wildlife Resources Agency
}

October 2019

Prepared by

OAK RIDGE NATIONAL LABORATORY

Oak Ridge, TN 37831-6283

managed by

UT-BATTELLE, LLC

for the

US DEPARTMENT OF ENERGY

under contract DE-AC05-00OR22725 



\section{CONTENTS}

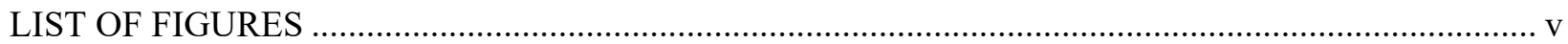

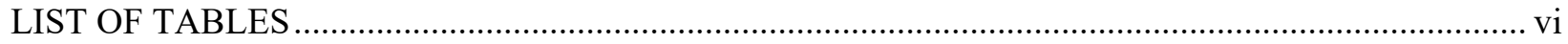

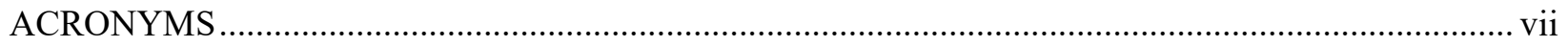

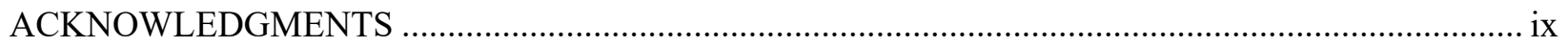

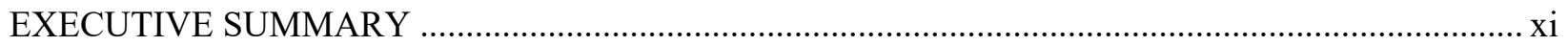

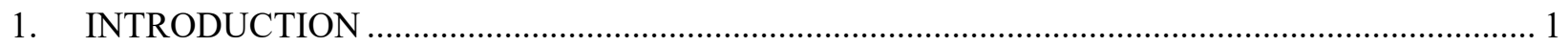

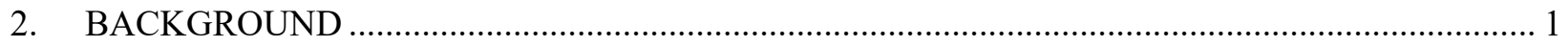

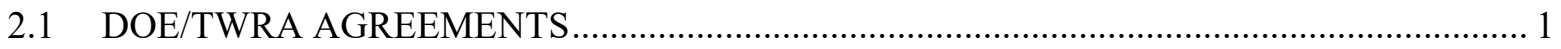

2.2 LEGISLATIVE AND REGULATORY REQUIREMENTS FOR WILDLIFE

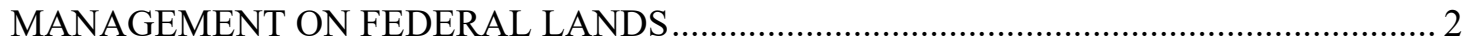

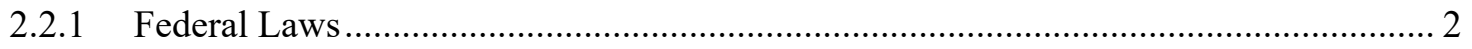

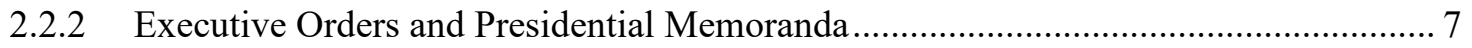

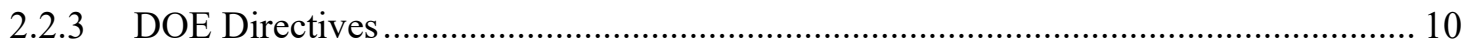

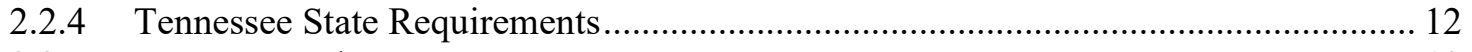

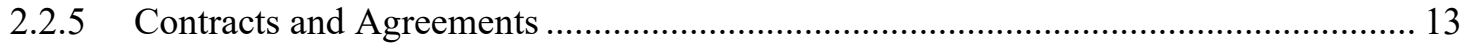

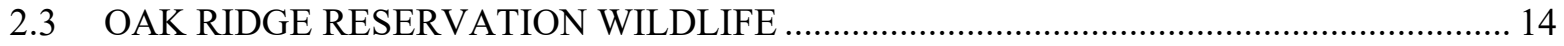

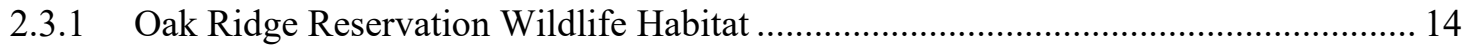

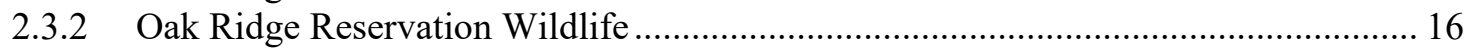

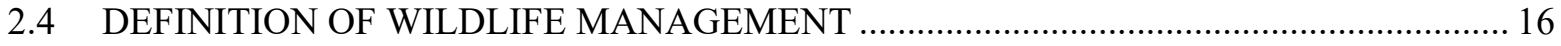

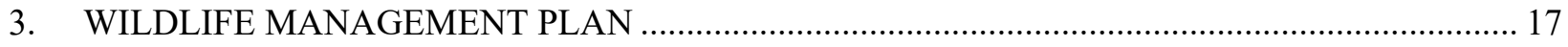

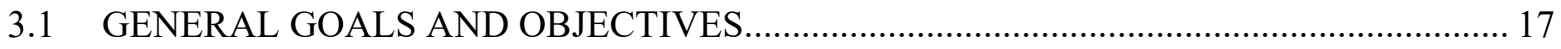

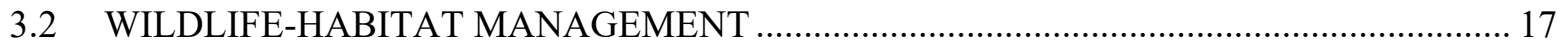

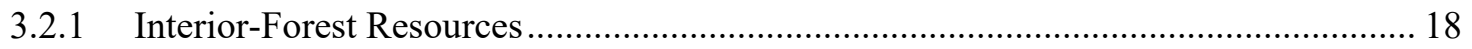

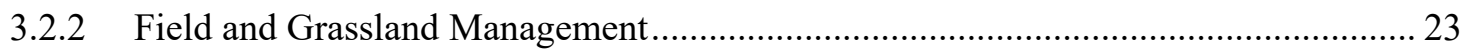

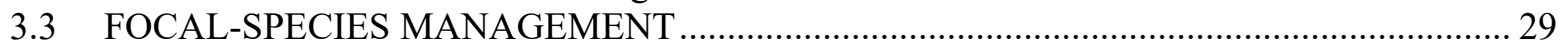

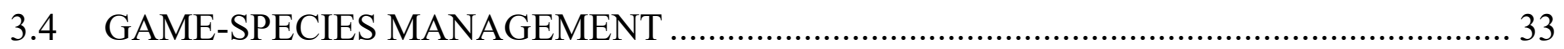

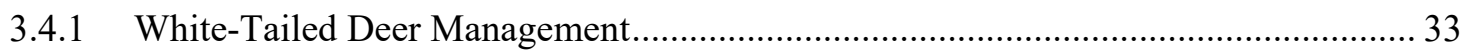

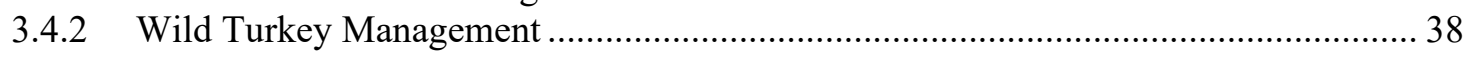

3.4.3 Canada Goose Management ..................................................................................... 41

3.5 MANAGEMENT OF THE THREE BEND SCENIC AND WILDLIFE

3.6 NUISANCE WILDLIFE MANAGEMENT ........................................................... 42

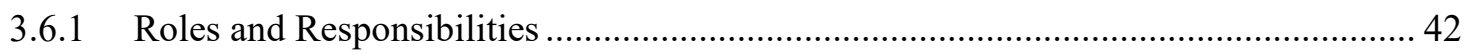

3.6.2 Protocol for Reducing Nuisance Wildlife Problems ............................................... 43

3.6.3 Nuisance Wildlife Management Issues around Facilities ....................................... 44

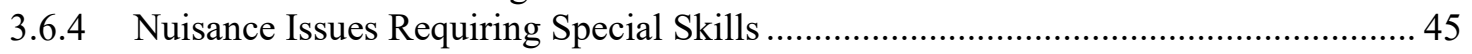

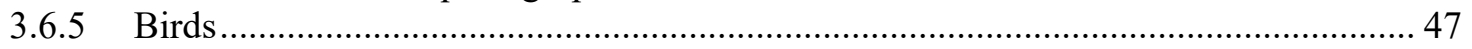

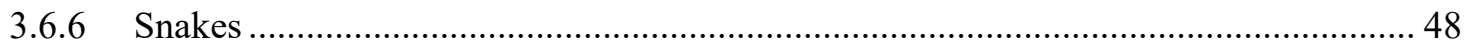

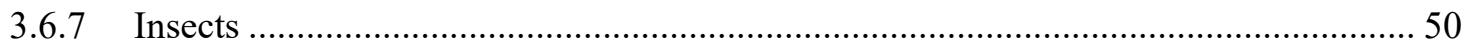

3.7 SENSITIVE SPECIES INVENTORY, PROTECTION, AND MANAGEMENT ...................50

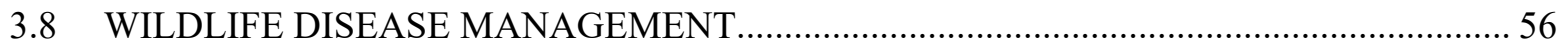

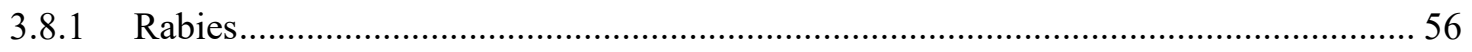

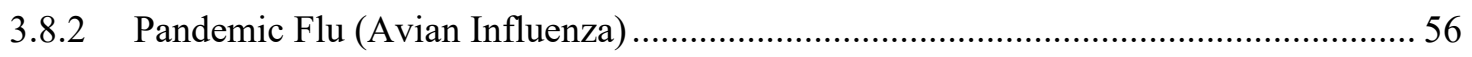

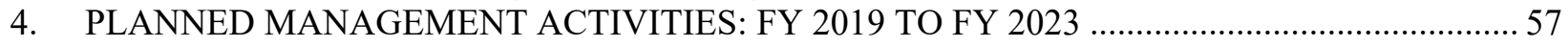

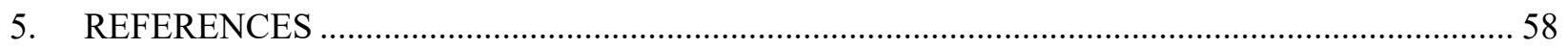

APPENDIX A. MEMORANDUM OF UNDERSTANDING BETWEEN THE UNITED STATES

FISH AND WILDLIFE SERVICE, DEPARTMENT OF THE INTERIOR, AND THE

DEPARTMENT OF ENERGY REGARDING IMPLEMENTATION OF EXECUTIVE 
ORDER 13186, "RESPONSIBILITIES OF FEDERAL AGENCIES TO PROTECT

MIGRATORY BIRDS” AND SELECTED PORTIONS OF EXECUTIVE ORDER 13186..........A-1 APPENDIX B. SELECTED PORTIONS OF DOE ORDER 450.1, ENVIRONMENTAL

PROTECTION PROGRAM, CHANGE 2 (DECEMBER 7, 2005). B-1 APPENDIX C. OUTLINE OF SELECTED PARTS OF THE TENNESSEE LAWS RELATED

TO WILDLIFE C-1 APPENDIX D. VERTEBRATE WILDLIFE SPECIES OF THE OAK RIDGE RESERVATION ........ D-1 APPENDIX E. DEFINITION OF WILDLIFE MANAGEMENT . E-1 APPENDIX F. WILDLIFE MANAGEMENT ACTIVITIES FISCAL YEAR 1983 THROUGH F-1 


\section{LIST OF FIGURES}

Figure 1. Forest types on the ORR

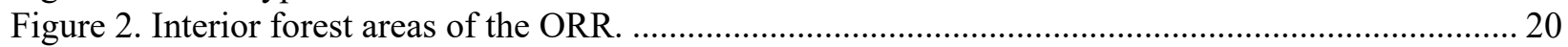

Figure 3. Interior forest in the Walker Branch Watershed on the ORR .............................................. 21

Figure 4. Interior forest in an old-growth area on the ORR............................................................. 22

Figure. 5. Controlled burn of switchgrass field at East Tennessee Technology Park, February 25,

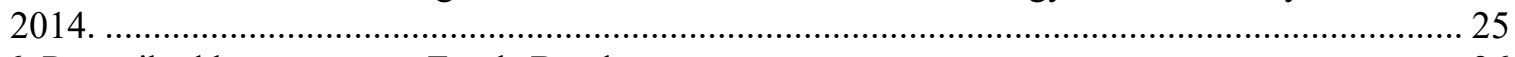

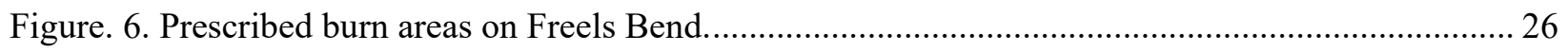

Figure. 7. Prescribed burn at Freels Bend as viewed from the air in September 2019.......................... 27

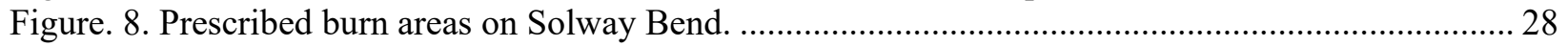

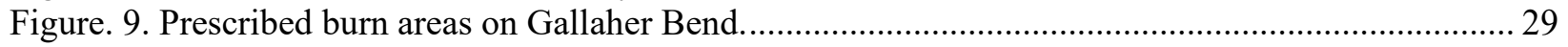

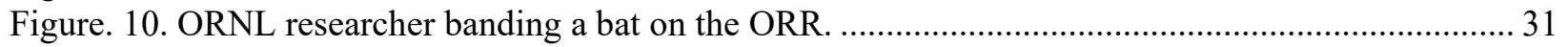

Figure. 11. Wildlife Acoustics SM4Bat acoustic monitor and high-frequency microphone used by

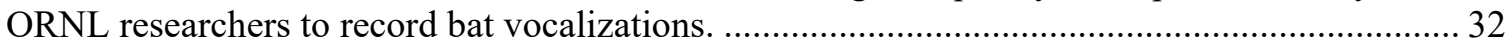

Figure. 12. First documented bald eagle nest on the ORR (April 2011)............................................... 32

Figure. 13. Number of deer/vehicle collisions on the ORR and vicinity, as obtained from the Oak Ridge Police Department, each year from 1978-2018 ............................................................... 34

Figure 14. Historical white-tailed deer harvest for the ORR from 1985-2018 ................................... 35

Figure 15. University of Tennessee student displays buck for aging analysis for TWRA and

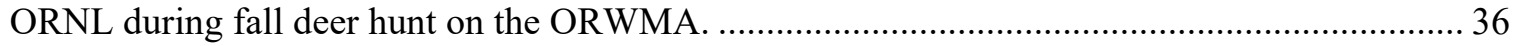

Figure 16. Former TWRA ORWMA Manager Aubrey Deck demonstrates to students how to age

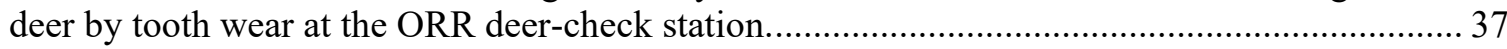

Figure 17. University of Tennessee Student Chapter of the Wildlife Society students measure

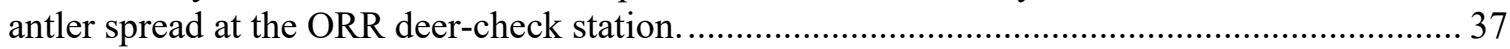

Figure 18. Sodium iodide detectors at the ORR deer-check station used to measure gamma

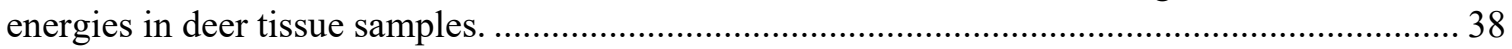

Figure 19. Beta scintillation detector (Ludlum probe) at the ORR deer-check station used to

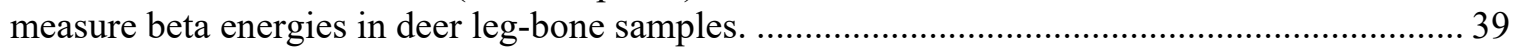

Figure 20. ORNL employee measures spur of harvested turkey at the ORWMA check station................ 39

Figure 21. Turkey leg is analyzed for beta energies using beta scintillation detector (Ludlum

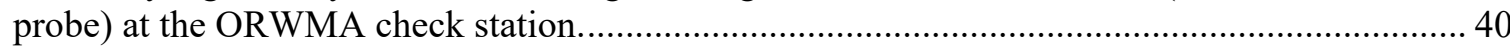

Figure 22. Readout from sodium iodide detector is evaluated for gamma energies from turkey

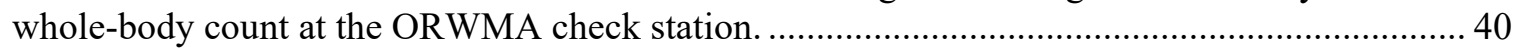

Figure 23. Historical wild turkey harvested and retained numbers for the ORR from 1997-2018........... 41

Figure 24. Raccoons removed after being found in a dumpster at ORNL.............................................. 44

Figure 25. Black bear trapped at the HFIR facility at ORNL (June 2012) ............................................ 46

Figure 26. Number of eggs addled/removed during yearly ORR Canada goose nest checks, 2005-

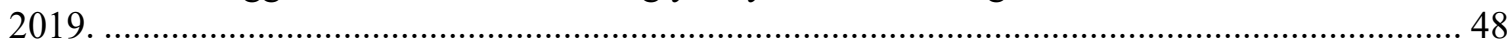

Figure 27. Number of Canada geese captured during yearly summer roundups on the ORR, 20052019 . 48

Figure 28. Northern water snake found in a pump house reservoir at ORNL. 49

Figure 29. ORR Wildlife Technician Sarah Darling and Researcher Liz Znidersic setting up an Acoustic Recording Device at a beaver pond on the ORR. 55 


\section{LIST OF TABLES}

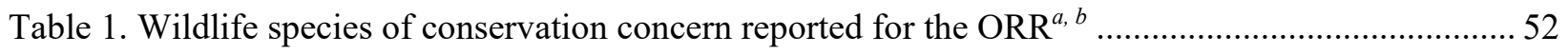




\section{ACRONYMS}

\begin{tabular}{|c|c|}
\hline $\mathrm{AEC}$ & Atomic Energy Commission \\
\hline APHIS & Animal and Plant Health Inspection Service \\
\hline CERCLA & Comprehensive Environmental Response, Compensation, and Liability Act \\
\hline CEQ & Council on Environmental Quality \\
\hline CFR & Code of Federal Regulations \\
\hline CRD & contractor requirements document \\
\hline DOE & US Department of Energy \\
\hline EMS & environmental management system \\
\hline EPA & Environmental Protection Agency \\
\hline ESA & Endangered Species Act \\
\hline FR & Federal Register \\
\hline FWCA & Fish and Wildlife Coordination Act \\
\hline FY & fiscal year \\
\hline HFIR & High-Flux Isotope Reactor \\
\hline ISMS & Integrated Safety Management System \\
\hline MBTA & Migratory Bird Treaty Act \\
\hline MOU & memorandum of understanding \\
\hline NEPA & National Environmental Policy Act \\
\hline NMFS & National Marine Fisheries Service \\
\hline ORNL & Oak Ridge National Laboratory \\
\hline ORR & Oak Ridge Reservation \\
\hline ORWMA & Oak Ridge Wildlife Management Area \\
\hline PIF & Partners in Flight \\
\hline QDM & quality deer management \\
\hline$T \& E$ & Threatened and Endangered \\
\hline TCA & Tennessee Code Annotated \\
\hline TDEC & Tennessee Department of Environment and Conservation \\
\hline TWRA & Tennessee Wildlife Resources Agency \\
\hline USC & United States Code \\
\hline USDA & US Department of Agriculture \\
\hline USFWS & US Fish and Wildlife Service \\
\hline UT & University of Tennessee \\
\hline WMA & Wildlife Management Area \\
\hline
\end{tabular}





\section{ACKNOWLEDGMENTS}

In addition to the authors listed on the cover of this report, several individuals have contributed to the continual development of this document. They have made significant contributions to conception or development but no longer make written contributions and/or have significantly influenced the plan through intellectual contribution but not writing. The authors wish to acknowledge Shannon Young, W. Kelly Roy, J. E. Evans, Pat Parr, Jamie Herold, and Chris DeRolph for their contributions in these areas. The authors also thank DOE Reservation Management for their continuing support. 



\section{EXECUTIVE SUMMARY}

This document outlines a plan for management of the wildlife resources on the US Department of Energy's (DOE's) Oak Ridge Reservation. Management includes wildlife population control through restoration of wildlife species; preservation, management, and enhancement of wildlife habitats; coordination of wildlife studies and characterization of areas, hunting, trapping, removal, and habitat manipulation; wildlife damage control; and law enforcement. Wildlife resources are divided into several categories, each with a specific set of objectives and procedures to attain the goals. These objectives are management of (1) wildlife habitats to ensure that all resident wildlife species exist on the Reservation in viable numbers; (2) focal species to promote healthy populations on designated land units; (3) game species for research, education, recreation, and public safety; (4) the Three Bend Scenic and Wildlife Management Refuge Area; (5) nuisance wildlife, including nonnative species, to achieve adequate population control for the maintenance of health and safety on the Reservation; (6) sensitive species (i.e., state or federally listed as Endangered, Threatened, Of Special Concern, or In Need of Management) through preservation and protection of both the species and habitats critical to the survival of those species; and (7) wildlife disease. Achievement of the objectives is a joint effort between Oak Ridge National Laboratory and the Tennessee Wildlife Resources Agency (TWRA) through agreements between DOE and the University of Tennessee (UT)-Battelle LLC, between TWRA and DOE, and between Tennessee Department of Environment and Conservation (TDEC) and DOE. Implementation of objectives is to be informed by leading-edge research and a strong collaborative approach between UTBattelle and TWRA. 



\section{INTRODUCTION}

The 32,208-acre (13,438-ha) Oak Ridge Reservation (ORR) was designated a Wildlife Management Area (WMA) on November 30, 1984, through a cooperative agreement between the Tennessee Wildlife Resources Agency (TWRA) and the US Department of Energy (DOE) Oak Ridge Office.

This management plan (1) describes wildlife management on the ORR/WMA and (2) establishes longterm wildlife goals, with specific objectives for fiscal years (FYs) 2019 through 2023. This document updates and replaces previous versions of the Wildlife Management Plan for the ORR (Giffen, Evans, and Parr 2012; Giffen, Evans, and Parr 2007).

Management of wildlife on an area as large as the ORR is necessary to ensure public safety (e.g., reduce deer/vehicle collisions, reduce nuisance wildlife-human interactions) and to attempt to optimize wildlife health and diversity. Maintaining important habitat is essential to the preservation of all species. Characterizing habitat and understanding wildlife requirements are necessary to make decisions that could affect species or habitats and to evaluate the potential impacts of proposed activities. Information on the species and habitat types present, wildlife diversity, and protected habitat locations is also essential in land-use planning and decision-making. Additionally, information collected through the wildlife program will be used in regional forest and wildlife management throughout the state.

This document provides the framework for compliance with state and federal laws in place for the protection and management of wildlife populations on federal lands. In following the guidelines of a formal wildlife management plan, DOE shows that it recognizes the importance of protecting, managing, and enhancing wildlife populations. Furthermore, the establishment of a formal plan provides the basis for DOE to comply with guidelines and regulations pertaining to wildlife populations. Active management and regular surveys of wildlife populations on the ORR attest to DOE's commitment to the protection of these populations, as is required under the applicable statutes.

\section{BACKGROUND}

\subsection{DOE/TWRA AGREEMENTS}

The cooperative agreement of November 30, 1984, between DOE and TWRA was renewed for an additional 5 years on December 1, 1989. It was renewed as a license agreement for an additional 2 years on December 1, 1994, and every 5 years from November 1996 to November 2016.

TWRA has the responsibility to provide Wildlife Officers/Managers for enforcing Tennessee game and fish laws, rules, and regulations. TWRA also agrees, consistent with the government's programmatic use of lands, to carry out other wildlife-oriented projects and to develop the area for wildlife species by the application of scientific management techniques that are compatible with good land use practices and in coordination with the ORR Wildlife Ecologist and/or appointed designee (e.g., ORR Wildlife Technician). The ORR Wildlife Ecologist coordinates with TWRA on planned activities to facilitate a variety of wildlife management programs, as directed by the Oak Ridge National Laboratory (ORNL) Natural Resources Manager, DOE Reservation Management Branch Chief, and DOE Reservation Manager or designee. 


\subsection{LEGISLATIVE AND REGULATORY REQUIREMENTS FOR WILDLIFE MANAGEMENT ON FEDERAL LANDS}

DOE is committed to wildlife management and conservation. The department works not only with TWRA but also with the US Fish and Wildlife Service (USFWS), US Department of Agriculture Animal and Plant Health Inspection Service (USDA-APHIS), and other agencies to be a good steward of its land and the natural resources on it.

Several regulatory requirements direct DOE's wildlife management on the ORR, including

- federal laws, executive orders, and presidential memoranda;

- DOE directives (e.g., orders, guidance);

- Tennessee state laws and regulations; and

- contracts and agreements for managing DOE sites.

Some of these items directly require protection and management of wildlife, while others indirectly protect them through requirements to protect the ecosystems or habitats they use or to manage invasive species that might compete with them.

\subsubsection{Federal Laws}

A number of federal laws require or encourage federal agencies to actively manage natural resources, including wildlife, on their lands. Most of these laws are implemented through enforceable regulations that DOE must follow. (Summaries of some of these laws and their implementing regulations are available on the DOE headquarters website.)

The following laws are listed in chronological order of their initial passage by Congress. Each law has been amended at least once. The following discussions reflect the most recent versions of each law, including amendments.

\subsubsection{Migratory Bird Treaty Act}

The Migratory Bird Treaty Act (MBTA) (Title 16, United States Code [USC], Sects. 703-712) of 1918 implements treaties - signed by the United States, Canada, Japan, Mexico, and the former Soviet Unionfor the protection of shared migratory bird resources. The act protects migratory birds by governing the taking, killing, possession, transportation, and importation of such birds; their eggs, parts, and nests; and any product, manufactured or not, from such items.

The USFWS has developed a list of migratory birds that are protected under this act (USFWS 2011). The list can be found in Title 50, Code of Federal Regulations (CFR), Part 10.13, or at http://www.gpo.gov/fdsys/pkg/FR-2010-03-01/pdf/2010-3294.pdf. (The latter list provides updated scientific and common names that conform to the most recent taxonomy, with cross references to the names in the CFR list.)

The USFWS has also published a list of 125 bird species (Title 70, Federal Register [FR], Part 12710, March 15, 2005, available at http://migratorybirds.USFWS.gov) that are not native to the United States and, therefore, are not protected under the MBTA. 


\subsubsection{Fish and Wildlife Coordination Act}

The Fish and Wildlife Coordination Act (FWCA) (16 USC 661-667e) of 1934 recognizes the vital contribution of wildlife resources, both animals and plants, to the nation. The act requires federal agencies to consult with the USFWS and appropriate state wildlife agencies when they plan to conduct any activity involving the impoundment, diversion, deepening, control, or modification of a body of water. It requires equal consideration and coordination be given to conservation of fish and wildlife as to other waterresource values during project planning involving water bodies larger than 10 acres (4 ha). Federal agencies must assess the impacts of their planned activity on wildlife resources and modify project plans by justifiable means and measures to prevent loss or damage to those resources. Reports and recommendations prepared by these agencies are to document project effects on wildlife and identify measures that can be adopted to prevent loss or damage to wildlife resources.

The FWCA authorizes the secretaries of Agriculture and Commerce to aid and cooperate with federal and state agencies to protect, rear, stock, and increase the supply of game and fur-bearing animals. The FWCA also directs the secretaries to study the effects of polluting substances (e.g., domestic sewage; mine, petroleum, and industrial wastes; silt from erosion) on wildlife. In addition, this act authorizes the preparation of plans to protect wildlife resources, completion of wildlife surveys on any public lands, and use of surplus federal property for wildlife conservation purposes.

\subsubsection{Bald Eagle Protection Act}

The Bald Eagle Protection Act (16 USC 668-668d) of 1940 protects bald and golden eagles by prohibiting, except under certain specified conditions, the taking or possession of and commerce in such birds. (Although the short title of the act mentions only bald eagles, its provisions also apply to golden eagles.) The act imposes criminal and civil penalties on anyone who, unless exempted, takes; possesses; sells; purchases; barters; offers to sell, purchase, or barter; transports; exports; or imports at any time or in any manner a bald or golden eagle, alive or dead, or any part, nest, or egg of those eagles. "Take" means to pursue, shoot, shoot at, poison, wound, kill, capture, trap, collect, molest, or disturb. "Transport" means to convey or carry by any means or to deliver or receive for conveyance.

\subsubsection{Sikes Act}

The Sikes Act (16 USC 670a-670o) of 1960 calls for cooperation with state fish and game agencies in planning and managing wildlife habitat on federal lands. This act is particularly relevant to wildlife management on the ORR, because it specifically mentions what are now lands controlled by DOE. It states that the "Secretary of the Interior shall develop, with the prior written approval of the Atomic Energy Commission (AEC) [now a part of DOE], a comprehensive plan for conservation and rehabilitation programs to be implemented on public land under the jurisdiction of the Chairman" of the AEC (now the secretary of DOE). "Each such plan shall be developed after the Secretary of the Interior makes, with the prior written approval of the Chairman ... and in consultation with the state agencies, necessary studies and surveys of the land concerned to determine where conservation and rehabilitation programs are most needed." The act further states that "each comprehensive plan developed ... shall be consistent with any overall land-use and management plans for the lands involved." Programs shall include, but not be limited to, specific habitat-improvement projects and related activities that provide adequate protection for species of fish, wildlife, and plants considered threatened or endangered.

The phrase "public land" includes all lands under the jurisdiction of DOE. The phrase "conservation and rehabilitation programs" means to "... utilize those methods and procedures which are necessary to protect, conserve, and enhance wildlife, fish, and game resources to the maximum extent practicable ... consistent with any overall land-use and management plans for the lands involved." 


\subsubsection{National Environmental Policy Act}

The National Environmental Policy Act (NEPA) (42 USC 4321-4347) of 1969 declares that it is a national policy to encourage productive and enjoyable harmony between people and the environment and to promote efforts to better understand and prevent damage to ecological systems and natural resources that are important to the nation. In the act, Congress states that it is the continuing responsibility of the federal government to use all practicable means to create and maintain conditions under which people and nature can exist in productive harmony and to fulfill the social, economic, and other requirements of present and future generations.

NEPA requires all federal agencies to consider the effects of their actions on the environment; employ an interdisciplinary approach in decision-making; and develop means to ensure that unquantified environmental values are given appropriate consideration, along with the economic and technical aspects of the actions. Thus, when DOE proposes an action, it must develop a NEPA document (e.g., categorical exclusion, environmental assessment, environmental impact statement) to consider the potential impacts. Compliance with several other wildlife conservation acts (e.g., the Endangered Species Act [ESA], FWCA) is often integrated with NEPA implementation.

Additionally, 10 CFR 1021 establishes procedures that DOE shall use to comply with Section 102(2) of NEPA (42 U.S.C. 4332(2)) and the Council on Environmental Quality (CEQ) regulations for NEPA implementing procedures (40 CFR parts 1500-1508). 10 CFR 1021 states that... "it is DOE's policy to follow the letter and spirit of NEPA; comply fully with the CEQ Regulations; and apply the NEPA review process early in the planning stages for DOE proposals." It should be noted that a DOE action, as defined in 40 CFR 1508.18, is any action that is subject to DOE's control and responsibility. 10 CFR 1021, DOE implementing procedures, can be found at https://www.energy.gov/nepa/downloads/10-cfr-1021-nationalenvironmental-policy-act-implementing-procedures-doe-2011. These procedures are to be used in conjunction with the CEQ regulations in 40 CFR parts 1500-1508, which can be found at https://ceq.doe.gov/laws-regulations/regulations.html.

Additional guidance and requirements most relevant to DOE can be found at https://www.energy.gov/nepa/nepa-guidance-requirements.

\subsubsection{Endangered Species Act}

The purpose of the ESA (16 USC 1531-1544) of 1973 is to preserve plants and animals facing extinction. It mandates the conservation of proposed and listed Threatened and Endangered (T\&E) species and the designated critical habitats supporting them. The act prohibits the harm, harassment, trade, or capture of endangered species and provides for the protection of threatened species. The USFWS ${ }^{1}$ maintains lists of designated T\&E species in 50 CFR 17 and updates them as needed.

Section 7 of the ESA requires all federal agencies, including DOE, to ensure that any action they authorize, fund, or carry out does not jeopardize the continued existence of T\&E species or result in the destruction or adverse modification of designated critical habitats that are important in conserving those species. The USFWS and National Marine Fisheries Service (NMFS) have established informal and formal consultation procedures in 50 CFR 402, "Consultation by Federal Agencies," that implement this section of the act.

If DOE proposes an action on the ORR and if no previous NEPA documentation exists for the area involved in any alternative under consideration, a biological survey and evaluation might be required to

\footnotetext{
${ }^{1}$ The USFWS shares responsibility for administering the ESA with the NMFS in the Department of Commerce. NMFS is responsible for only marine species; therefore, that agency would not be involved in any T\&E species consultations on the ORR.
} 
determine whether any T\&E species are or could be present. Initial consultation with the USFWS can take from 30 to 45 days. However, field surveys, if required, could extend in excess of 1 year to identify seasonal issues. If a listed T\&E species might be affected by the action, a detailed biological assessment of potential impacts can be prepared independently or concurrently with the NEPA document and included as an appendix to that document. A biological opinion issued by the USFWS at the conclusion of consultation can include a statement authorizing take of a T\&E species that might occur incidental to an otherwise legal activity.

Section 7(a) of the act requires federal agencies to use their authorities to further the purposes of the act by carrying out programs to conserve listed T\&E species. Section 9 lists actions that are prohibited under the act, including damaging or destroying endangered plants on federal lands or taking a listed species unless such taking is incidental to an otherwise legal activity and has been specifically allowed.

The USFWS's Environmental Online Conservation System provides the Information for Planning and Consultation tool to assist with ESA consultation and planning. This tool shall serve as a supplement to, not a replacement for, on-the-ground assessments for actions that are suspected to impact natural resources on the ORR. Importantly, the tool is based on the USFWS's current knowledge of species occurrence records, which is not exhaustive. Moreover, it omits important information regarding sensitive and critical habitats and resources that are subject to state and local laws and regulations. The Information for Planning and Consultation tool can be found at https://ecos.fws.gov/ipac/.

\subsubsection{Federal Noxious Weed Act}

The Federal Noxious Weed Act (7 USC 2814²) of 1974 requires each federal land-managing agency to establish integrated management systems to control or contain undesirable plant species targeted under cooperative agreements with state agencies. Such systems are to be developed using an interdisciplinary approach that can include general land management practices such as manipulating wildlife grazing strategies or improving wildlife habitat. The interdisciplinary approach should include participation by personnel with experience in wildlife biology and consider the ecological consequences of implementing the program. The Invasive Plant Management Plan for the Oak Ridge Reservation (Parr et al. 2004, Quarles et al. 2011, McCracken and Giffen 2017) implements this protection for wildlife on the ORR.

\subsubsection{Fish and Wildlife Conservation Act}

The FWCA (16 USC 2901-2912) of 1980 is commonly known as the "Nongame Act." The purpose of the act is to provide financial and technical assistance to states for the development, revision, and implementation of conservation plans and programs for nongame fish and wildlife. It encourages federal agencies, such as DOE, to use their statutory and administrative authority to protect and promote the conservation of nongame fish and wildlife and their habitats.

\subsubsection{Comprehensive Environmental Response, Compensation, and Liability Act}

The purpose of the Comprehensive Environmental Response, Compensation, and Liability Act (CERCLA) of 1980 (also referred to as "Superfund") (42 USC 9601 et seq.) is to clean up sites contaminated by hazardous-substance releases and ensure that the public is compensated for naturalresource injuries caused by such releases. The act designates the president of the United States as the trustee on behalf of the public for federally protected or managed natural resources. This responsibility has been delegated to federal agencies, including DOE. (See Section 2.2.2.2, "Executive Order 12580:

\footnotetext{
${ }^{2}$ Sections 2801-2813 were repealed by Pub. L. 106-224, June 20, 2000.
} 
Superfund Implementation.") The act defines natural resources as "land, fish, wildlife, biota, air, water, groundwater, drinking supplies, and other such resources."

As a natural-resource trustee for land it manages, DOE has a broad responsibility for such natural resources under its jurisdiction. ${ }^{3}$ After notification or discovery of a natural-resource injury, loss, or threat, DOE will take appropriate actions (DOE 1993). These actions can include conducting a preliminary survey of areas affected by a discharge or release to determine whether natural resources are or might be impacted; cooperating with the on-scene Coordinator/Regional Project Manager in coordinating assessments, investigations, and planning; and carrying out a plan for restoration, rehabilitation, replacement, or acquisition of equivalent natural resources.

DOE, as a natural-resource trustee, can assess damages “... for injury to, destruction of, or loss of natural resources ..." following a release of hazardous substances. Assessments are made on the basis of "residual" injury that was not or could not be addressed by the selected remedy. Damages to natural resources can occur through both the release of hazardous substances and through the cleanup remedy itself. Restoration actions are meant to return affected resources to baseline conditions and may compensate the public for all losses until baseline conditions are restored.

In addition to documentation from the Office of Environmental Guidance (DOE 1993), the Federal Facility Agreement between DOE, the Tennessee Department of Environment and Conservation (TDEC), and the Environmental Protection Agency (EPA) provides guidance on the CERCLA process that is specific to the ORR, including timelines and identification of Applicable or Relevant and Appropriate Requirements (ARARs). Although some or all ARARs can be waived because of the inherent remedial action of CERCLA, such waivers must be justified and agreed upon in writing by all three parties. The Federal Facility Agreement can be found at https:/www.energy.gov/sites/prod/files/2014/03/f8/

Oak Ridge FFA.pdf. TDEC makes available online most communication and records of decision for all CERCLA actions in Tennessee.

\subsubsection{North American Wetlands Conservation Act}

Section 4408 of the North American Wetlands Conservation Act (16 USC 4401-4414) of 1989 requires the head of each federal agency responsible for federal lands and waters to cooperate with the director of the USFWS to restore, protect, and enhance the wetland ecosystems and other habitats for migratory birds, fish, and wildlife within the lands and waters of the agency.

\subsubsection{Other Laws}

DOE and its operating contractors are also subject to laws and regulations pertaining to radiation (e.g., the Atomic Energy Act) and contaminants regulated under other laws (e.g., the Resource Conservation and Recovery Act and the Toxic Substances Control Act) that are present on its lands as a result of past and continuing activities. Although this plan is not intended to deal with such issues, where relevant, reference will be made to such contaminants in wildlife and their impacts.

\footnotetext{
${ }^{3}$ A guidance document has been prepared to assist DOE program and field organizations in understanding and meeting their natural-resource-trustee responsibilities, Integrating Natural Resource Damage Assessment and Environmental Restoration Activities at DOE Facilities (DOE 1993). Other guidance on natural resource damage assessment can be found under the "Policy and Guidance" button on the DOE Environmental Policy and Guidance website (http://homer.ornl.gov/oepa/).
} 


\subsubsection{Executive Orders and Presidential Memoranda}

Executive orders and presidential memoranda also provide direction to DOE in managing its lands. The following summaries cover those that pertain, directly or indirectly, to wildlife management.

\subsubsection{Executive Order 11990: Protection of Wetlands}

Executive Order 11990, signed May 24, 1977 (published May 25, 1977, in 42 FR 26961 ${ }^{4}$ ), establishes wetland protection as the official policy of all federal agencies. The order directs each agency to provide leadership "to minimize the destruction, loss or degradation of wetlands, and to preserve and enhance the natural and beneficial values of wetlands." The executive order applies to federally undertaken, financed, or assisted construction and improvements in or with significant impacts on wetlands.

Agencies are to avoid adverse impacts on wetlands whenever there is a practicable alternative. Work conducted or funded by a federal agency should not call for new construction in wetlands unless the head of the agency finds that there is no practicable alternative to such construction and the proposed action includes all practicable measures to minimize damage to wetlands. In making this finding, the head of the agency can take into account economic, environmental, and other pertinent factors. Agencies are also required to provide for early public review of any plans or proposals for new construction in wetlands.

Under this executive order, DOE must preserve and enhance the natural and beneficial values of wetlands when (1) acquiring, managing, and disposing of its lands and facilities; (2) undertaking, financing, or assisting construction and improvements; and (3) conducting any activities and programs affecting land use, including, but not limited to, water and related land-resources planning, regulating, and licensing activities.

In carrying out the activities just described, DOE must consider a proposal's effect on the survival and quality of the wetlands. Among the values of wetlands to be considered are maintenance of natural systems, including conservation and long-term productivity of existing flora and fauna; species and habitat diversity and stability; hydrologic utility; fish, wildlife, timber, food, and fiber resources; and scientific uses.

DOE's regulations implementing this executive order are found in 10 CFR 1022, "Compliance with Floodplain and Wetland Environmental Review Requirements." They can be accessed at http://cfr.regstoday.com/10cfr1022.aspx.

\subsubsection{Executive Order 12580: Superfund Implementation}

This executive order, signed January 23, 1987 (published January 29, 1987, in 52 FR $2923^{5}$ ), addresses various federal agency activities in implementing the statutory provisions and regulations of CERCLA, as described previously. It delegates various presidential responsibilities imposed under CERCLA to officials in federal department agencies, including naming DOE as a federal trustee. Accordingly, DOE acts as a natural-resource trustee for those resources it manages. Site-specific guidance, which involves

\footnotetext{
${ }^{4}$ Executive Order 12608 (September 9, 1987), Elimination of Unnecessary Executive Orders and Technical Amendments to Others, amended Section 6 of this executive order.

${ }^{5}$ Executive Order 12777 (October 18, 1991), Implementation of Section 311 of the Federal Water Pollution Control Act of October 18, 1972, as Amended, and the Oil Pollution Act of 1990, replaced Section 1 of this executive order. Executive Order 13016 (August 28, 1996), Amendment to Executive Order No. 12580, added new subsections (c)(3) and (d)(3) to Section 4. Executive Order 13286 (February 28, 2003), Amendment of Executive Orders, and Other Actions, in Connection with the Transfer of Certain Functions to the Secretary of Homeland Security, amended this executive order by removing reference to the Federal Emergency Management Agency and inserting the Department of Homeland Security.
} 
mandatory collaboration and agreement among DOE, EPA, and TDEC can be found at https://www.energy.gov/sites/prod/files/2014/03/f8/Oak_Ridge_FFA.pdf.

\subsubsection{Executive Order 13112: Invasive Species}

This executive order, signed February 3, 1999 (published February 8, 1999, in 64 FR 6183), directs all federal agencies to address invasive-species concerns and refrain from actions likely to increase invasivespecies problems. The purpose of this executive order is to prevent the introduction of invasive species; to provide for their control; and to minimize the economic, ecological, and human health impacts such species cause.

The Invasive Plant Management Plan for the Oak Ridge Reservation (Parr et al. 2004, Quarles et al. 2011, McCracken and Giffen 2017) implements this executive order and interacts with this wildlife management plan to protect ORR wildlife from the impacts of invasive species.

\subsubsection{Executive Order 13186: Responsibilities of Federal Agencies to Protect Migratory Birds}

This executive order, signed January 10, 2001 (published January 17, 2001, in 66 FR 3853), requires federal agencies - within existing budgets, missions, and responsibilities - to avoid or minimize the negative impact of their actions on migratory birds (see Section 2.2.1.1, "Migratory Bird Treaty Act"). Agencies must actively protect birds and their surroundings by, for example, restoring and enhancing habitat, preventing or abating pollution that affects birds, and incorporating migratory-bird conservation into agency planning processes.

This executive order requires each agency to develop a memorandum of understanding (MOU) with the USFWS to promote the conservation of migratory bird populations. DOE's MOU with the USFWS was approved on August 3, 2006, and was published on November 13, 2006 (71 FR 66170). It was effective until August 3, 2011. The new MOU between DOE and USFWS, which replaces the 2006 MOU, was published on September 12, 2013 and can be found at https://www.energy.gov/sites/prod/files/2013/10/f3/ Final $\% 20$ DOE-FWS\%20Migratory $\% 20$ Bird $\% 20$ MOU.pdf.

The MOU commits DOE to cooperate with the USFWS to "substantially contribute to the conservation and management of migratory birds and their habitats." It affirms DOE's commitment to "[take] its environmental stewardship role seriously and [advocate] a proactive management stance toward the natural environment." The MOU details the individual and collective obligations of DOE and the USFWS, some of which are listed subsequently.

The MOU states that DOE shall consult with USFWS whenever impacts to migratory birds or their habitat are suspected.

- Both DOE and the USFWS shall

- protect, enhance, and manage habitats of migratory birds, to the extent practicable;

- promote monitoring, research, and information exchange related to migratory bird conservation and program actions that may affect migratory birds, and provide access to information on environmental contaminants and other avian stressors that are relevant to the conservation of migratory birds;

- identify and pursue training opportunities for appropriate DOE and DOE contractor employees in appropriate methods and techniques to inventory, monitor, assess, evaluate, and manage migratory bird populations and to avoid and minimize adverse effects;

- participate in the interagency Council for the Conservation of Migratory Birds;

- periodically evaluate the measures taken under this MOU; and 
- $\quad$ support efforts to promote the ecological, economic, and recreational values of migratory birds by supporting outreach and educational activities and materials.

- DOE shall

- engage USFWS for coordination regarding proposed actions that may have direct and indirect adverse effects on migratory birds or their habitats;

- engage USFWS for coordination prior to DOE operations and activities with significant adverse effects on migratory birds and their habitats, to initiate appropriate actions to avoid or minimize the take of migratory birds;

- engage USFWS on the development and implementation of strategies to continually improve the conservation of migratory birds and their habitats in the conduct of environmental cleanup activities at DOE sites, and make information relevant to migratory bird conservation at its environmental cleanup sites available to USFWS;

- engage USFWS on the development and implementation of strategies to improve or enhance the conservation of migratory birds and their habitats at several National Environmental Research Parks, including the Oak Ridge Site, Oak Ridge, TN (ORR);

- engage USFWS on the development and implementation of strategies to improve or enhance the conservation of migratory birds and their habitats at water impoundment structures (e.g., dams and retention ponds) at three DOE sites, including the ORR;

- engage USFWS on the exchange of best available scientific information regarding current and emerging technological measures and practices to avoid or minimize adverse effects of energy technologies on migratory birds through various identified forums;

- consider USFWS recommendations and suggested practices regarding energy development to avoid or minimize direct and indirect effects on migratory birds and their habitats; and

- advise private parties and landowners seeking to interconnect electricity generating sources to DOE owned power transmission grids, to coordinate with the servicing USFWS Regional Office to determine applicable conservation requirements under the MBTA.

On December 22, 2017, the US Department of the Interior released M-Opinion 37050 (https:/www.doi.gov/sites/doi.gov/files/uploads/m-37050.pdf), which addressed whether incidental take is prohibited under the MBTA. This opinion states that an individual or entity may destroy an active nest while conducting any such activity where the purpose of the action is not to kill migratory birds or destroy their nests or contents. On April 11, 2018, the department released a memorandum on the "Guidance on the recent M-Opinion affecting the Migratory Bird Treaty Act." The document, which can be found at https://theiwrc.org/wp-content/uploads/2018/05/m-opinion-memo.pdf, includes frequently asked questions regarding implementation of the M-Opinion. On June 14, 2018, the department released a memorandum on the "Destruction and Relocation of Migratory Bird Nest Contents," which provides further guidance to the M-Opinion 37050. This memorandum can be found at https://www.fws.gov/ policy/m0407.pdf.

Currently, any act to purposefully kill (with intent) or destroy a bird, its eggs, or its nest is a violation of the Migratory Bird Treaty Act, regardless of whether that action occurs as part of an otherwise legal activity (e.g., spraying nests off of a wall before painting is not a legal act). Importantly, and in addition to these regulatory requirements, the existing MOU states that DOE shall consult with USFWS whenever impacts to migratory birds or their habitat are suspected.

See Appendix A for the complete DOE/USFWS MOU and selected portions of the executive order that detail DOE's responsibilities. 


\subsubsection{Executive Order 13148: Greening the Government through Leadership in Environmental Management}

Executive Order 13148, signed on April 21, 2000 (published April 26, 2000, in 65 FR 24595), requires federal agencies to incorporate environmental management systems (EMSs) into the agency's day-to-day decision-making and long-term-planning processes.

This executive order revoked the presidential memorandum for the heads of executive departments and agencies on environmentally and economically beneficial practices on federal landscaped grounds dated August 22, 1994. That memorandum required federal agencies' landscaping programs to consider use of environmentally sensitive landscaping practices and native plants. It promoted the sustainable management of federal facility lands through implementation of cost-effective, environmentally sound landscaping practices and programs to reduce adverse impacts to the natural environment. Although this presidential memorandum has been revoked, this executive order requires agencies to incorporate the guidance generated by it into their landscaping practices and calls for the guidance to be updated, if necessary. Use of native plants is important in providing suitable habitat for native wildlife.

\subsubsection{DOE Directives}

DOE directives include orders, policies, guidance, and regulations that provide for management of DOE lands. The ones most applicable to wildlife protection and management are described subsequently.

\subsubsection{DOE O 450.1 Change 2: Environmental Protection Program (December 7, 2005)}

This order is DOE's major environmental directive and establishes a general framework for DOE's environmental protection programs. It promotes implementation of sound stewardship practices that are protective of the air, water, land, and ecological resources impacted by DOE operations, allowing DOE to meet or exceed compliance with applicable environmental and resource-protection laws, regulations, and DOE requirements in a cost-effective way. Appendix B provides excerpts of this order and DOE O 436.1, which supersedes DOE O 450.1, that are specific to wildlife management on the ORR. Although DOE O 450.1 was cancelled, its guidance is relevant to various orders and memoranda until they are updated.

This DOE order applies to all DOE elements that are responsible for managing and operating DOE facilities. It requires them to ensure that the site Integrated Safety Management System (ISMS) includes an EMS. (This integration of an EMS into an ISMS is referred to as ISMS/EMS). An EMS is a continuing cycle of planning, implementing, evaluating, and improving processes and actions undertaken to achieve environmental goals. To implement this order, DOE elements must prepare EMSs that protect natural resources, including biota; protect site resources from wildland and operational fires (see the specific guidance on wildland fires in the last paragraph of this section); and promote the long-term stewardship of a site's natural resources.

DOE Operations, Field, and Site Office Managers are responsible for integrating, where appropriate, beneficial landscaping practices at their facilities into all new landscaping programs. They must also ensure that the site's annual budgetary processes include the funding and resources needed to implement this order. They must conduct environmental monitoring to evaluate, among other things, the potential impacts to the biota in the vicinity of a release from a DOE activity. The analytical work supporting environmental monitoring must be implemented using a consistent system for collecting, assessing, and documenting environmental data of known and documented quality.

The order includes additional requirements that contractors must follow. Section 2.2.5 includes further discussion of these requirements. 
DOE has developed a series of guides describing suggested nonmandatory approaches for meeting the requirements of this order. DOE G 450-1.4, Wildland Fire Management Program, (published February 11, 2004) suggests ways DOE sites can implement the requirement of the order to protect resources from wildland and operational fires, including prescribed burns instituted to improve wildlife habitat, restore natural ecological processes, and achieve the management objectives adopted in the approved land-use planning and management process for the site.

\subsubsection{DOE P 450.7: Environment, Safety, and Health Goals (August 2, 2004)}

The purpose of this policy is to establish environment, safety, and health goals for DOE personnel and its contractors. It states DOE's policy that it expects its employees and contractors to "respect ... the environment."

\subsubsection{DOE P 454.1: Use of Institutional Controls (April 9, 2003)}

This policy delineates how DOE will use institutional controls to manage resources, facilities, and properties under its control and implement its programmatic responsibilities. The policy guides sitespecific and programmatic decisions on DOE's planning, maintenance, and implementation of institutional controls; addresses responsibilities related to DOE's role as a steward of federal lands and properties; and identifies activities that DOE needs to accomplish. The policy helps ensure that institutional controls to protect the public and the environment will be established in accordance with the requirements of DOE O 450.1, described above, by integrating them into the EMS implementation framework.

DOE uses a wide range of institutional controls as part of its efforts to protect and manage the environment, including natural resources. DOE's line management (e.g., Operations Office Managers, Field Office Managers) has primary responsibility for implementing this policy for properties under its control.

\subsubsection{DOE G 454.1-1: Implementation Guide for Use with DOE P 454.1, Use of Institutional Controls (October 14, 2005)}

This guide suggests nonmandatory approaches for meeting the requirements of DOE P 454.1. It provides information to assist DOE program and field offices in understanding what is necessary and acceptable for implementing the provisions of the policy. It also identifies issues that need to be addressed when considering the use of institutional controls to support DOE's diverse missions. Appendix A of the guide lists statutory, regulatory, and other directives that are drivers for uses of institutional controls at DOE sites, some of which are specific to protection and management of wildlife.

\subsubsection{DOE O 436.1: Departmental Sustainability (2011)}

This order supersedes DOE O 450.1A. This order meets actions of federal agencies as outlined in EO 13112 and the Presidential Memorandum (2014) to create and improve pollinator habitat.

\subsubsection{DOE O 430.1C: Real Property Asset Management (August 19, 2016)}

This order establishes approaches to the management of real property assets that balance mission needs with safety, security, cost, and sustainability. Requirements are set forth that ensure that environmental sustainability and natural resource preservation are considered and incorporated into planning and budgeting. This includes, but is not limited to, regular documentation and preparation of planning guidance and reports to ensure that sustainability standards are met and natural resources preserved. 
Construction or renovation of buildings greater than 5,000 gross $\mathrm{ft}^{2}$ must meet federal sustainability guiding principles as outlined in Guiding Principles for Sustainable Federal Buildings and Associated Instructions (https://www.energy.gov/eere/femp/guiding-principles-sustainable-federal-buildings) and Executive Order 13693, Planning for Federal Sustainability in the Next Decade. Although Executive Order 13693 was revoked by Executive Order 13834, Regarding Efficient Federal Operations, DOE O $430.1 \mathrm{C}$ requires that its guidance be incorporated into planning.

\subsubsection{Tennessee State Requirements}

Laws, rules, and regulations of the state of Tennessee are also applicable to DOE's management of wildlife on the ORR. Tennessee laws relating to wildlife resources are found in Title 70 of the Tennessee Code Annotated (TCA), an outline of the most applicable parts of which is provided in Appendix C of this report.

The primary state agencies dealing with wildlife protection are TDEC (http://www.state.tn.us/ environment/) and TWRA (http://www.state.tn.us/twra/).

TDEC was created to protect and improve the quality of the state's land, air, water, and recreational resources. The department administers a variety of programs to safeguard human health and the environment, including protecting endangered species of plants. Rules and regulations that apply to TDEC are available at http://www.tennessee.gov/sos/rules/0400/0400.htm.

TWRA is responsible for the management of wildlife, including game animals, nongame species, fish, and T\&E species. The director of TWRA may enter into agreements with federal agencies for administration and management of an area, such as the ORR, established or used for wildlife management. TWRA also studies nongame wildlife to develop population, distribution, habitat, needs, limiting factors, and biological and ecological data (TWRA 2018). This information is used to determine management measures necessary to sustain nongame wildlife and develop programs designed to ensure the continued ability of nongame endangered or threatened wildlife to perpetuate themselves. TWRA includes both hunting (http://www.state.tn.us/twra/wildlife.html) and nongame programs (http://www.tn.gov/twra/nongame.html). TWRA manages the ORR hunts for species such as deer, turkey, Canada goose, and ducks.

Rules and regulations that apply to TWRA can be found at http://www.state.tn.us/sos/rules/1660/ 1660.htm. Proclamations can be found at http://tnsos.org/rules/wildlifeproclamations.php.

\subsubsection{Endangered or Threatened Species Lists}

The Tennessee Nongame and Endangered or Threatened Wildlife Species Conservation Act of 1974 (TCA 70-8-105) requires the Tennessee Wildlife Resources Commission to propose a list (TWRA 2016, TWRA 2018) of those native species or subspecies of wildlife that are determined to be endangered and threatened within the state. This act protects from take, possession, transport, export, process, or sale of any state or federally listed nongame wildlife. The act applies equally to other nongame species that so closely resemble listed species that enforcement personnel would have difficulty differentiating them from listed species. Take is defined as any action that results in direct adverse impacts to nongame wildlife, which includes to harass, hunt, capture, or kill nongame wildlife.

The Rare Plant Protection and Conservation Act of 1985 (TCA 70-8-301) directs TDEC to develop a state list of Endangered, Threatened, and Of Special Concern plants; conduct investigations on their status and conservation needs; and conduct education programs concerning rare plant conservation. 
A list of Tennessee T\&E wildlife species is available at https://www.tn.gov/content/tn/twra/ wildlife.html\#endangered, and a more inclusive list of animals that are considered rare or sensitive by the state of Tennessee is available at https://www.tn.gov/content/dam/tn/environment/documents/na animallist2016.pdf.

\subsubsection{Habitat Protection}

Tennessee law protects aquatic habitats from pollution (TCA 70-4-206). Specifically, it states that "no pollution, including, but not limited to, dye waste, petroleum products, brine waste, or refuse from a mine, sawmill or construction activity, or industrial or domestic sewage, or any deleterious or poisonous substance or activity shall be thrown or allowed to run into, wash into or take place in public or private waters in quantities injurious to fish life or other aquatic organisms, or which could be injurious to the propagation of fish, or which results in the destruction of habitat for fish and aquatic life."

\subsubsection{Contracts and Agreements}

\subsubsection{Management Contract}

The contractor shall support DOE in its responsibilities for land-use planning and land-management activities as well as natural-resource management for the DOE ORR, which consists of 32,208 acres $(13,438 \mathrm{ha})$ of federally owned land. The contractor's responsibilities are land and facility planning for the ORNL site, coordinating and conducting research, and conducting operational and maintenance activities within the National Environmental Research Park. Information on contaminant- and environmental-monitoring activities on the ORR is available in the Annual Site Environmental Report (DOE 2010). These reports are available online at https://www.directives.doe.gov.

Attachment 2 to DOE O 450.2 (discussed previously), "Contractor Requirements Document" (CRD), delineates the responsibilities that contractors must meet to comply with that order. The CRD requires contractors to use an EMS incorporated into an ISMS to integrate the numerous environmental requirements placed on them by existing statutes, regulations, and policies. Contractors must provide for the systematic planning, integrated execution, and evaluation of programs for compliance with all applicable environmental-protection requirements. They must include policies, procedures, and training to identify activities with significant environmental impacts; manage, control, and mitigate the impacts of those activities; and assess performance and implement corrective actions where needed. They must promote the long-term stewardship of the ORR's natural resources. They must also ensure the early identification of, and appropriate response to, potential adverse environmental impacts associated with DOE operations, including, as appropriate, preoperational characterization and assessment as well as effluent and surveillance monitoring. They must assist DOE in meeting the requirements of Executive Order 13148 (see Section 2.2.2.5). This assistance includes incorporating, where appropriate, environmentally and economically beneficial landscape practices into all new landscaping programs, policies, and practices for the ORR.

As part of integrating EMSs into their ISMSs, contractors must include protection of natural resources, including biota, and protection of site resources from wildland and operational fires. Some requirements from the CRD are listed in Appendix B.

\subsubsection{DOE Agreements with TDEC and TWRA}

DOE has entered into an agreement with state agencies. TWRA conducts general wildlife management on the ORR through an agreement with DOE. TWRA also actively manages the Three Bend Scenic and Wildlife Management Refuge Area (Three Bend Area) through this agreement with DOE. Currently, most 
of TWRA's vegetation management efforts on the ORR are focused at the three bends area through exotic invasive plant control, game habitat management, and maintenance/creation of early successional zones (e.g., old fields).

Through an agreement between DOE and the state of Tennessee, the state has oversight over 2,966 acres in the northwest corner of the ORR. The area was designated as the Black Oak Ridge Conservation Easement Area (BORCE) in April 2005, to be set aside under CERCLA for damage done to Watts Bar Lake by DOE actions (TWRA 2006). The area is managed in accordance with a management plan that is developed by TWRA with input from TDEC and the public. The active vegetation management of this area by TWRA has traditionally been minimal, largely because it is a forested landscape that receives the attention of UT-Battelle. The ORR Forester and Tennessee Department of Forestry have conducted prescribed burns, and the ORR Ecosystem Management Coordinator conducts regular invasive plant management primarily along DOE boundaries, roadways, and field edges in the BORCE.

DOE and the state have entered into a voluntary agreement, the Tennessee Oversight Agreement (available at https:/www.tn.gov/content/dam/tn/environment/remediation/documents/ oakridgereservation/ESOA OakRidge Nov2017.pdf. In a spirit of partnership and cooperation, DOE and the state have agreed to find ways to achieve clean air, water, and land on the ORR. The agreement is designed to assure the citizens of Tennessee that their health, safety, and environment are being protected through existing programs and substantial new commitments by DOE. Through a program of independent monitoring and review by TDEC's DOE Oversight Division, the state will advise and assist DOE to ensure that its activities on the ORR do not adversely impact public health, safety, or the environment.

\subsection{OAK RIDGE RESERVATION WILDLIFE}

\subsubsection{Oak Ridge Reservation Wildlife Habitat}

The ORR is mostly contiguous eastern deciduous forest. Before government acquisition as a security buffer for military activities, the approximately 1,000 individual farmsteads on the area now included in the ORR consisted of forest, woodlots, open grazed woodlands, and fields. A review of period topographic maps indicated that $49 \%$ of the area was forested (Johnston 2011). Results of remote-sensing analyses show that in 1994 about $70 \%$ of the ORR was in forest cover and about $20 \%$ was transitional and consisted of old fields, agricultural areas, cutover forestlands, roadsides, and utility corridors (Washington-Allen et al. 1995). Forested areas (hardwood and pine, with many areas in blocks greater than 100 acres [40 ha]) are found throughout the Reservation (Parr and Hughes 2006). Cutover forestland includes approximately 1,100 acres (445 ha) of pine plantations killed in 1993-1994 and 1999-2000 by southern pine beetles. These areas are now regenerating or have been replanted. Less than $2 \%$ of the ORR remains as open agricultural fields (Mann et al. 1996). The forests are mostly oak-hickory, pinehardwood, or pine. Minor areas of other hardwood-forest cover types are found throughout the ORR, including northern hardwoods, eastern red cedar, a few small natural stands of hemlock or white pine, and floodplain forests. Figure 1 shows ORR forests by forest groupings based on forestry compartment maps from ORNL/TM-2015/98; Forest Management for the DOE Oak Ridge Reservation: An Interdisciplinary Approach for Managing a Heritage Resource. 


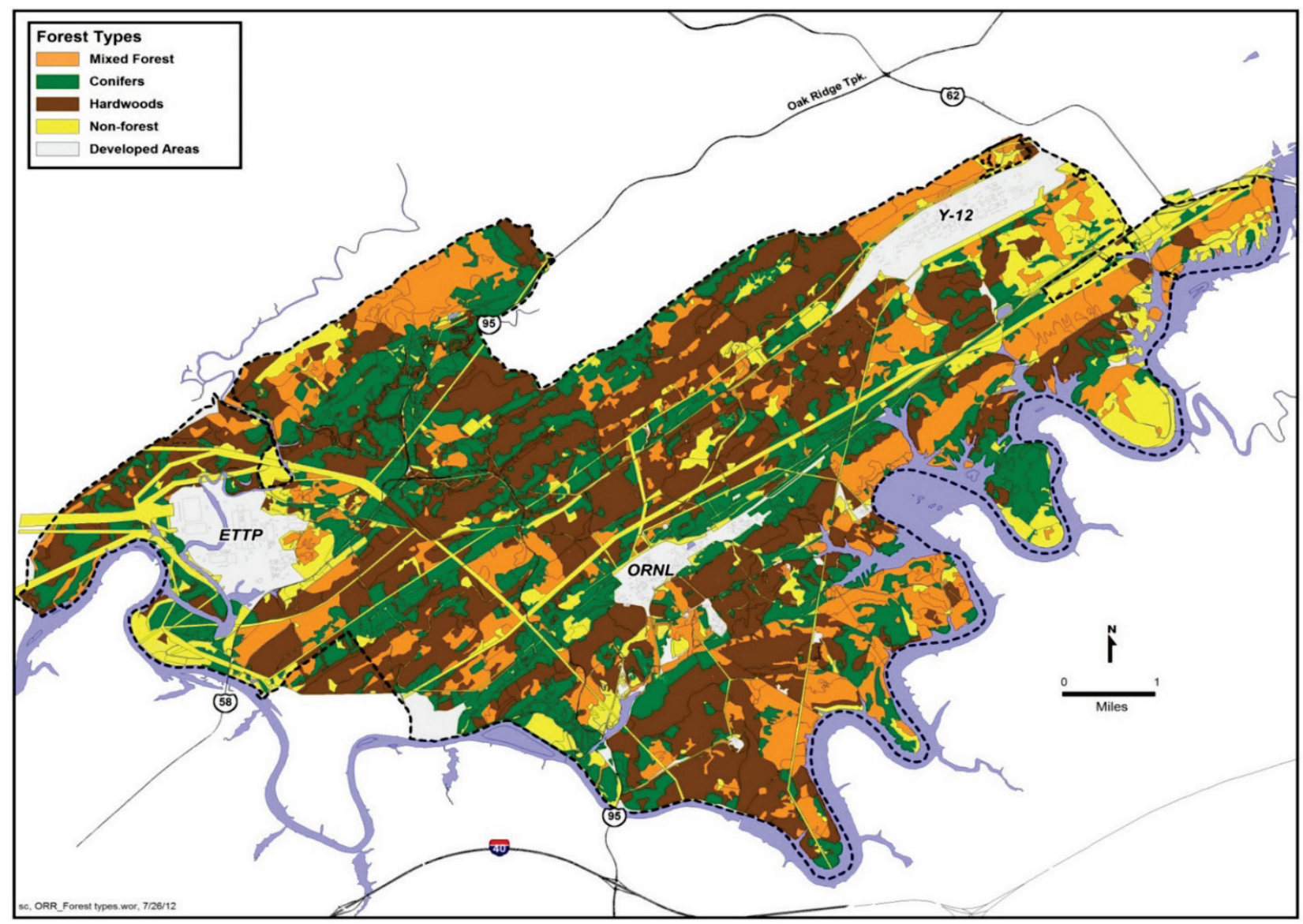

Figure 1. Forest types on the ORR.

Outstanding features of the ORR for wildlife include its large areas of unfragmented, mature eastern deciduous hardwood forest and its overall habitat diversity, particularly in comparison with surrounding land uses. Such areas are increasingly uncommon in the region and the nation. Overall, the ORR provides a diversity of wildlife habitats both imbedded within this forest matrix and due to other activities that have occurred since the area was created in the 1940s. Thus, in addition to a variety of forested habitats and pine plantations, the ORR contains managed native grasslands and forest edge, which together provide considerable habitat diversity than can support a variety of wildlife species. Maintaining this habitat matrix is central to maintaining biodiversity on the ORR. Habitat features include the following:

- Mature hardwood forest

- Interior forest

- Early successional grassland

- Mid-successional (shrublands/shrub-scrub)

- Unique or important vegetation communities (including rare and/or endangered plants)

- Relic glades, cedar barrens, and exposed talus

- Planted hardwoods and pines

- Creeks and small streams

- Riparian and floodplain forest

- Perennial wetlands and beaver impoundments

- Ephemeral wetlands (marshes and vernal ponds)

- Bottomlands, flatwoods, and sphagnum swamps 
- Karst and epikarst features (outcrops, caves, sinks, seeps, and springs)

- Seminatural utility corridors

- Developed and semi-developed areas and roads

\subsubsection{Oak Ridge Reservation Wildlife}

The unique suite of habitat features of the ORR supports an estimated 63 fish species; 69 reptile and amphibian species; up to 213 species of migratory, transient, and resident birds; 49 mammal species, and innumerable invertebrate taxa. Among these, 25 vertebrate species are federal- or state-listed (Endangered, Threatened, or In Need of Management) (Mitchell et al. 1996; Giffen, Reasor, and Campbell 2009; Giffen, Reasor, and Campbell 2011, McCracken et al. 2015). Additionally, 62 of the recorded bird species (includes all ORR historical records) are listed by Partners in Flight (PIF) as species of regional importance (PIF 2017). PIF was launched in 1990 in response to growing concerns about declines in the populations of many land-bird species and to emphasize the conservation of birds not covered by existing conservation initiatives. The central premise of PIF has been that the resources of public and private organizations in North and South America must be combined, coordinated, and increased to achieve success in conserving bird populations in this hemisphere. PIF is a cooperative effort that involves partnerships among federal, state, and local government agencies; foundations; professional organizations; conservation groups; industry; the academic community; and private individuals. Monitoring by PIF has also determined that 15 of the 62 species that are top conservation priorities in the region are area-sensitive forest species that are present on the reservation during their respective breeding season. Lists of vertebrate wildlife found on the ORR are presented in Appendix D.

The ORR was once the largest contiguous tract of forest within the Valley and Ridge Physiographic Province (Parr, Byrd, Johnston, and Giffen, 2015). Although the ORR is now highly fragmented by recent and ongoing facility and road expansions, as viewed from the air, it remains a relatively large and nearly contiguous island of greenspace within a landscape that is dominated by urban development and agriculture. Many ecological communities (e.g., cedar barrens, river bluffs, and wetlands) with rare and unique biota exist within the larger framework of mixed hardwoods, pine plantations, and early successional fields on the ORR (Pounds, Parr, and Ryon 1993).

\subsection{DEFINITION OF WILDLIFE MANAGEMENT}

Wildlife management is the practice of integrating habitat requirements, wildlife population needs, and human interaction to maintain and enhance biodiversity, provide opportunities for human recreation, and protect public health and safety. Wildlife management is an interdisciplinary science, with the goal of applying science-based research and ideas to active management of wildlife species, populations, communities, habitats, and whole ecosystems. The diversity of wildlife species and their abundance results from the types and amount of habitat available and how they are influenced by human activity. Habitat can be managed to achieve a specific goal, or management can result from manipulations through other land uses (e.g., waste management sites, clearing, utility right-of-way areas). Wildlife management is further defined in Appendix E. 


\section{WILDLIFE MANAGEMENT PLAN}

\subsection{GENERAL GOALS AND OBJECTIVES}

The overall goals of wildlife management on the ORR are as follows:

- to maintain and enhance biodiversity on the ORR;

- to preserve healthy wildlife populations and habitats compatible with the DOE mission;

- to assist DOE in efficiently balancing its mission with federal, state, and public natural resource laws, regulations, policy, objectives, and stakeholder perspectives;

- to integrate research, recreation, forest stewardship, and other land-use practices with wildlife management objectives under multiple-use objectives; and

- to minimize wildlife damage to property and threats to public safety.

- To accomplish these goals, management in the areas listed below is recommended, as permitted by resources and as mandated by the agreement between DOE and TWRA pursuant to the Sikes Act of 1974:

- habitat management for species of conservation concern, including state-listed taxa and wildlife identified by the state as sensitive or rare;

- inventory, protection, and restoration of focal wildlife species;

- game species management, including planned adaptive harvest of deer and turkey;

- $\quad$ wildlife damage management (e.g., deer/vehicle collisions, other nuisance wildlife concerns);

- nongame opportunities (e.g., nature walks, greenbelt enhancements);

- restoration, enhancement, and maintenance of wildlife corridors; and

- restoration, enhancement, and maintenance of unique or critical habitat.

A summary of historical wildlife management activities on the ORR is contained in Appendix F.

\subsection{WILDLIFE-HABITAT MANAGEMENT}

The ORR is a premier site in the southeastern United States of relatively undisturbed, unfragmented, primarily natural habitat (TNC 1995). The major objective of this wildlife management plan is to maintain and preserve this regionally and nationally important refuge for wildlife diversity. There are, in addition, opportunities to improve general wildlife diversity on the ORR as follows:

- maintenance, enhancement, and restoration of landscape heterogeneity,

- management of native grassland communities (native grasses, shrubs, and forbs),

- promotion of forest management practices that benefit wildlife,

- maintenance of contiguous forest and wildlife corridors,

- development and maintenance of natural riparian zones and functional wetlands, and

- enhancement of habitat for focal wildlife species.

The aforementioned goals would further define the objectives and methods for implementing the recommended practices. These habitat management measures facilitate a total ecosystem approach to support biodiversity at all levels (Parr and Evans 1992, Slocombe 1993). Management for biodiversity (e.g., species richness) ensures that the full suite of resources on the ORR is maintained and that both resident and transient/migratory species are protected within and beyond the ORR's borders. Under a biodiversity management strategy, all species, especially those about which little or nothing is known (e.g., most invertebrates), are important to overall environmental integrity (Slocombe 1993, 1998, Layzer 2012, Steenberg et al. 2019). Maintenance, enhancement, and restoration of a broad spectrum of habitats, 
with emphasis on imperiled ecosystems, are long-term goals. Focal species remain important, but their management is implemented in a way that first considers the broader environment and overall landscape heterogeneity. Thus, the resources discussed subsequently are to be considered together as an integrated unit. Management out of context of any of the resources will not further the goals of this plan. It should also be noted that additional work is underway to further develop this plan to account for landscape and habitat features that will typically fall within either interior forest or grassland communities. These include, but are not limited to, karst features (caves, sinks, outcrops) and aquatic resources (seeps and small springs) that are typically considered marginal or unimportant because of their small size, nondescriptiveness, and the rather cryptic diversity that often resides within them.

\subsubsection{Interior-Forest Resources}

The ORR's extensive forest area, amounting to approximately $70 \%$ of the total ORR footprint (Parr, Byrd, Johnston, and Giffen, 2015) is valuable not just for its size but also because of the presence of large contiguous forest tracts (Figure 2) (Giffen, Wade, and Mueller 2012). Contiguous forest provides habitat for several plant and animal species that are not associated with smaller patches with high edge-to-forest ratios. This is especially true for certain increasingly rare bird species. Deep-forest habitat is located away from large openings and typically has more than $70 \%$ canopy cover. Some researchers have used the benchmark of 50 acres (20 ha) of forest with 10 acres ( 4 ha) of forest interior to identify habitat for forest interior bird species (Jones, McCann, and McConville 2001).

As human populations continue to increase and expand, available large tracts of contiguous forest are becoming smaller and are broken into a greater number of pieces. Forest area is lost to clearing of land for industry, agriculture, and residential development, and the remaining forest is further fragmented by associated roads, paved and unpaved, and utility corridors. Fragmentation creates an "edge effect" that alters habitat conditions such as moisture regime, microclimate, and light penetration and can result in the introduction and spread of invasive species and predators harmful to forest-dependent species. Nesting forest birds increasingly fall prey to predators associated with edge habitat such as feral cats, raccoons, and certain snake species. The creation of cleared areas throughout forests also opens the area to the brown-headed cowbird, a common nest parasite that uses edge habitat and parasitizes nests of forest birds. Cowbirds fly in from the edges to lay their eggs in the nests of forest birds, where the larger, more aggressive cowbird young outcompete the fledglings of the forest-bird species. As more edges are created through the forest, cowbird penetration and associated nest predation on forest species increase (Gates and Gysel 1978; Robbins 1980; Robinson et al. 1995). Studies conducted by wildlife biologist Stanley Temple indicate that the edge effect extends into a forest as much as $183 \mathrm{yd}(200 \mathrm{~m})$ (Temple and Cary 1988). Thus, some researchers have used this distance as a criterion for identifying "interior" forest areas that would remain unaffected by forest fragmentation. When the $183 \mathrm{yd}(200 \mathrm{~m})$ buffer area is taken into consideration, the true nonimpacted interior forest can be eliminated or reduced to very small and/or narrow areas when encroached upon by surrounding roads, powerline corridors, and other openings. Historically, the ORR supported approximately 3,900 acres (1,580 ha) of interior forest. This acreage has decreased significantly on the ORR because of additional clearing for new buildings, additional waste burial grounds, roads, project laydown areas, powerline rights-of-way, and road widening.

In addition to increased predation and nest parasitism, forest fragmentation creates routes of incursion for invasive plant species. Newly created forest edges are disturbed areas, and as such create forest-field interfaces where invasive plants can thrive. As a result, nonnative invasive plants can establish and grow quickly, altering the natural habitat features of forest edges, thus impacting the ability of wildlife to enter and leave the forest. While edges increase, the resulting quality of edge habitat for wildlife is much reduced. Species such as deer, turkeys, and forest-dwelling birds and bats need open corridors at forest edges to travel to foraging grounds, and many ectothermic taxa, particularly reptiles, specialize or depend on forest edge interfaces for thermoregulation and foraging. The ORR supports several state-threatened, 
endangered, and in-need-of-management birds, amphibians, reptiles, fish, invertebrates, and mammals, including the federally listed gray bat (Myotis grisescens), Indiana bat (Myotis sodalis), and northern long-eared bat (Myotis septentrionalis), which can be impacted by forest fragmentation.

An important barometer in the determination of forest-habitat quality is the presence of certain neotropical migrant bird species. Unfortunately, bird populations in both grassland and forest communities in North America are being lost at an incredible rate (Rosenberg et al. 2019). Although the ORR continues to support many such species, including the Acadian flycatcher (Empidonax virescens), ovenbird (Seiurus aurocapillus), hooded warbler (Setohaga citrina), northern parula (Setophaga Americana), Kentucky warbler (Geophlypis formosa), and Louisiana waterthrush (Parkesia motacilla), significant declines cannot be overlooked.

Figures 3 and 4 show representative interior forest areas on the ORR. Because of its large size, natural value, and geographic location, the ORR holds significant value to wildlife and recreational opportunities in the broader eastern United States. ORR managers should recognize that actions that impact natural resources on the ORR do translate to observable impacts to resources and public recreation well beyond its borders. Notably, recent and ongoing facility expansions reduce the overall natural integrity of wildlife populations and their habitat in broader eastern Tennessee (see cover image, courtesy CR DeRolph) through elimination of interior forest and wildlife corridors that connect the Blue Ridge, Ridge and Valley, and Southwestern Appalachians ecoregions. A strategic plan to preserve and enhance natural corridors is needed at the local (corridors within the ORR) and regional (the ORR as a regional corridor) scale. ORR managers and decision-makers should embrace this responsibility through relevant research that is aimed at identifying and enhancing corridors and through consultation with other federal, state, and local entities to implement a strategic plan that is beneficial to Tennessee, its citizens, and its wildlife resources.

Forest fragmentation can be mitigated by reduced and careful placement of facilities and roads, minimizing road widenings, and allowing the forest canopy to close over existing roads where possible. Opportunities for public recreation (e.g., hiking and bicycle trails) also should be managed to consider effects on wildlife. Higher trail density and trail width further isolates wildlife and can present direct sources of mortality. 


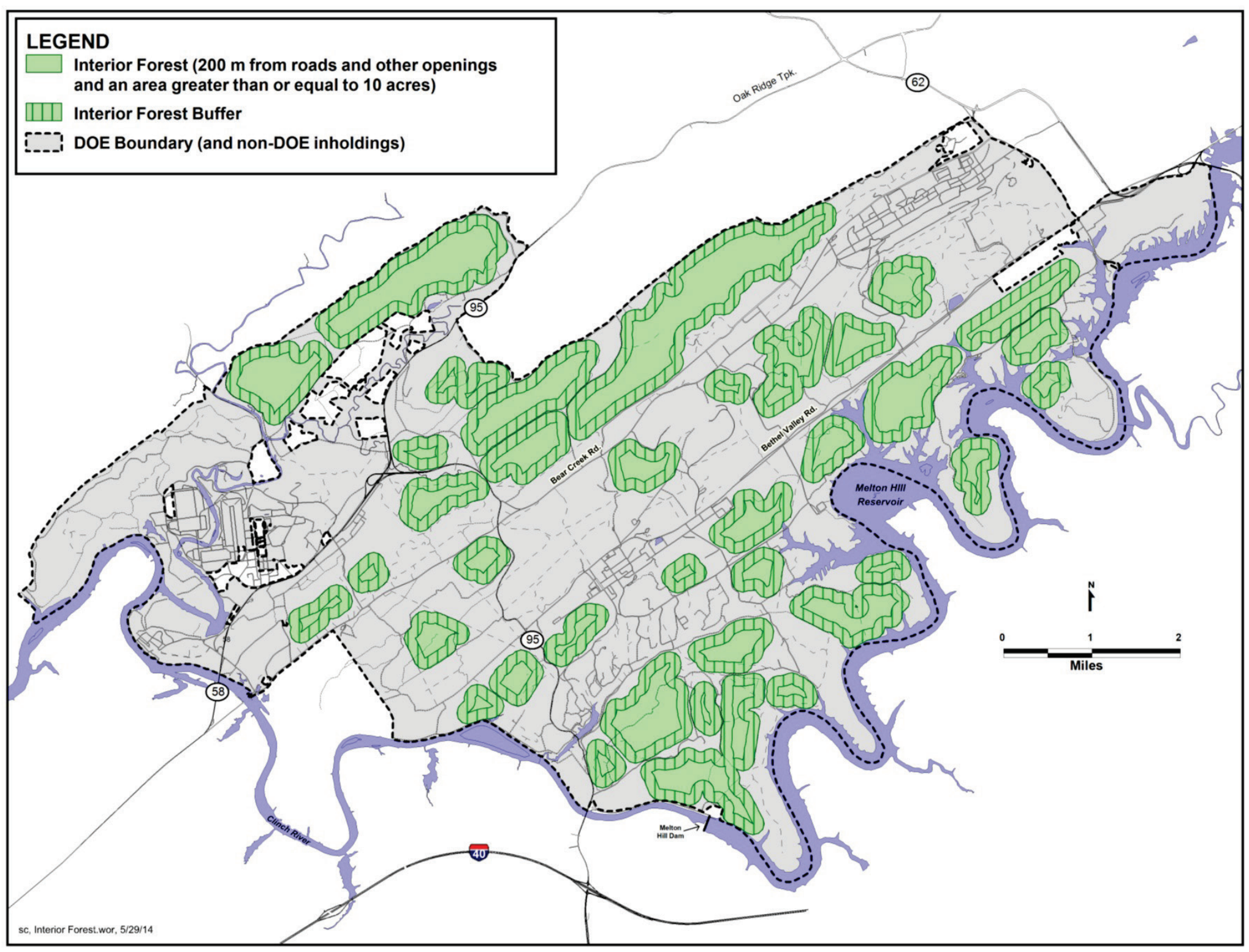

Figure 2. Interior forest areas of the ORR. 


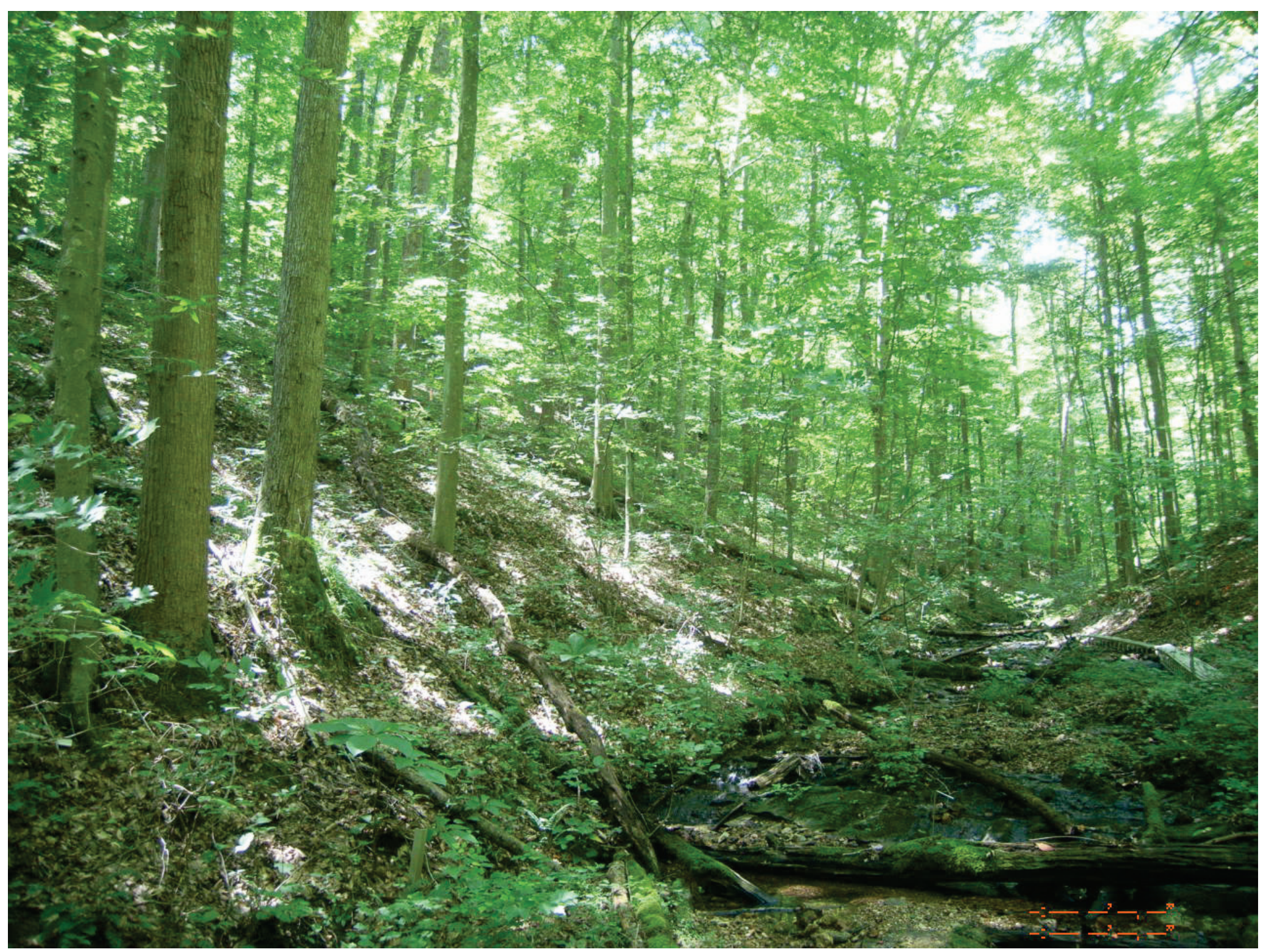

Figure 3. Interior forest in the Walker Branch Watershed on the ORR. (Photo by N. R. Giffen.) 


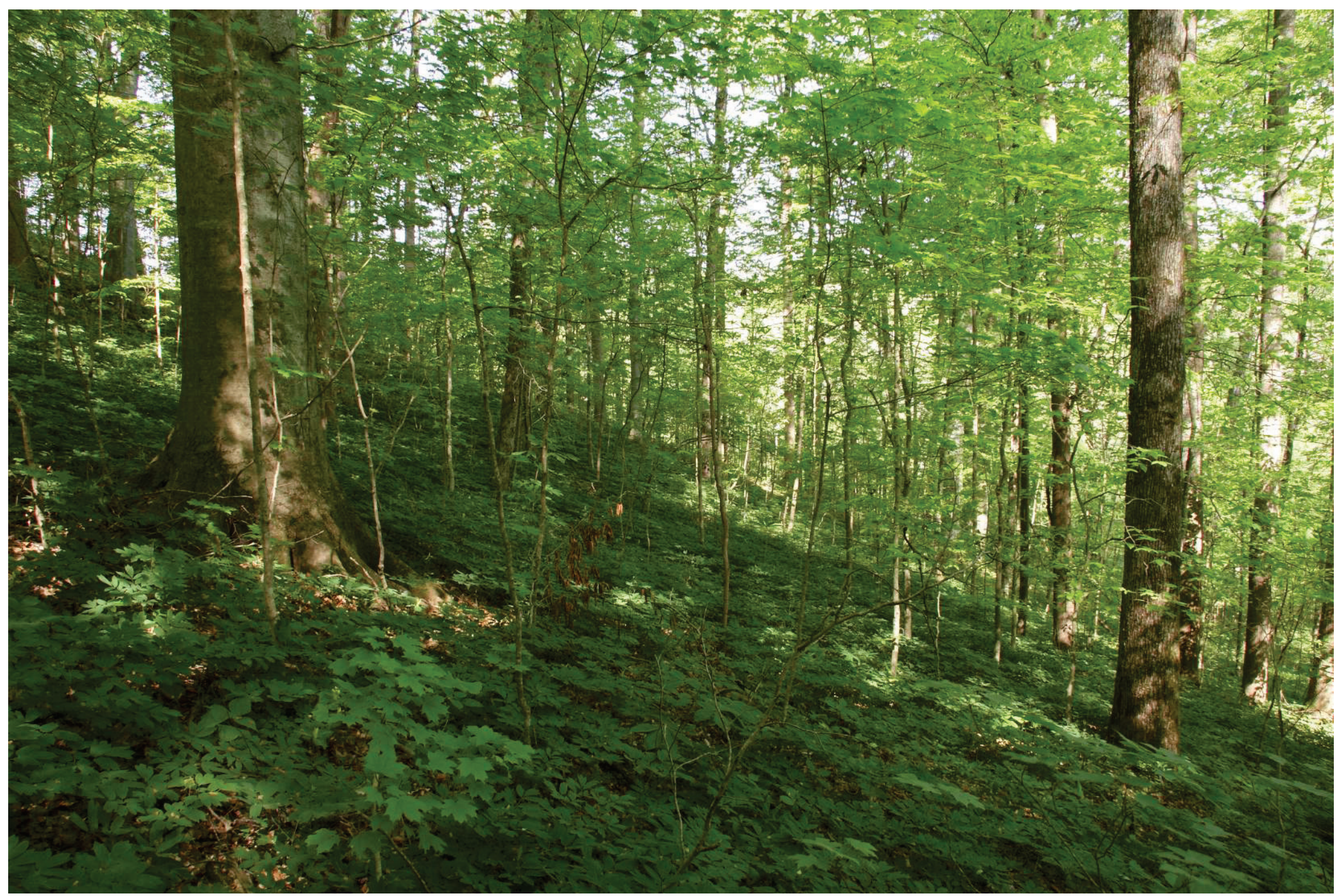

Figure 4. Interior forest in an old-growth area on the ORR. (Photo by N. R. Giffen.) 


\subsubsection{Field and Grassland Management}

Extensive field and grassland community management is an important component of natural resource management on the ORR (Ryon, Parr, and Cohen 2007). Management for these habitats is critical for shrub, grass, and forb-dependent wildlife, which include several focal species. An emerging question for wildlife managers is whether the ORR contained, or contains now, adequate contiguous grassland to support such grassland-dependent focal species as, for example, grasshopper sparrows (Ammodramus savannarum). However, a more applicable question is whether the ORR has the potential to improve its role in providing habitat that is suitable, minimally, during dispersal and transitory life history events. A habitat need not exist in the archetypal state for a given species or ecological type, nor does it need to provide resources for an organism's entire life cycle to be important. Moreover, the ideal habitat during one stage or life history event can be lower in perceived quality than the habitat with which the organism is most often associated.

Grasshopper sparrows and Henslow's sparrows (Ammodramus henslowii) were present on Freels Bend at least until the mid-2000s, and state-listed reptiles such as northern pinesnakes (Pituophis melanoleucus melanoleucus) and slender glass lizards (Ophisaurus attenuatus) once relied (possibly still) on pocketed grasslands and early successional habitat on the ORR for various aspects of their life history. Effort is underway to identify likely causes for the current absence or low abundance of many of these taxa. The forgoing hypothesis for the absence of some grassland-dependent birds is that clearcutting and fire in such large and contiguous natural areas generated changes to natural communities that were too sudden and drastic for sensitive wildlife to respond favorably. For pinesnake and glass lizards, historical location records indicate that much of the ORNL campus, the Spallation Neutron Source, and landfills and borrow areas eliminated open woodlands and barrens across several geologic bands where loose, infertile soils and pocketed barrens would have supported viable populations. Not mutually exclusive, it is also possible that the most important habitat to each of these taxa on the ORR differs from what is typical in nearby regions (e.g., the Interior Plateau). For instance, avian taxa that are often associated with early successional habitat may historically have exploited more open woodland as opposed to contiguous early successional communities. The current association of these taxa with early successional habitat may largely be the result of their being pushed into suboptimal habitat via loss of suitable open woodland (Hanberry and Thompson 2019), particularly within the Ridge and Valley of eastern Tennessee where open woodland was historically more common. Accordingly, a transition to management strategies that promote diverse mosaics of natural grassland and woodland communities will be a focus for the ORR (for examples and relevant reviews, see Seymour et al. 2002; Puettmann et al. 2012; Fahey et al. 2018; and Hanberry and Thompson 2019). This strategy is particularly relevant where human encroachment reduces wildlife cover and refuge at a landscape scale. Loss of overstory cover and a general paucity of contiguously vegetated areas reduces viable wildlife corridors and increases exposure risk (both for wildlife and to humans). Thus, maintenance of habitat mosaics that consist of both grassland communities and forest cover presents multiple advantages to humans and wildlife at local and regional levels.

A reasonable approach to promote such pocketed grasslands that benefits both native plant communities and wildlife is to control undesirable taxa through active management and allow regeneration and/or recolonization of desirable taxa through both active and passive strategies. On the ORR, this is accomplished through a multifaceted approach that includes application of herbicide on undesirable plant species, disking, prescribed burning, and seeding of native plants. Prescribed burning is a major tool that is used on the ORR to maintain large fields in native shrubs, warm-season grasses, and forbs. These burns are supervised by the ORR forester in coordination with the Tennessee Division of Forestry and TWRA, with planning input from the ORR Ecosystem Management Coordinator and Wildlife Ecologist. Burns are generally conducted in the early spring and fall and typically occur over a contiguous area. Some areas of the ORR in which prescribed burns are conducted are shown in Figures 5-9. A reassessment of 
the frequency and spatial scale of prescribed burns is a major goal for wildlife management staff for the next few years. This will be implemented through experimental approaches that differ in frequency and scale but remain in line with fuel reduction goals. 


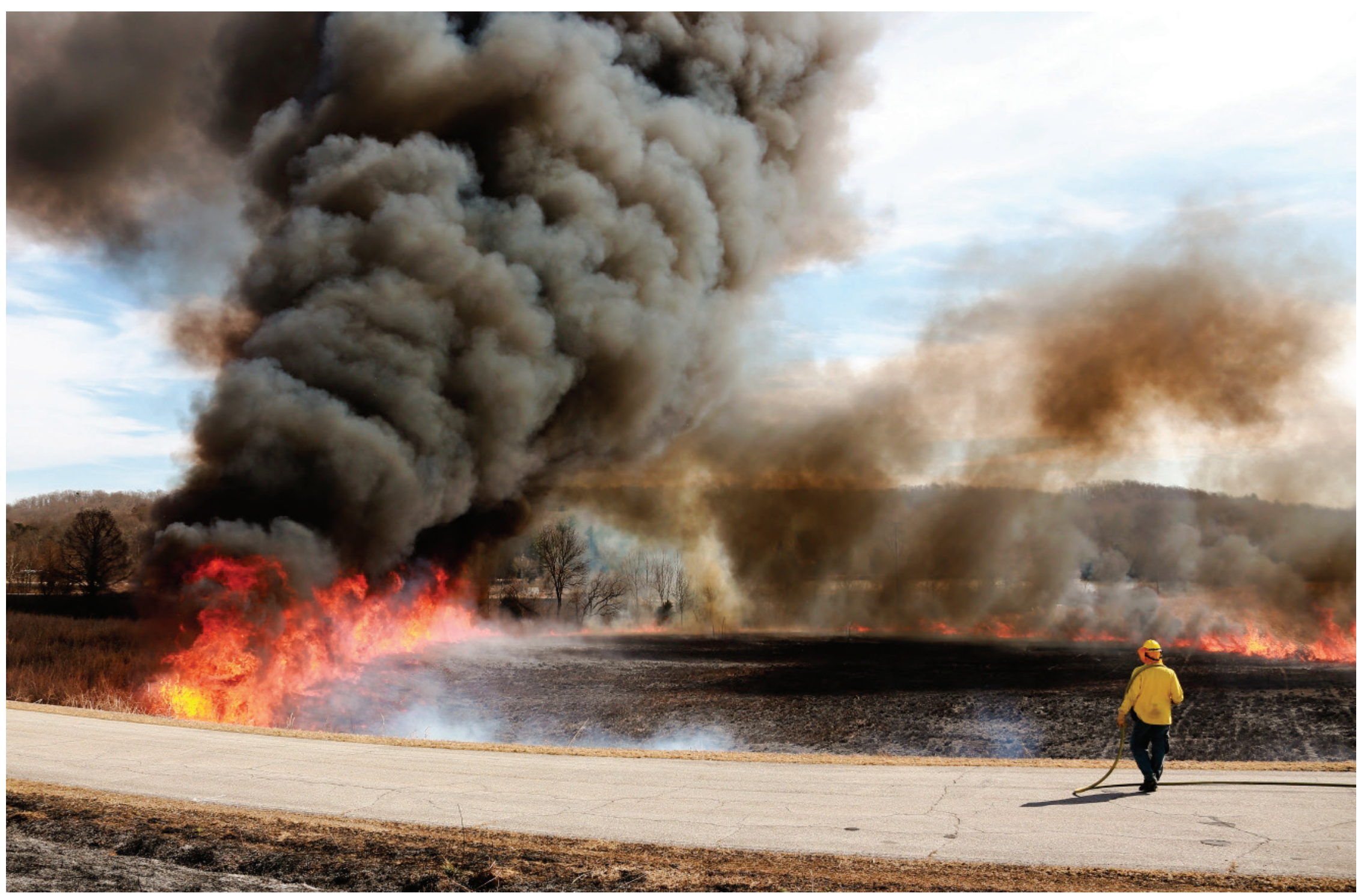

Figure. 5. Controlled burn of switchgrass field at East Tennessee Technology Park, February 25, 2014. 


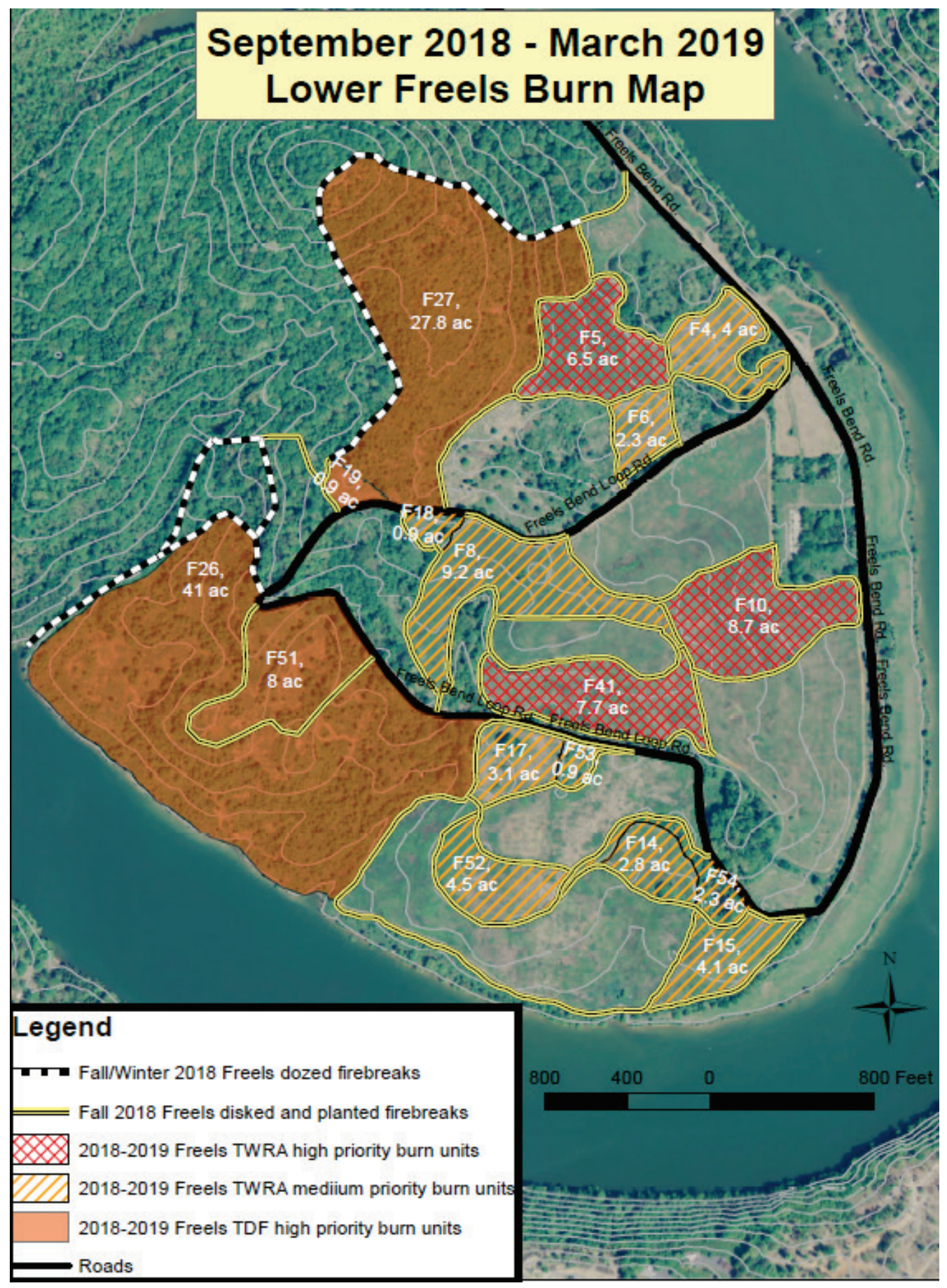

Figure. 6. Prescribed burn areas on Freels Bend. 


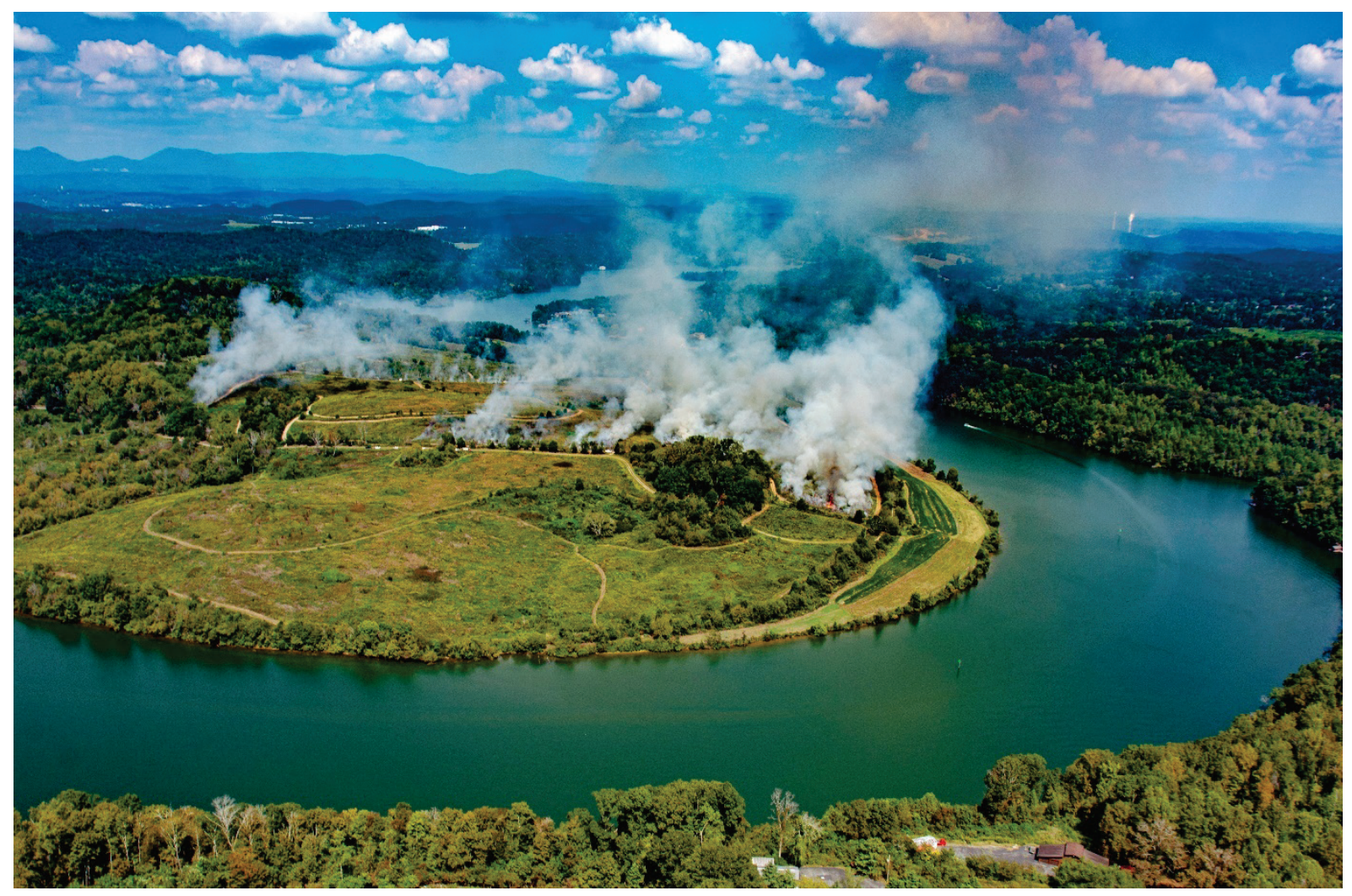

Figure. 7. Prescribed burn at Freels Bend as viewed from the air in September 2019. (Photo by E. T. Carter.) 


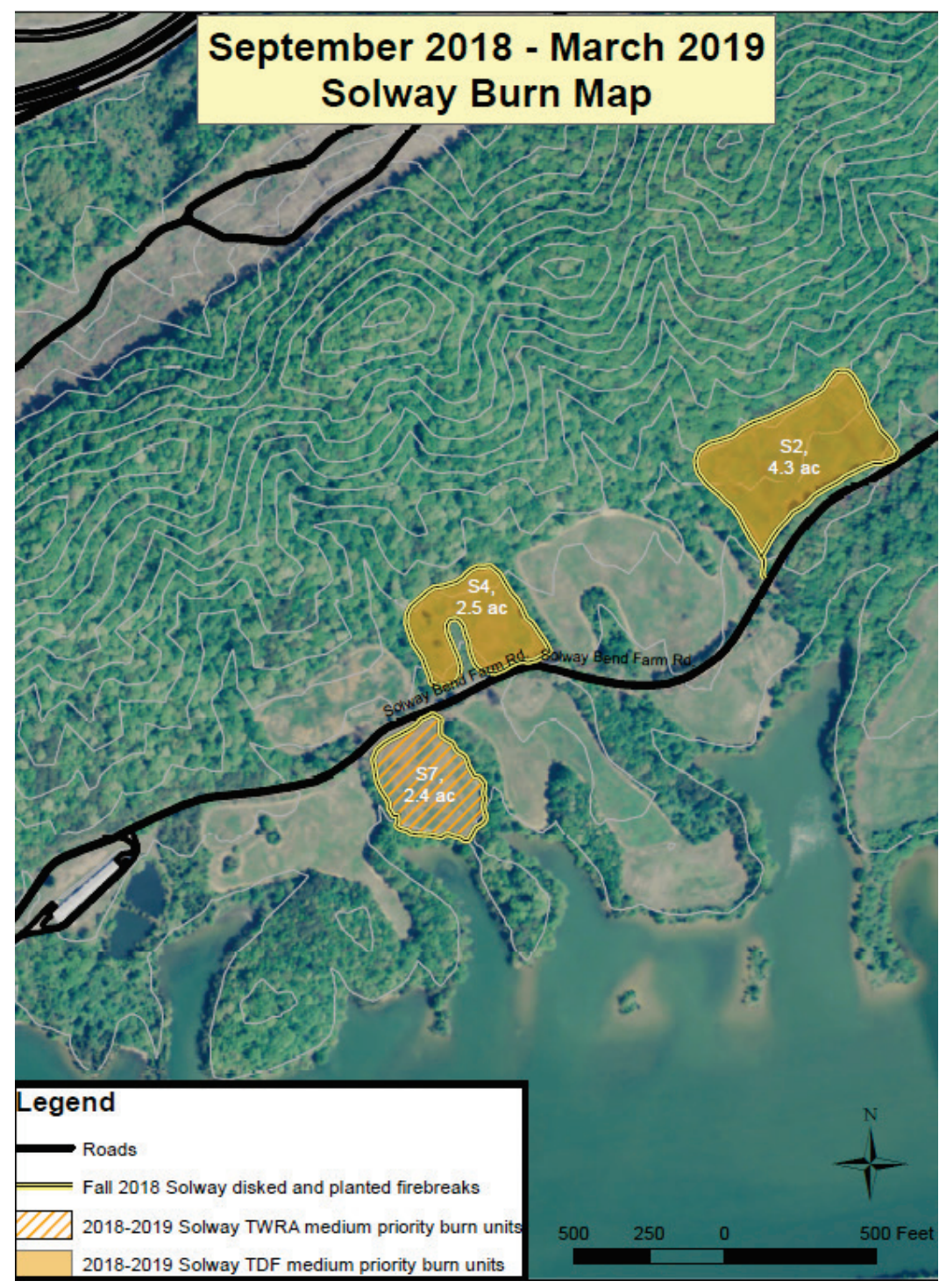

Figure. 8. Prescribed burn areas on Solway Bend. 


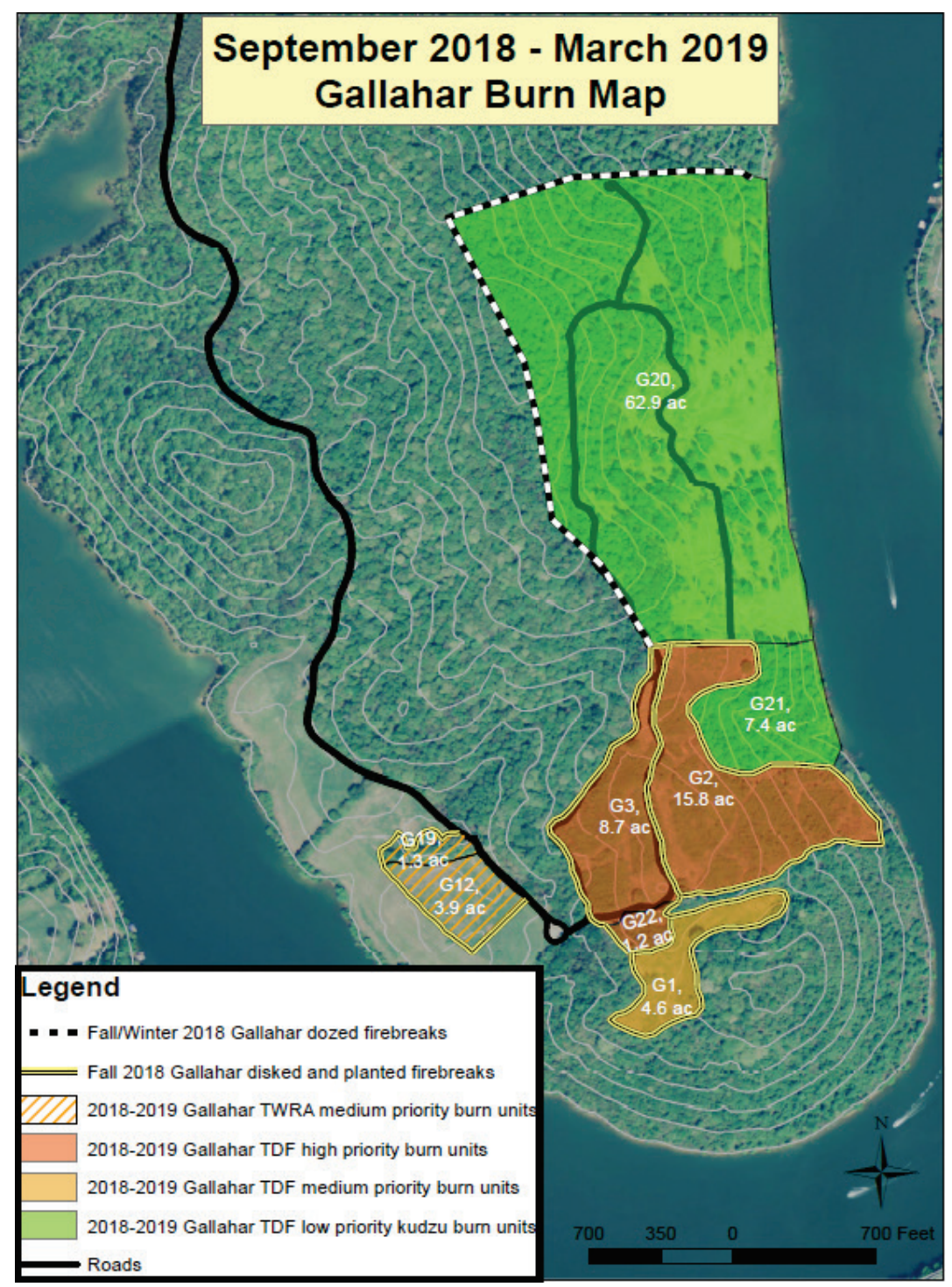

Figure. 9. Prescribed burn areas on Gallaher Bend.

\subsection{FOCAL-SPECIES MANAGEMENT}

Focal species and their habitats can be important ecologically and/or economically for introduction, restoration, or research. Management of such species can involve manipulating wildlife habitat, creating "artificial habitat" (e.g., platforms, nesting boxes), or maintaining suitable habitat that is already present. Limiting factors and conditions can be manipulated and restructured in ways that favor population viability. This method is applicable to game, nongame, and sensitive wildlife species. The long-term goals for focal-species management are to restore or reintroduce populations with the aid of targeted research and monitoring. However, it is important to maintain a broad perspective and to consider how management of focal species affects other plant and wildlife resources.

Five steps are suggested here to establish an effective focal-species/habitats program: (1) select focal species through consideration of conservation status/value and human wants/needs; (2) establish the focal species' habitat requirements through literature search and active research and monitoring; (3) determine management needs and costs to create the desired habitat; (4) consider how management actions impact 
other plant and wildlife resources and integrate accordingly; and (5) conduct follow-up studies on the survival and establishment of these species and others that are potentially impacted by the action. The following wildlife species/groups will be focal species in management on the ORR through the identified mechanisms:

- federally listed bat species, such as Indiana bat and northern long-eared bat, through inventory, monitoring, roost tree clearing restrictions, and habitat protection and enhancement (Figures 10 and $11)$;

- state-listed and rare woodland bat species through inventory and habitat enhancement (forestry management practices);

- all state- or federally listed taxa that are currently or historically supported on the ORR through inventory, monitoring, and habitat protection and enhancement;

- grassland obligate bird species, such as grasshopper sparrow and eastern meadowlark, through habitat restoration and maintenance;

- forest-area-sensitive neotropical birds through monitoring and implementation of clearing restrictions on projects that could cause interior forest fragmentation;

- bald eagle through protection of potential and existing nesting habitat (Figure 12);

- invertebrate species, such as native bee species, Monarch butterflies and others through inventory, tagging (of Monarchs), and habitat restoration and maintenance; and

- all nongame taxa on the ORR that are considered rare or otherwise regionally absent through inventory, monitoring, and habitat protection and enhancement.

Past work evaluated bald eagle habitat suitability on the ORR (Buehler 1994). More frequent bald eagle sightings on the ORR during the breeding season in recent years may indicate an increased potential for additional nesting on the property in the future, in line with the expansion of nesting locations that has occurred statewide. Protection of existing and potential bald eagle nesting habitat has been a major goal, and, in 2017, an active bald eagle nest was discovered in a Melton Hill lake cove close to Gallaher Bend.

A study of grasslands conducted on the ORR in 2010 and 2011 provided recommendations for improving habitat for northern bobwhite (Brinkley and Buehler 2012). This was in line with participation of the TWRA in the North American Bird Conservation Initiative, which includes the Northern Bobwhite Conservation Initiative (TWRA 2005).

Important habitat to be protected in focal-species management includes the following:

- contiguous forest;

- grassland/forb communities;

- early successional stage/old field;

- shrubland;

- live or dead trees with exfoliating bark and/or crevices;

- cedar barrens, glades, and exposed talus;

- caves/exposed karst; and

- ephemeral wetlands (including flatwoods and swamps).

This list will be updated as new information and research becomes available. 


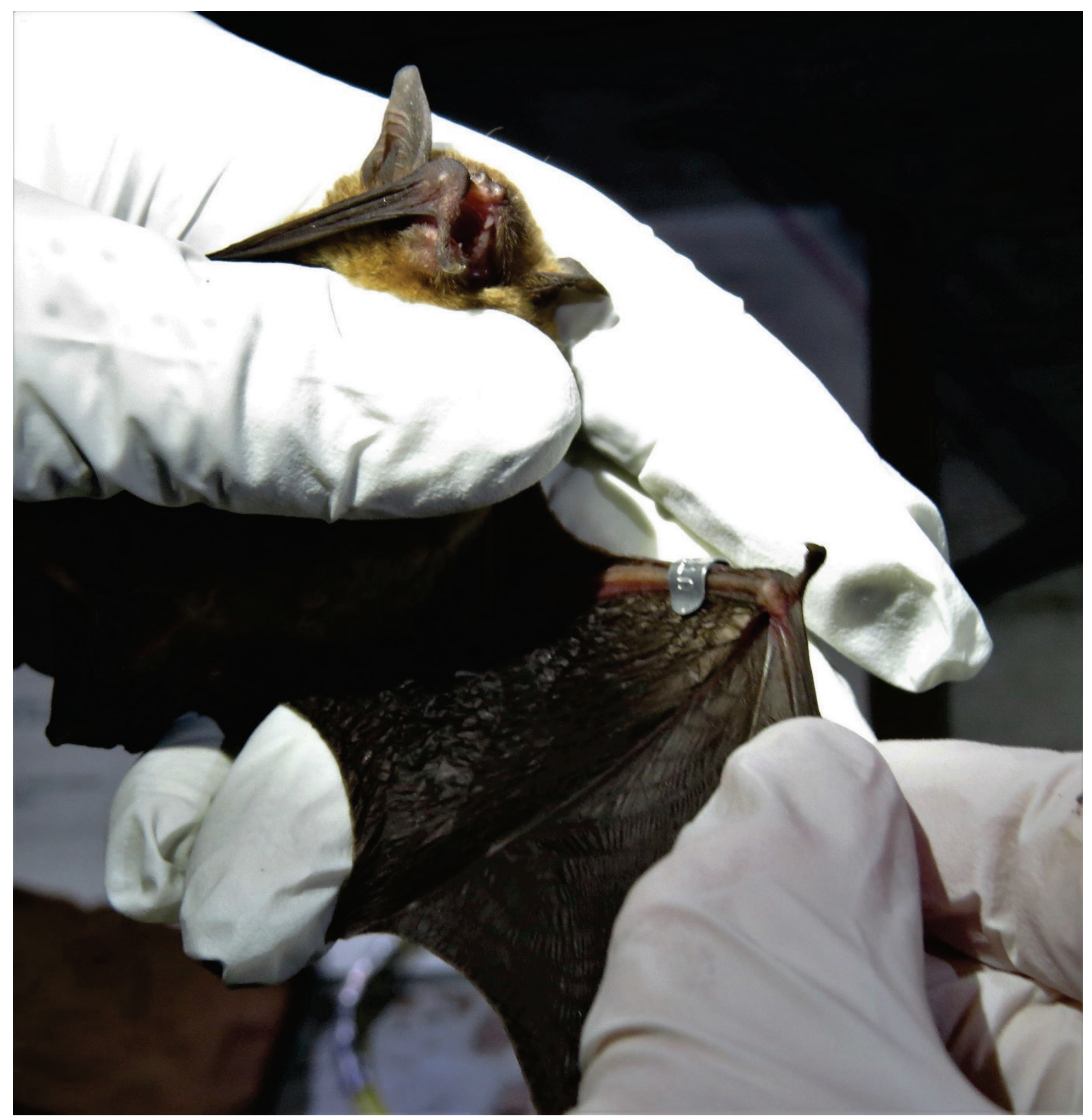

Figure. 10. ORNL researcher banding a bat on the ORR. (Photo by M. K. McCracken.) 


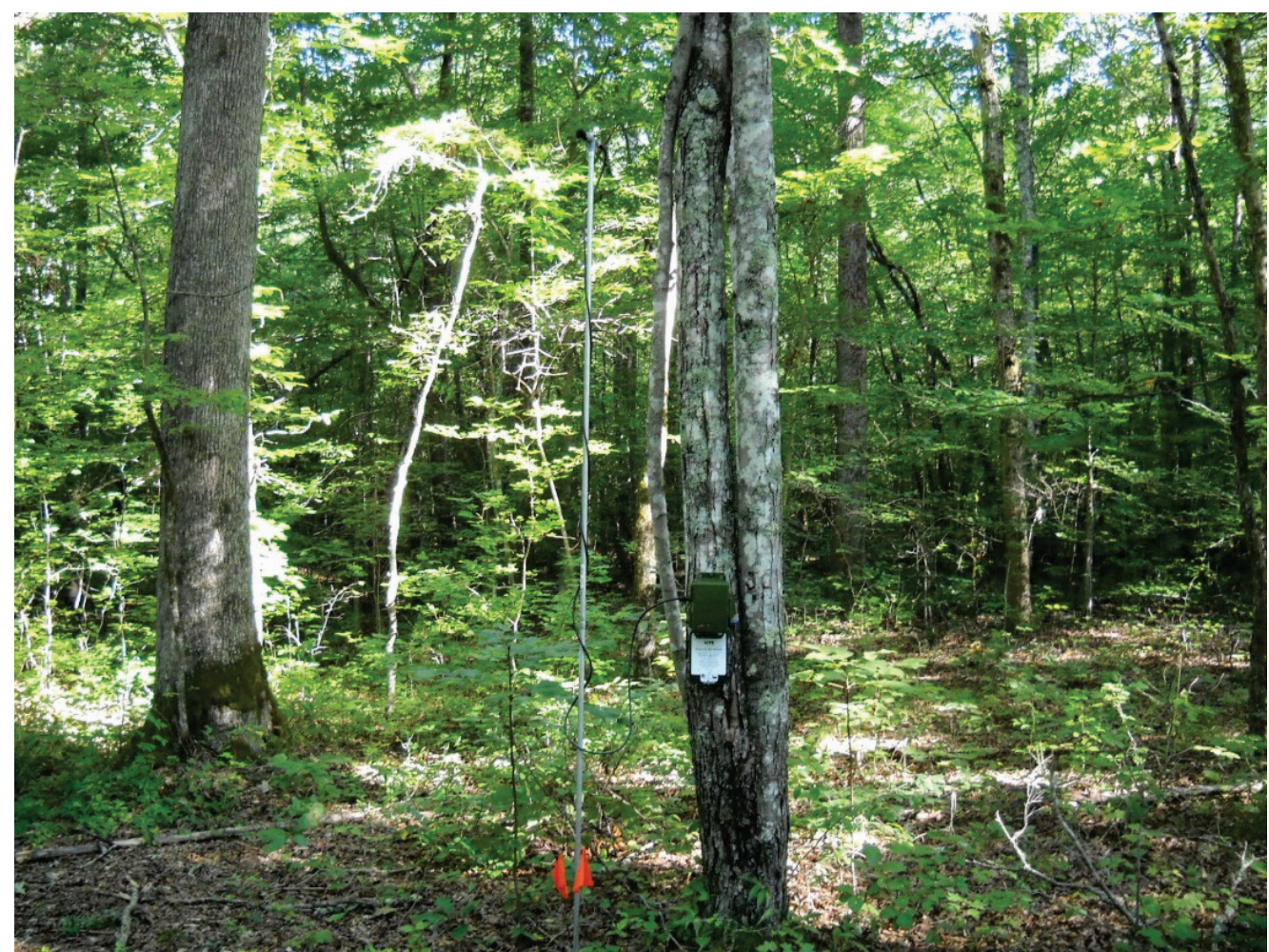

Figure. 11. Wildlife Acoustics SM4Bat acoustic monitor and high-frequency microphone used by ORNL researchers to record bat vocalizations. (Photo by M. K. McCracken.)

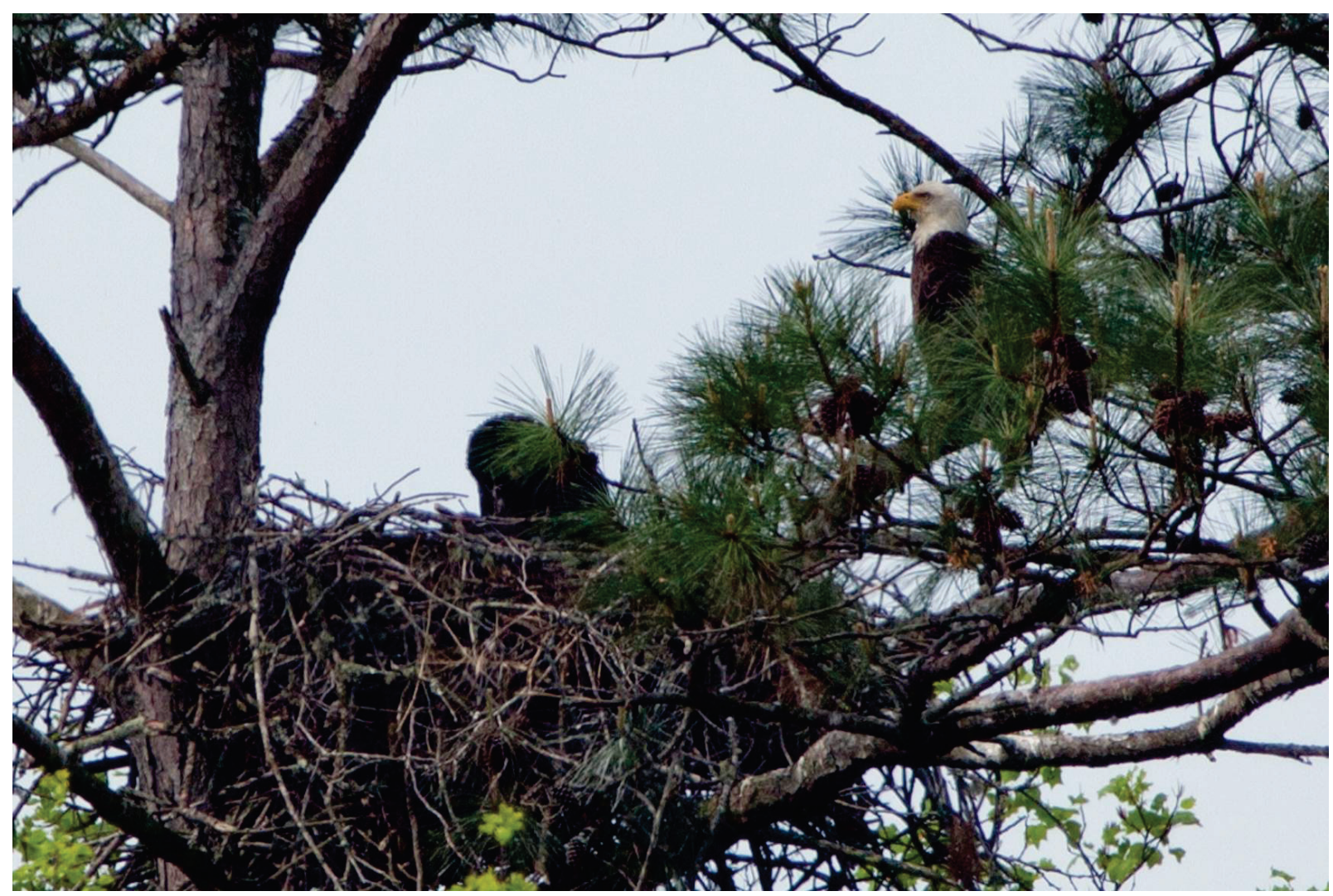

Figure. 12. First documented bald eagle nest on the ORR (April 2011). (Photo by J. K. Richards.) 


\subsection{GAME-SPECIES MANAGEMENT}

The goal of game-species management is to effectively combine public recreation with population control of game species (e.g., white-tailed deer, wild turkey, and Canada geese) for both ecological integrity and public-health-and-safety reasons.

Active hunting programs for white-tailed deer and wild turkey act as the primary method of population control for these species on the ORR. Hunting is only one aspect of a multifaceted approach to Canada goose management on the Reservation.

The success of the hunting program on the ORR is bolstered by the existence of hunting on adjacent parcels through agreements between TWRA and other entities. These adjacent parcels are also included under the Oak Ridge WMA (ORWMA), as defined by TWRA. The adjacent parcels include the following:

- the UT Forest Research and Education Center (managed by TWRA/UT), which encompasses about 2,270 acres (919 ha) (conducts deer and turkey hunts) and

- Haw Ridge Park (managed by TWRA/city of Oak Ridge), which encompasses 770 acres (312 ha) (conducts deer hunts).

\subsubsection{White-Tailed Deer Management}

The management and control of the white-tailed deer population on the ORR is critical in maintaining quality wildlife habitat and ensuring public safety. The impacts of deer overpopulation on habitat are well known. Heavy browsing by deer in overpopulated areas can result in significant impacts to understory growth, totally altering forest structure (Hough 1965; Ross, Bray, and Marshall 1970; Anderson and Loucks 1979; and Whitney 1984). Visible browse lines are evident, but decreasing, in many areas of the ORR.

Deer/vehicle collisions have risen significantly in the United States over the past 30 years or more. Yearly deer/vehicle collisions in the United States increased from approximately 200,000 in the 1970s to an estimated 500,000 in 1995. The National Safety Council Report estimated in 1995 that such collisions cost more than $\$ 125$ million in medical expenses, $\$ 940$ million in vehicle repairs, and $\$ 350$ million in wildlife loss. Besides being economically costly, deer/vehicle collisions are a threat to people traveling the roads (Huges, Saremi, and Paniati 1996). Between 2007 and 2016, 1,941 deer-vehicle collision deaths were reported across the United States, according to the Insurance Institute for Highway Safety. More recently, 1.5 million deer/vehicle collisions occur each year in the United States, resulting in at least \$1 billion in vehicle damage (available at https://m.iih).

The rise in collisions on the ORR elevated concerns for public health and safety, which led to the decision to implement a public hunting program. Public deer hunts were initiated in the fall/winter of 1985 to gain control of the burgeoning deer population and decrease the probability of deer/vehicle collisions. Since public hunting began, the number of deer/vehicle collisions has decreased from a peak in the mid-1980s (Figure 13). Driver awareness is promoted on the ORR during the rut season via warnings and advice posted on internal websites and at other locations. Tips related to motorists on the ORR (e.g., via ORNL Today) are included in Box 1. 


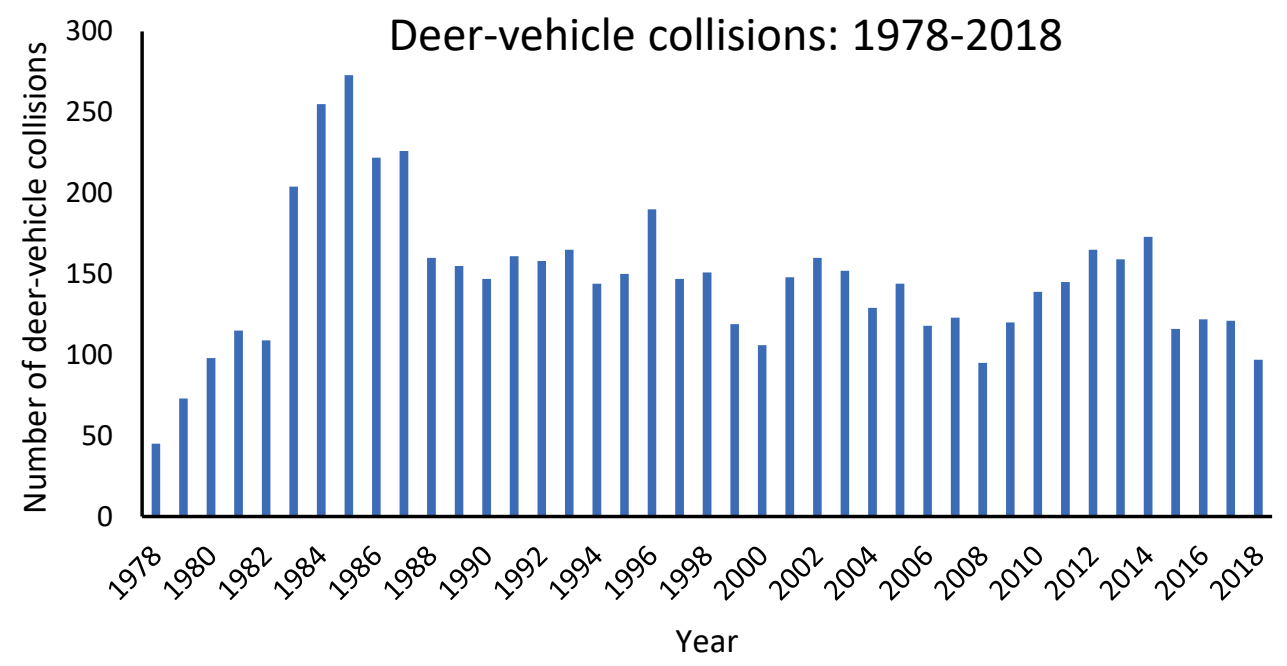

Figure. 13. Number of deer/vehicle collisions on the ORR and vicinity, as obtained from the Oak Ridge Police Department, each year from 1978-2018.

Box 1. Example of tips relayed to motorists on the ORR.

This is a reminder to people to watch for deer crossing the roadways. Although most deer-vehicle collisions occur in the fall and early winter, caution should be taken year-round. The chances of striking a deer and/or experiencing a serious wreck can be reduced by taking the following simple precautions:

- Use extreme caution when driving at dawn and dusk, when deer are most active, and visibility is poor.

- Slow down when approaching deer standing near roadsides. Deer may "bolt" or change direction at the last minute, and possibly run into the road in front of you.

- If you see a deer cross the road, use extreme caution. Expect other deer to follow.

- Use high beams when there is no oncoming traffic. High beams will illuminate the eyes of deer on the side of the road, giving you more reaction time. BUT, when a deer or other animals are noted on the road, dim your headlights as animals startled by the high beam may "freeze" rather than leaving the road.

- If a collision seems inevitable, don't swerve, but maintain full control of your vehicle. The alternative of swerving into oncoming traffic or a tree could be even worse than the collision with the deer.

- Observe speed limits. Excessive speed can increase the chances of a collision and worsen them when they occur.

- Always wear a seat belt. Most people seriously injured in deer/vehicle collisions are not properly restrained.

- Use special caution in areas posted with deer crossing signs.

The TWRA implemented a quality deer management (QDM) approach to the deer harvest on the ORR from 2003 through 2006. QDM is a strategy and philosophy that involves managing deer herds in a biologically and socially sound manner within existing habitat conditions. QDM encourages active participation in an antlerless deer harvest, where appropriate, and advocates protection of young bucks. The program is designed to protect yearling (1 1/2-year-old) bucks and many $21 / 2$-year-old bucks. This program also allows the harvesting of does. A major objective of a sound deer management program is to establish and maintain a 1:1 adult sex ratio, which is achieved through a doe harvest. Where there are well-established deer populations, a general rule is to harvest one doe per 50-100 acres (20-40 ha) each year. The goal is to maintain a deer herd below carrying capacity and maintain high recruitment; although 
this is currently based on qualitative assessment by the TWRA. Archery hunters were allowed to harvest three deer per hunt, with only one being antlered. While Oak Ridge had antler restrictions, the percentage of does in the harvest were higher than other years. The average buck age was also raised to 2.5 years for the first time since the mid-80s, when the hunts were initiated. The ORR returned to an either sex/no antler restriction strategy in 2007. As expected, the percentage of does in the harvest decreased, and the average buck age returned to 1.5 years. In 2016, an antlerless-only permit was offered to hunters during the hunts, and the percentage of does in the harvest raised again to $56 \%$. The average buck age remained low, but after a couple years of implementation, the average buck age has increased to 2 years old. Historical ORR harvest numbers are presented in Figure 14.

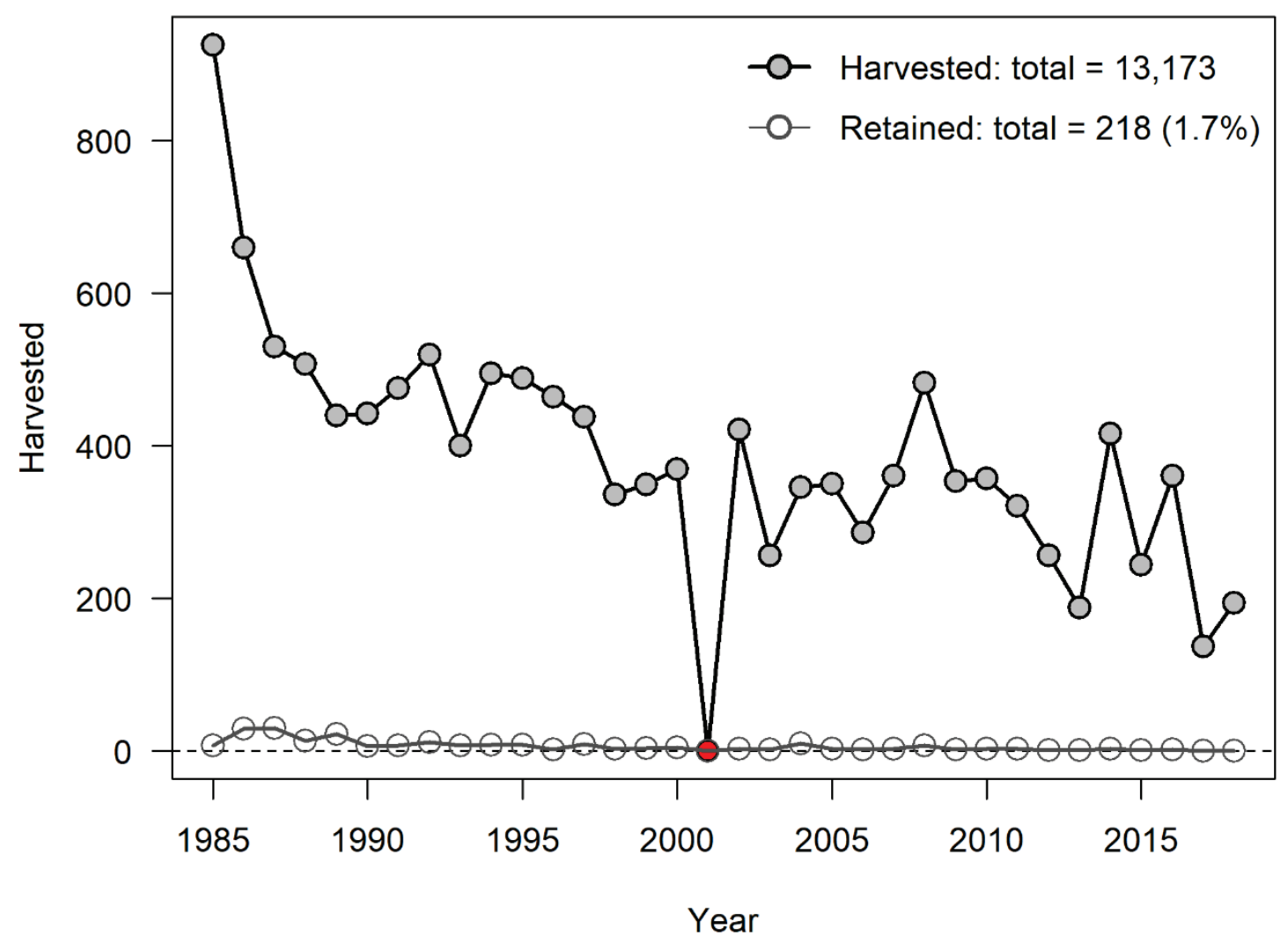

Figure 14. Historical white-tailed deer harvest for the ORR from 1985-2018. Deer hunts were not conducted in 2001 (indicated by red point) because of heightened security measures.

Since 1994, the amount of huntable acreage on the ORR has been reduced by 9,349 acres (3,783 ha). During this same time, acreage open to gun (shotgun/muzzleloader) hunting was reduced by 5,320 acres (2154 ha), 4,690 acres (1899 ha) of which have been redesignated as archery-only. The main reasons for these alterations were increased security requirements after 9/11, ORR land-use changes, and the removal of various sites from the ORWMA. The reduction in overall acreage for deer hunting coupled with increased acreage dedicated to archery hunting has presented greater challenges regarding the management of the white-tailed deer population on the ORR. Large areas left unhunted, particularly at the Y-12 National Security Complex, and extensive interior areas at ORNL that are archery-only hunting have resulted in localized increases in visible deer activity on certain parcels of land on the ORR.

Management options have been implemented to increase the deer harvest in currently inaccessible areas via hunting of specific parcels by badged employees only (initiated in 2008 for parcels at ORNL and Y-12). 
The ORWMA deer-check station is operated from ORNL Building X1303 on Bethel Valley Road. All successful hunters are required to bring their deer to this check station to fulfill the TWRA check-in requirements and have the animal checked for radiological contamination. In addition, data on antler size and deer age are collected at this station with assistance from the University of Tennessee Student Chapter of the Wildlife Society. Figures 15-17 depict activities undertaken at the deer-check station.

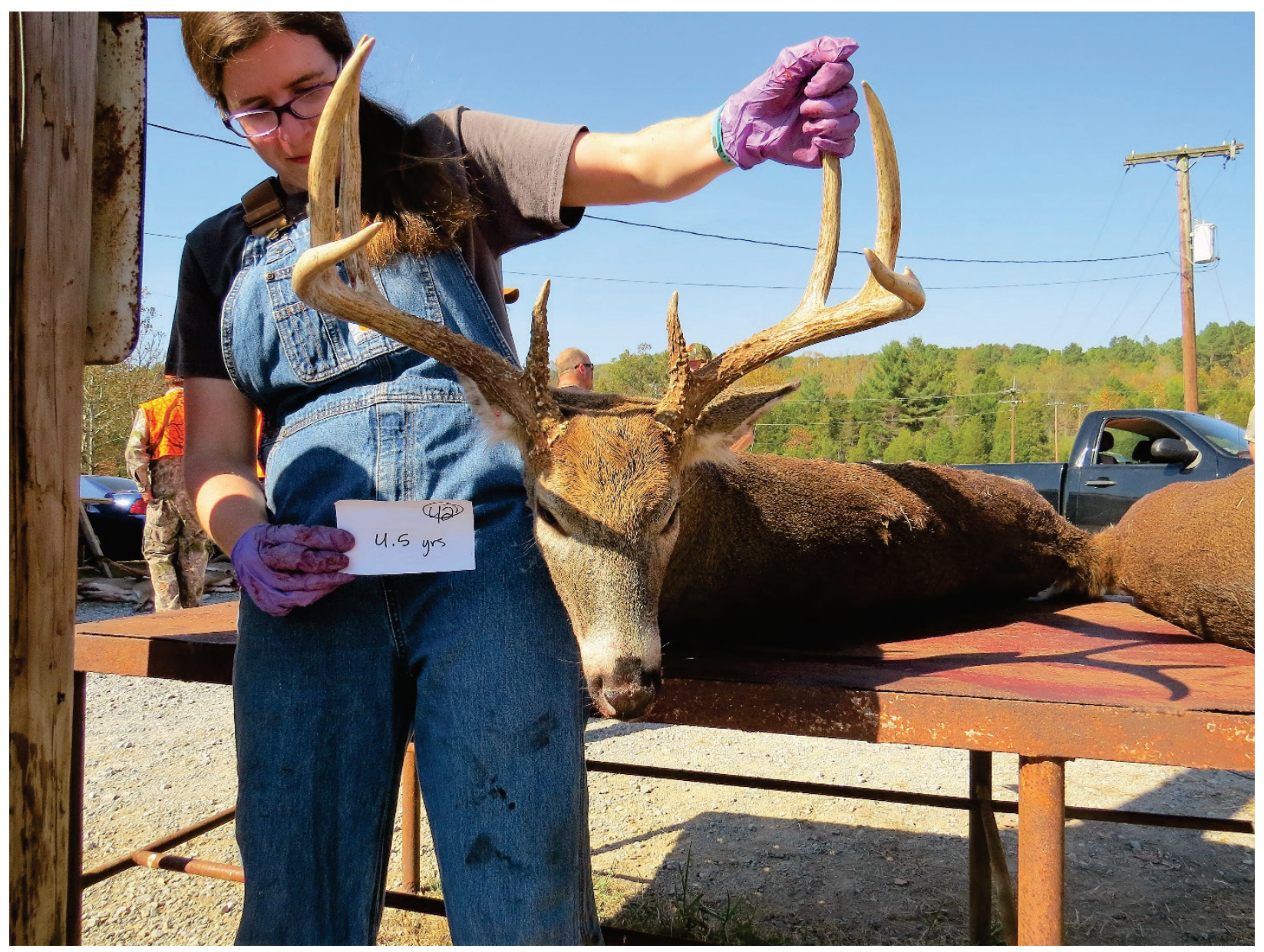

Figure 15. University of Tennessee student displays buck for aging analysis for TWRA and ORNL during fall deer hunt on the ORWMA. (Photo by S. E. Darling.) 


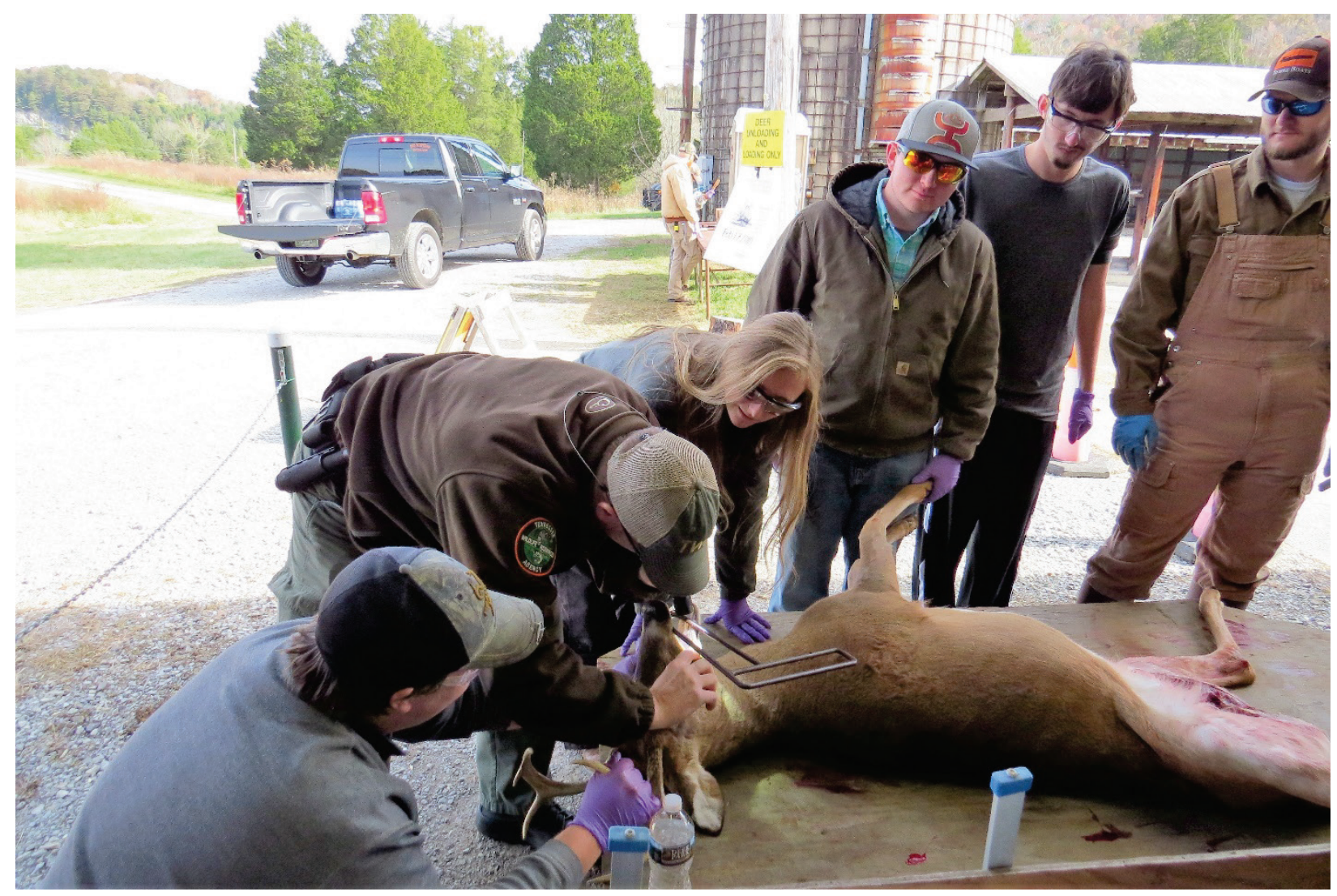

Figure 16. Former TWRA ORWMA Manager Aubrey Deck demonstrates to students how to age deer by tooth wear at the ORR deer-check station. (Photo by S. E. Darling.)

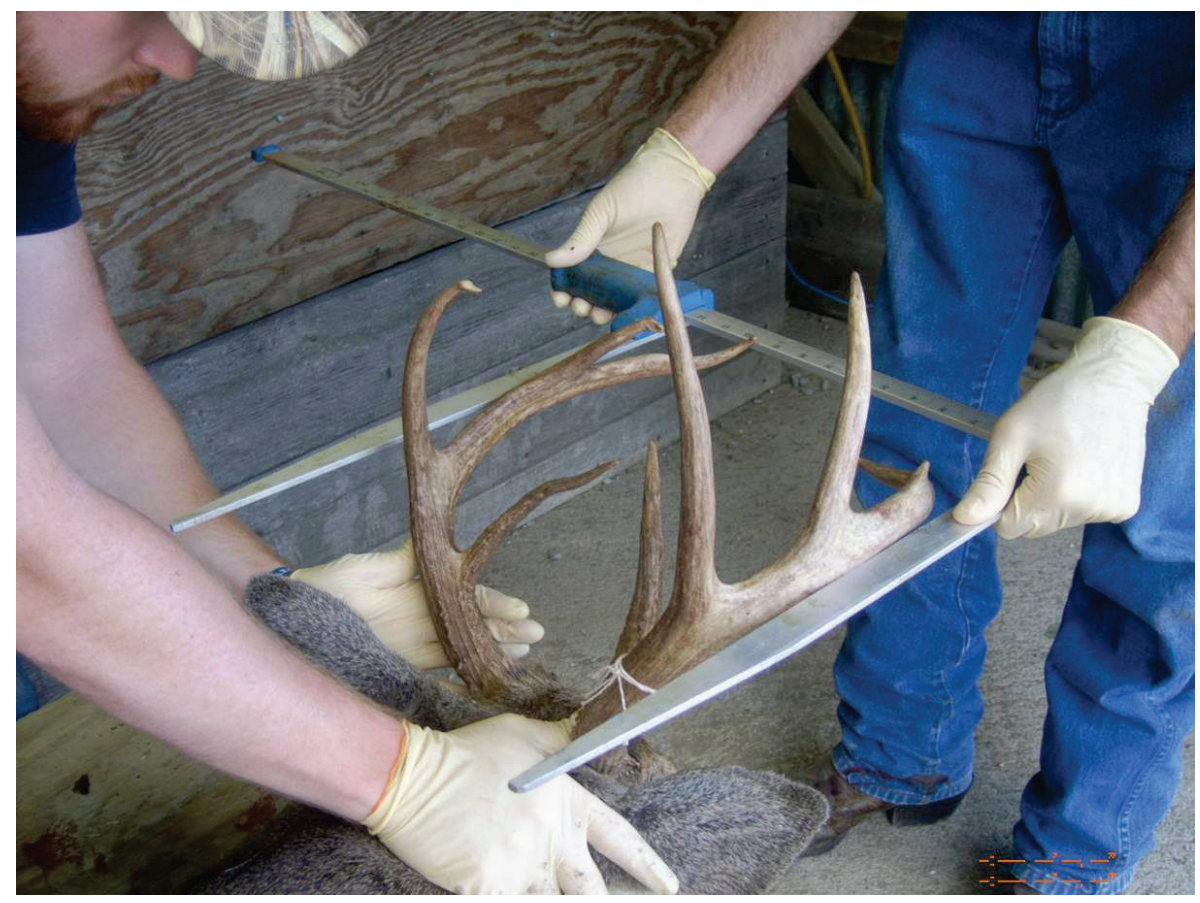

Figure 17. University of Tennessee Student Chapter of the Wildlife Society students measure antler spread at the ORR deer-check station. (Photo by N. R. Giffen.) 


\subsubsection{Wild Turkey Management}

In 1997, a public wild turkey hunt was approved in conjunction with a plan to monitor this species for contaminant levels. Hunting was applied because turkey numbers had dramatically increased on the ORR since the species' reintroduction in the mid- to late 1980s. From the approximately 40 turkeys originally restocked in 1985 and 1986, the population had grown to an estimated 600 to 1,000 birds by 1996. Two spring (April) weekend hunts are conducted every year on the ORWMA for bearded turkeys only. All successful hunters are required to check in turkeys at the ORWMA check station, where various measurements are taken, and birds are checked for radiological contamination (Figures 18-22). Historical harvest numbers are presented in Figure 23. The great success of this increased wild turkey population allowed for relocation of birds from the ORWMA to other areas in Tennessee during past TWRA restocking efforts. Since the early years of reintroduction, wild turkey numbers on the ORR have steadily increased.

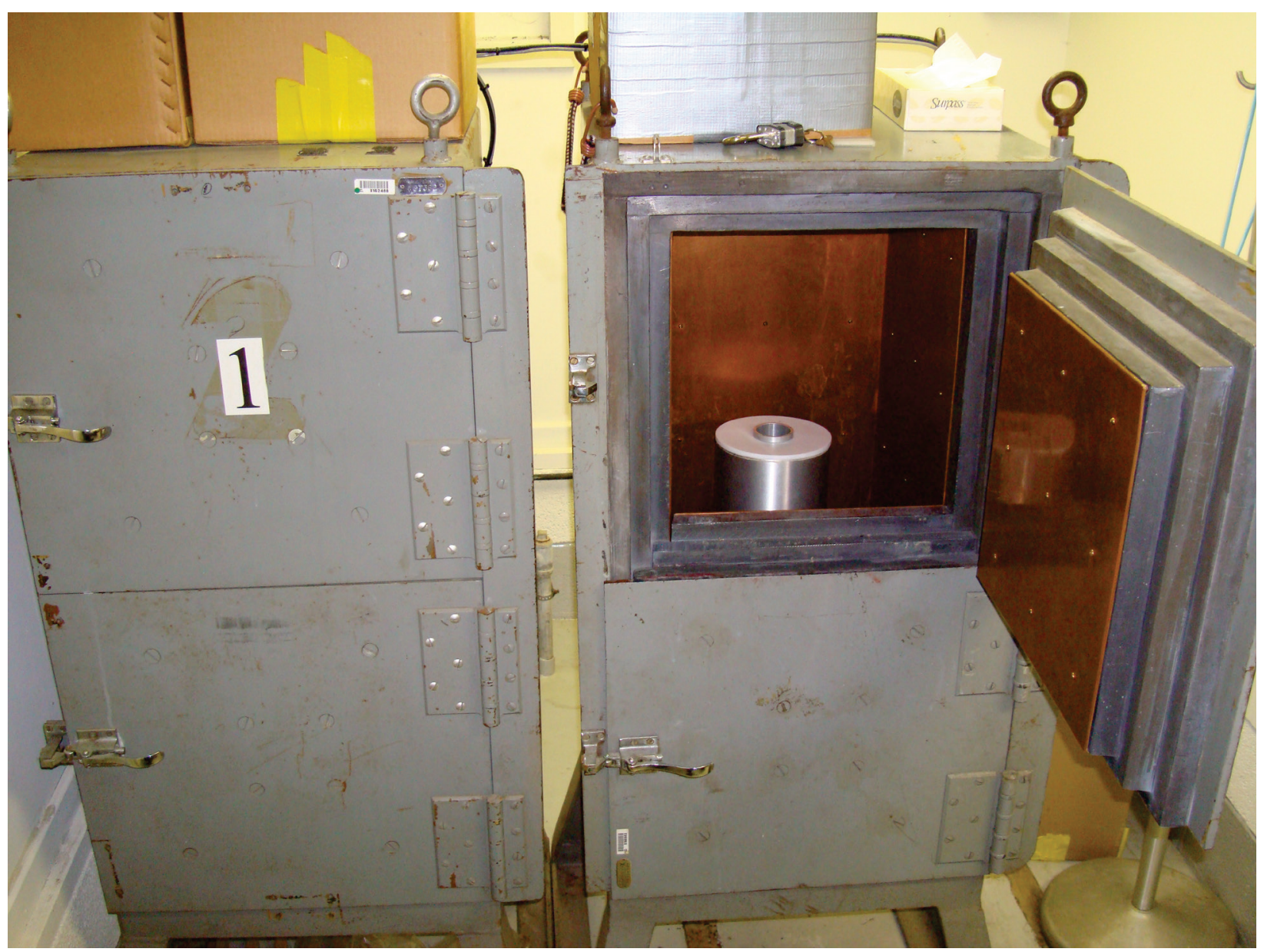

Figure 18. Sodium iodide detectors at the ORR deer-check station used to measure gamma energies in deer tissue samples. (Photo by N. R. Giffen.) 


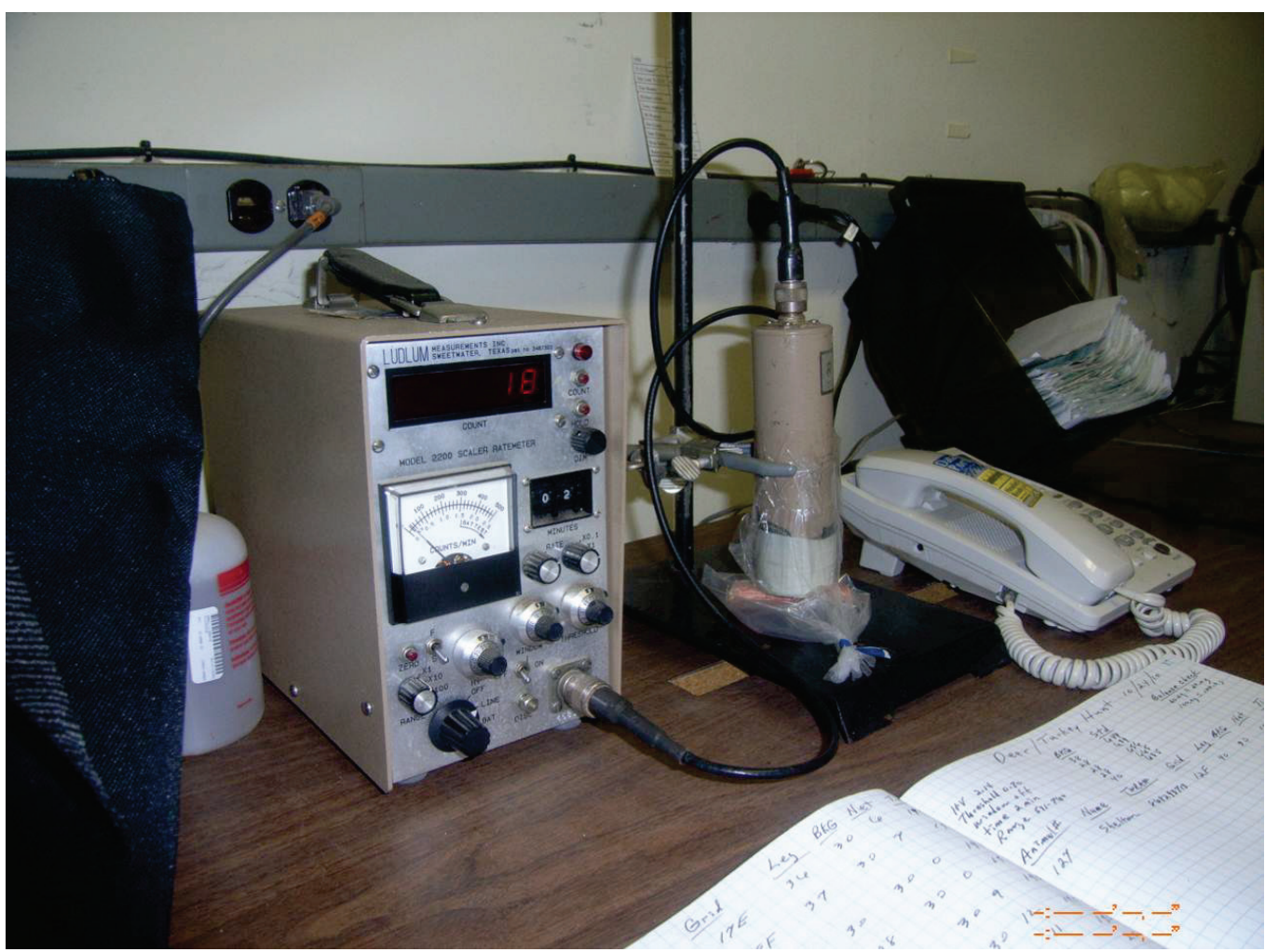

Figure 19. Beta scintillation detector (Ludlum probe) at the ORR deer-check station used to measure beta energies in deer leg-bone samples. (Photo by N. R. Giffen.)

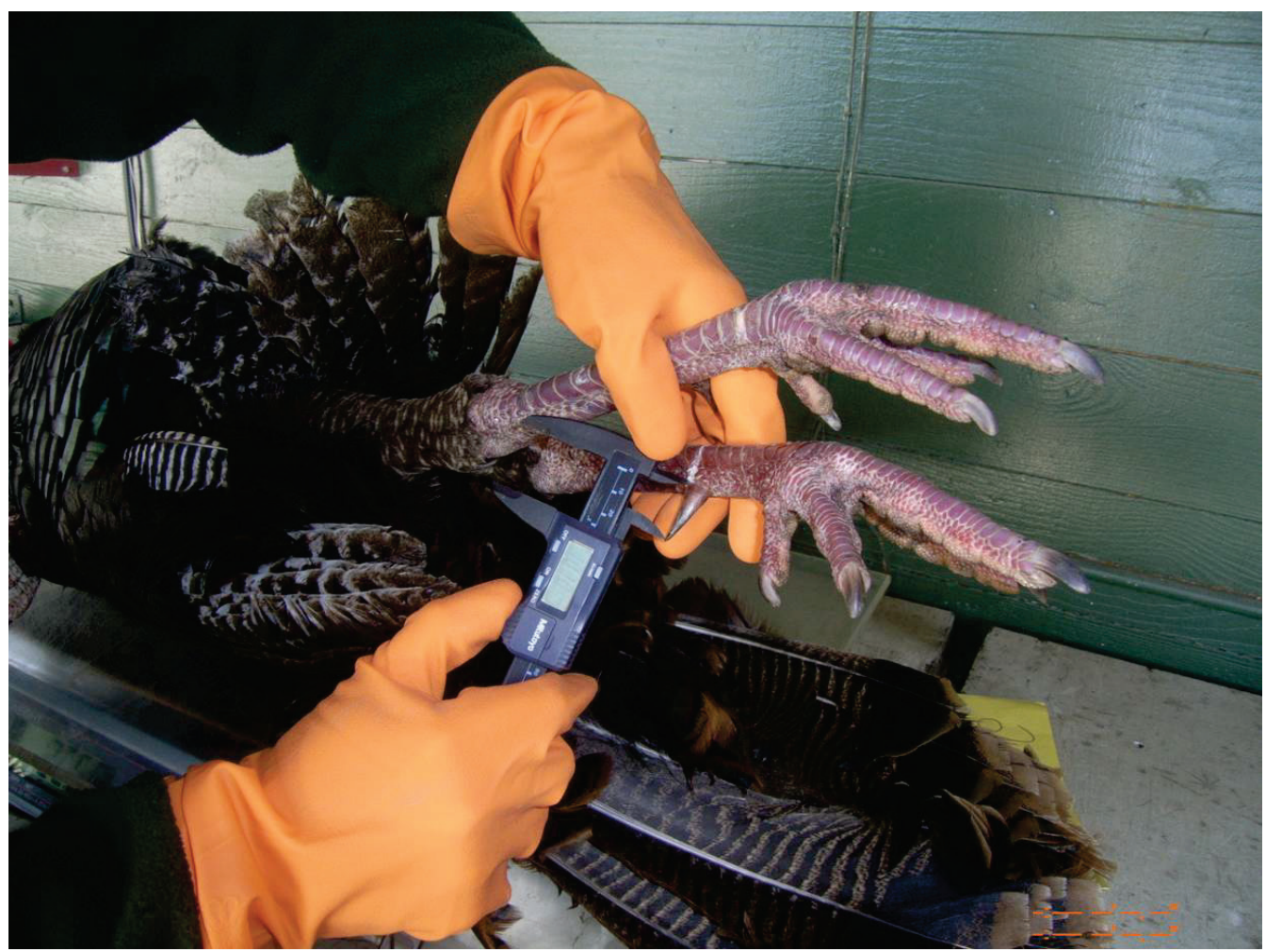

Figure 20. ORNL employee measures spur of harvested turkey at the ORWMA check station. (Photo by N. R. Giffen.) 


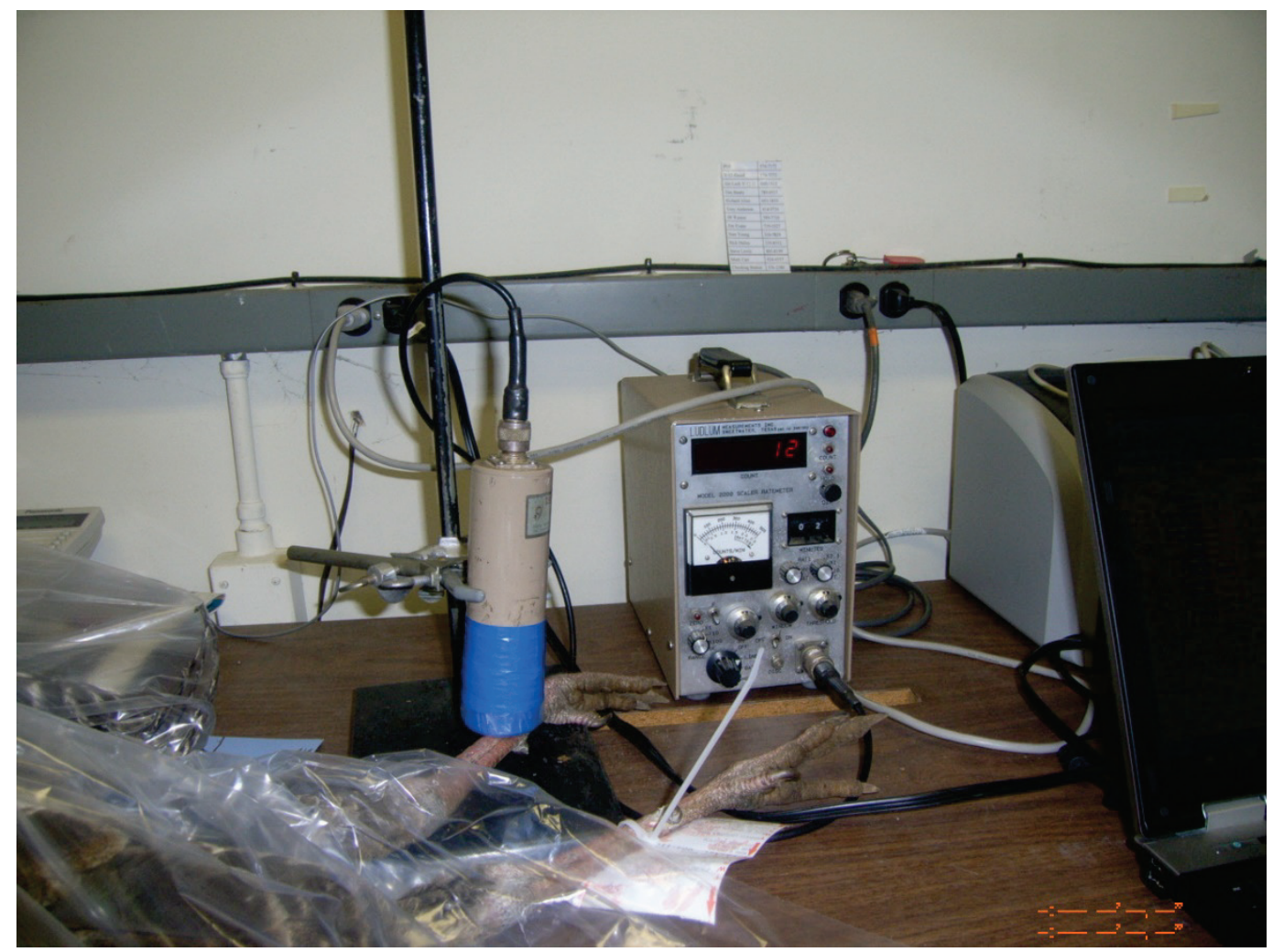

Figure 21. Turkey leg is analyzed for beta energies using beta scintillation detector (Ludlum probe) at the ORWMA check station. (Photo by N. R. Giffen.)

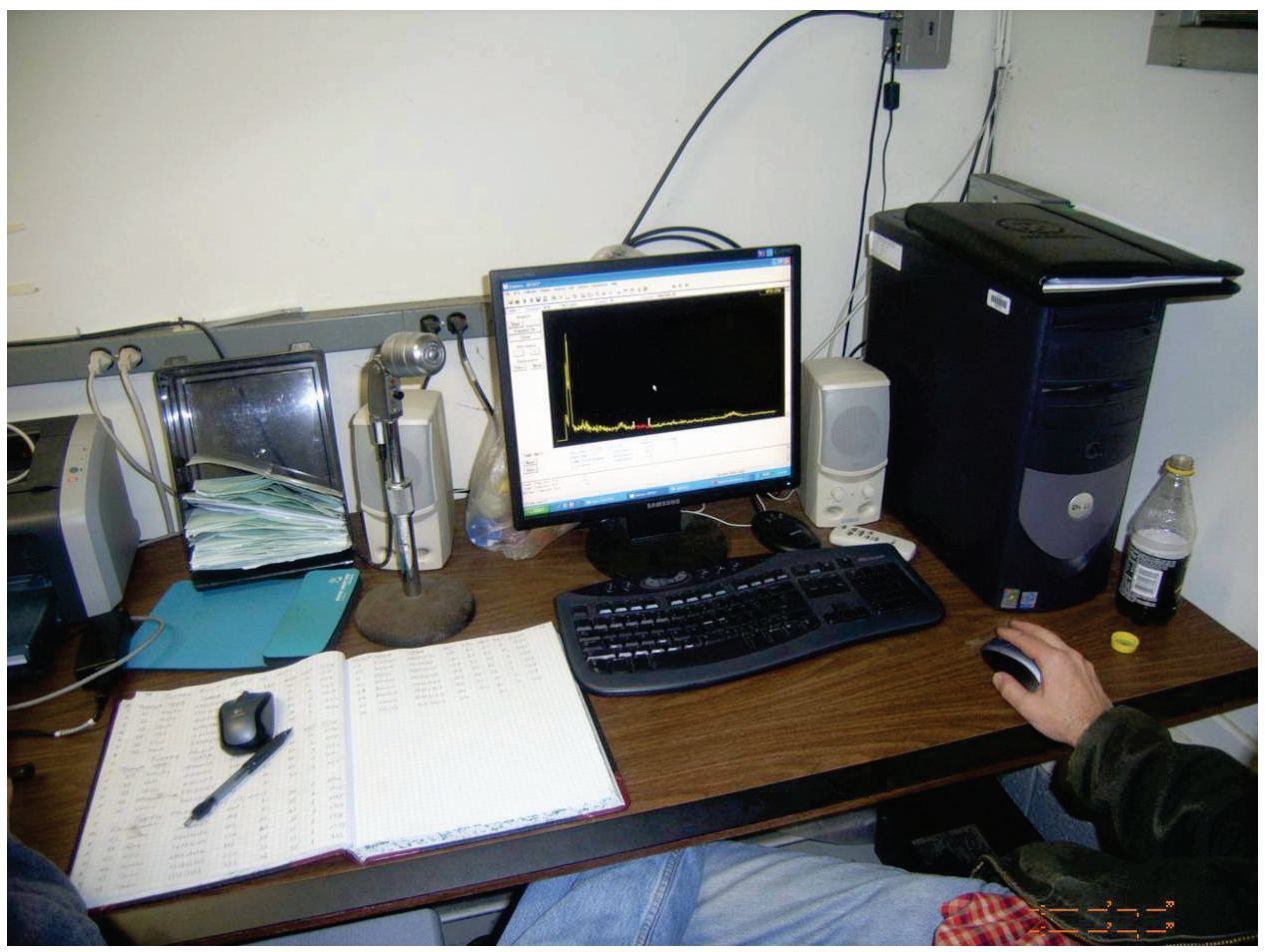

Figure 22. Readout from sodium iodide detector is evaluated for gamma energies from turkey whole-body count at the ORWMA check station. (Photo by N. R. Giffen.) 


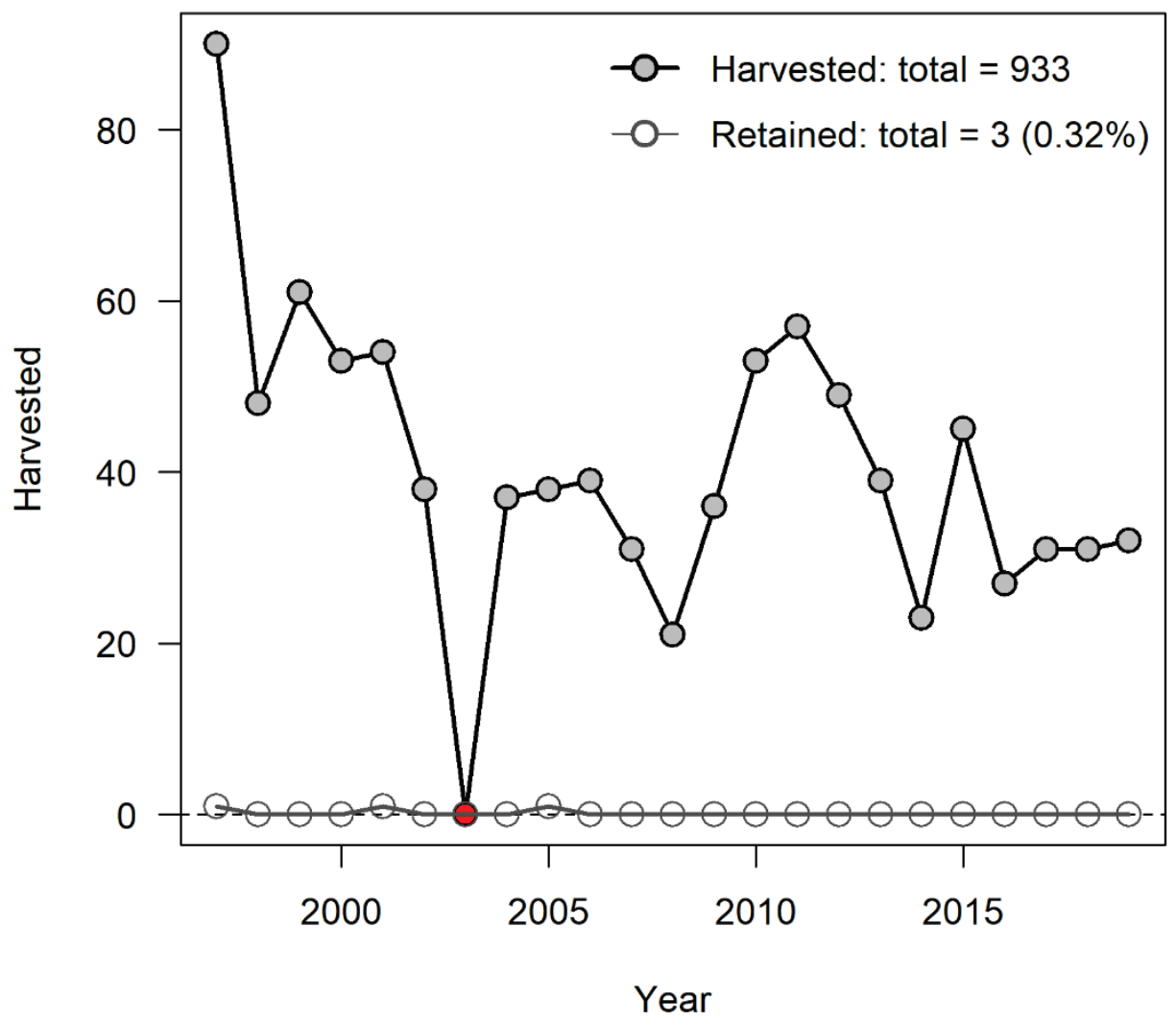

Figure 23. Historical wild turkey harvested and retained numbers for the ORR from 1997-2018. Turkey hunts did not take place in 2003 (red point) because of heightened security measures during that time.

\subsubsection{Canada Goose Management}

The USFWS published a final record of decision and final rule regarding resident Canada goose management in August 2006. This record of decision and final rule allow state wildlife agencies, landowners, and airports more flexibility in controlling resident Canada goose populations. This ruling strictly deals with resident populations and does not impact the protection afforded to migratory geese under the MBTA and Executive Order 13186, Responsibilities of Federal Agencies to Protect Migratory Birds (Appendix A.)

The ORR historically supported a large resident Canada goose population. These large nonmigratory flocks started to prosper in the area in the mid-1980s. Large areas of mowed grass associated with ponds and other water bodies created prime habitat for this species. Canada goose management on the ORR involves a multifaceted approach that is mainly aimed at resolving nuisance concerns. A major obstacle that impacted our ability to control the Canada goose population was the inability to hunt this species in the areas of the Reservation where they tend to congregate. Most goose population were found in the developed portion of the ORR around ponds and large areas of mowed grass. In these areas, geese presented health and safety concerns with their excessive droppings and sometimes aggressive behavior. The main methods used to control Canada geese on the ORR follow.

- Egg addling/oiling/euthanasia and nest removal under registration with the USFWS.

- Relocation of geese to other areas in East Tennessee in concert with the annual summer ORR goose roundup; conducted by the USDA, APHIS-Wildlife Services as permitted by the USFWS. 
- Development of goose habitat in natural areas of the ORR, away from the main employee population, with the focus of habitat development in the Three Bends Area.

- Hunting in the Three Bend Area.

- Harassment using several techniques: chasing, remote control boats on ponds, laser lights at night, and recorded goose distress calls.

- Modification of habitat around ponds to make areas less desirable to geese.

Management efforts have significantly reduced Canada goose populations on the reservation from several hundred in the mid-1990s to fewer than 15 in 2012. In recent years, resident Canada goose numbers have declined substantially, and goose management is less of a focus. Now, habitat manipulation, hunting, and roundups are the primary means of goose control.

\subsection{MANAGEMENT OF THE THREE BEND SCENIC AND WILDLIFE MANAGEMENT REFUGE AREA}

TWRA manages the Three Bend Area through an agreement with DOE. Under that agreement, the TWRA actively manages this approximately 3,000-acre (1214-ha) area for the development of wildlife habitat. A Three Bends Management Plan is undergoing a rewrite and will be presented at a later time by TWRA Manager Shannon Young. This area also acts as an important outdoor laboratory and educational facility. The following management activities are practiced on this site:

- management of native grasslands for both nongame and game species through spraying selective herbicides, disking, and prescribed burning;

- exotic invasive plant eradication;

- establishment and management of habitat for Canada geese as part of the ORR overall goose management program;

- Canada goose and duck hunts in areas of established habitat;

- control of feral hogs and other invasive wildlife;

- training of wildlife management students in trapping, wildlife damage control, bird identification, and other areas;

- summer outdoor education programs;

- community nature walks for public awareness of the natural resources of the area and management activities being undertaken; and

- research on plants and wildlife in an outdoor laboratory setting.

\subsection{NUISANCE WILDLIFE MANAGEMENT}

Please consult the Nuisance Wildlife Education and Prevention Plan for the Oak Ridge National Laboratory (Giffen and Darling, in press) for greater detail on nuisance wildlife issues and remedies.

\subsubsection{Roles and Responsibilities}

\subsubsection{ORR Wildlife Technician}

The ORR Wildlife Technician provides advice and facilitates the resolution of nuisance wildlife management concerns on the ORR, in addition to responding to nuisance wildlife problems on an asneeded basis. 


\subsubsection{TWRA Wildlife Manager}

The TWRA Wildlife Manager responds to nuisance wildlife problems as needed (available during business hours and on-call after hours for emergencies) by providing advice, trapping animals, supplying traps, translocating and euthanasia when necessary, and picking up trapped animals for removal.

\subsubsection{ORR Wildlife Ecologist}

The ORR Wildlife Ecologist provides advice and facilitates the resolution of nuisance wildlife management concerns on the ORR through coordination with the TWRA Wildlife Manager and ORR Wildlife Technician.

\subsubsection{USDA, APHIS-Wildlife Services}

USDA, APHIS-Wildlife Services is typically called to respond to large-scale nuisance wildlife problems, along with those issues that require specialized methods and expertise. In 2013, a contract between DOE and USDA was created to implement an intensive trapping effort at Y-12 to reduce wildlife-caused perimeter intrusion alarms at Y-12.

\subsubsection{Facility}

It is the responsibility of each facility to contact either the ORR Wildlife Ecologist, ORR Wildlife Technician, and/or the TWRA Wildlife Manager(s) for guidance on how to handle problems related to day-to-day wildlife nuisance issues.

\subsubsection{Protocol for Reducing Nuisance Wildlife Problems}

The following guidelines will reduce nuisance wildlife problems on the ORR:

- Do not transport wild and domestic animals from off-site onto the ORR.

- Do not release nuisance wildlife trapped on the ORR to off-site areas (Transport of animals off-site will be done only in certain special cases and under TWRA direction.). Any trapped feral cats should be scanned for radiological contamination then taken to a designated animal shelter.

- Do not feed resident wildlife and feral cats on the ORR.

- Secure all dumpsters and other garbage receptacles to avoid providing a steady food supply to potential nuisance animals.

- Keep building maintenance up to date to prevent entry of animals through holes, broken windows, and other openings.

- Provide ORR personnel with regular communications on how to prevent nuisance wildlife problems through presentations and day-to-day communications with employees.

Justifications for adhering to the aforementioned guidelines are the following:

- Release of animals from other areas to the ORR will only increase the current problem and facilitate spread of disease and/or contaminants.

- The feeding of resident wildlife and feral cats will provide a steady food supply, resulting in sustained and increased nuisance wildlife populations. It will also increase the chances of wildlife/human interactions that can cause health and safety concerns for employees.

- The release of ORR nuisance wildlife to off-site areas can result in the increase of nuisance problems in those areas (i.e., by transferring the problem to someone else), result in the spread of disease and/or 
contaminants, and introduce "foreign" animals into a situation in which they might be unable to compete with resident animals for existing resources.

- USDA, APHIS-Wildlife Services, TWRA, and the Tennessee Department of Health require euthanasia rather than relocation of all raccoons, foxes, coyotes, and skunks trapped in eastern Tennessee counties because of concerns regarding the potential spread of rabies.

\subsubsection{Nuisance Wildlife Management Issues around Facilities}

Nuisance wildlife issues around facilities on the ORR are caused by a variety of species and typically fall into the following categories:

- nesting, denning, or roosting inside buildings;

- digging burrows under buildings and other structures, and

- entering dumpsters and other garbage receptacles in search of food (Figure 24).

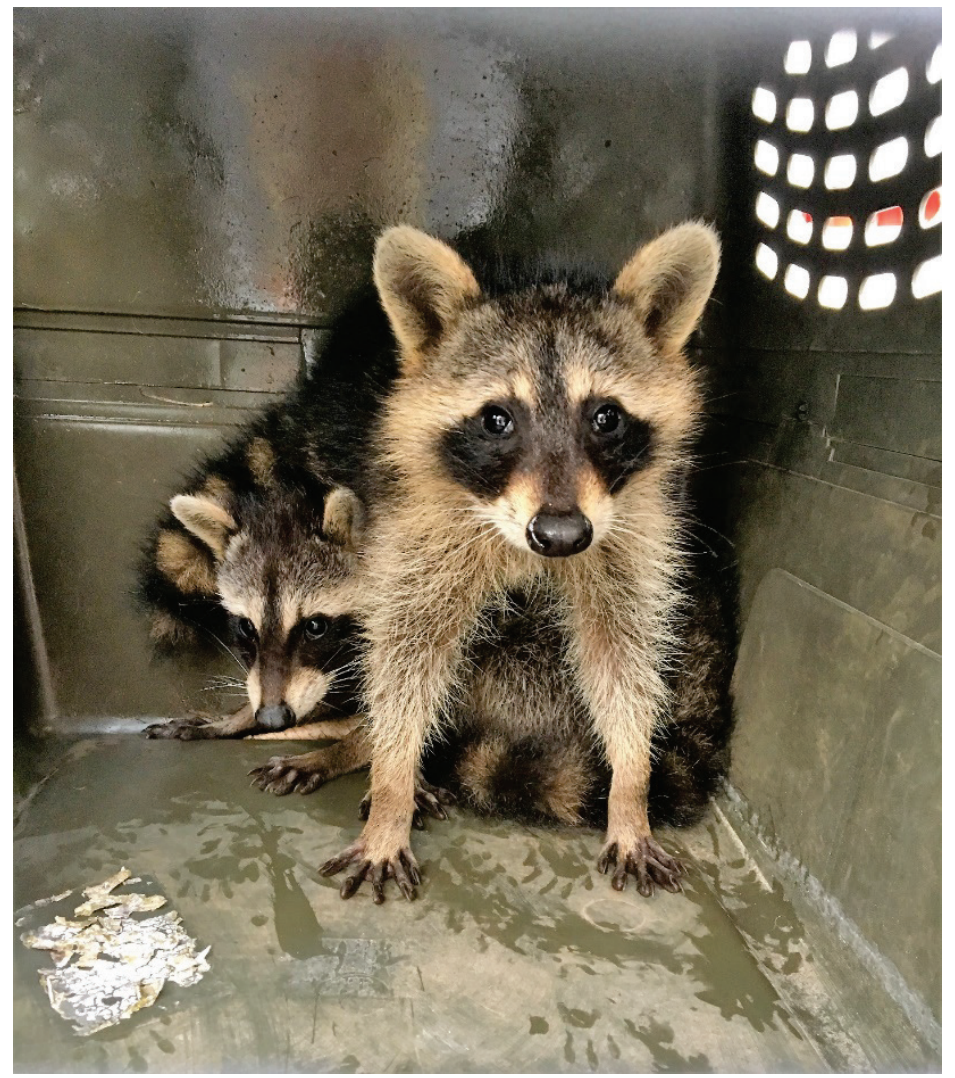

Figure 24. Raccoons removed after being found in a dumpster at ORNL. (Photo by S. E. Darling.)

The chief mammals causing nuisance problems on the ORR are raccoons, skunks, opossums, groundhogs, and cottontail rabbits. These nuisance animals can be handled with the use of baited live traps.

Live traps can be obtained from the TWRA Wildlife Manager or the ORR Wildlife Ecologist. The ORR Wildlife Technician(s) can also provide advice on baiting and the size of trap to use. Once the animal has been trapped, TWRA or the ORR Wildlife Technician can handle its removal. Employees should not handle the animal in any way because of the possibility of disease. TWRA and ORR wildlife professionals are trained to handle these animals and are properly vaccinated against disease, such as 
rabies. USDA, APHIS-Wildlife Services will handle larger trapping efforts in which significant population reduction of nuisance animals is the goal.

\subsubsection{Nuisance Issues Requiring Special Skills}

\subsubsection{Beaver Control}

Beaver control and trapping are specialized skills; therefore, only wildlife professionals such as TWRA or the ORR Wildlife Ecologist and/or Wildlife Technician(s) will handle beaver control issues. The removal of dams and other debris resulting from beaver activity will be the responsibility of the appropriate ORR facilities and operations personnel. Effort is underway to transition from lethal trapping to nonlethal pond levelers for beaver control where possible across the ORR.

\subsubsection{White-Tailed Deer Nuisance Issues}

White-tailed deer can become a nuisance through browsing on ornamental shrubs and trees in campus areas. Deer can also become entrapped between buildings and behind fences. On rare occasions deer can become disoriented and run through windows and open doors. Nuisance problems with white-tailed deer must be addressed by personnel with specialized skills and the proper equipment and permits to handle any given situation. TWRA is the agency with purview over white-tailed deer management in the state. All ORR nuisance problems involving deer will be handled by TWRA, with assistance from the ORR Wildlife Management Coordinator. Roads and grounds crews, ORNL wildlife staff, and TWRA will also aid in the removal of deer from roadways where deer/vehicle collisions have occurred, when necessary.

\subsubsection{Coyote Management}

In areas where they are hunted and trapped, coyotes can be extremely wary. However, in urban environments, such as the ORR campus areas where they live relatively free of harm, they may lose their fear of humans. This can sometimes lead to an unnatural boldness in these animals as they become accustomed to seeing humans and the sights and sounds of the urban environment, which in turn can lead to more confrontations between humans and coyotes.

The ORR supports a large coyote population. Coyotes are generally seen at dawn or dusk, but it is not unusual to see them in the middle of the day. The current management strategy is to make note of coyotes frequenting the ORR campus areas where there is the potential for contact with employees, then determine the appropriate actions on a case-by-case basis based on criteria mentioned previously, such as signs of animals showing no fear of humans or displaying aggression. Management options for animals displaying such behavior are culling or trapping and removal. Coyote management is mainly conducted by TWRA Wildlife Managers and/or USDA, APHIS-Wildlife Services.

\subsubsection{Bobcat Management}

Bobcats are an established resident on the ORR and throughout North America, primarily in forested areas and mountainous terrain with rocky outcrops. Bobcats are about twice the size of a housecat with a "bobbed" tail. They are an exceptional predator and can hunt a variety of prey from rats to small deer. Being extremely wary and secretive, they can be difficult to hunt and trap. In urbanized areas like the ORNL campus, however, they can become quite habituated to the presence of humans.

There is a seemingly healthy population of bobcats on the ORR, and they sometimes appear to be unfearful of humans. However, bobcats rarely attack humans, and their presence does not necessarily 
equate to aggressiveness. Bobcats can be scared away by loud noises or flashing lights, and TWRA can mitigate options for removal if needed.

\subsubsection{Black Bear Management}

In the past, ORR bear sightings were infrequent and characterized by animals passing through or remaining for only very short periods of time (a day or two). More recent records (2017-2018) have involved multiple sightings of a particular bear over longer durations (a week or more). Many are wandering males in search of food. The recent increase in sightings is indicative of the overall increase in the bear population in eastern Tennessee. Most active bear management on the ORR focuses on the need to ensure the safety of employees. Of concern are those bears that habitually frequent dumpsters in the vicinity of buildings where they could be encountered by humans. TWRA takes the lead on any required bear management on the ORR. Live-trapping and removal of animals to existing bear-population areas in eastern Tennessee is the most common management method used by the TWRA in these cases. The first black bear trapped on the ORR was in June 2012 (Figure 25). This event involved a subadult male bear that was frequenting one particular dumpster at the High-Flux Isotope Reactor (HFIR). The bear was trapped and moved to a WMA in Scott County, Tennessee.

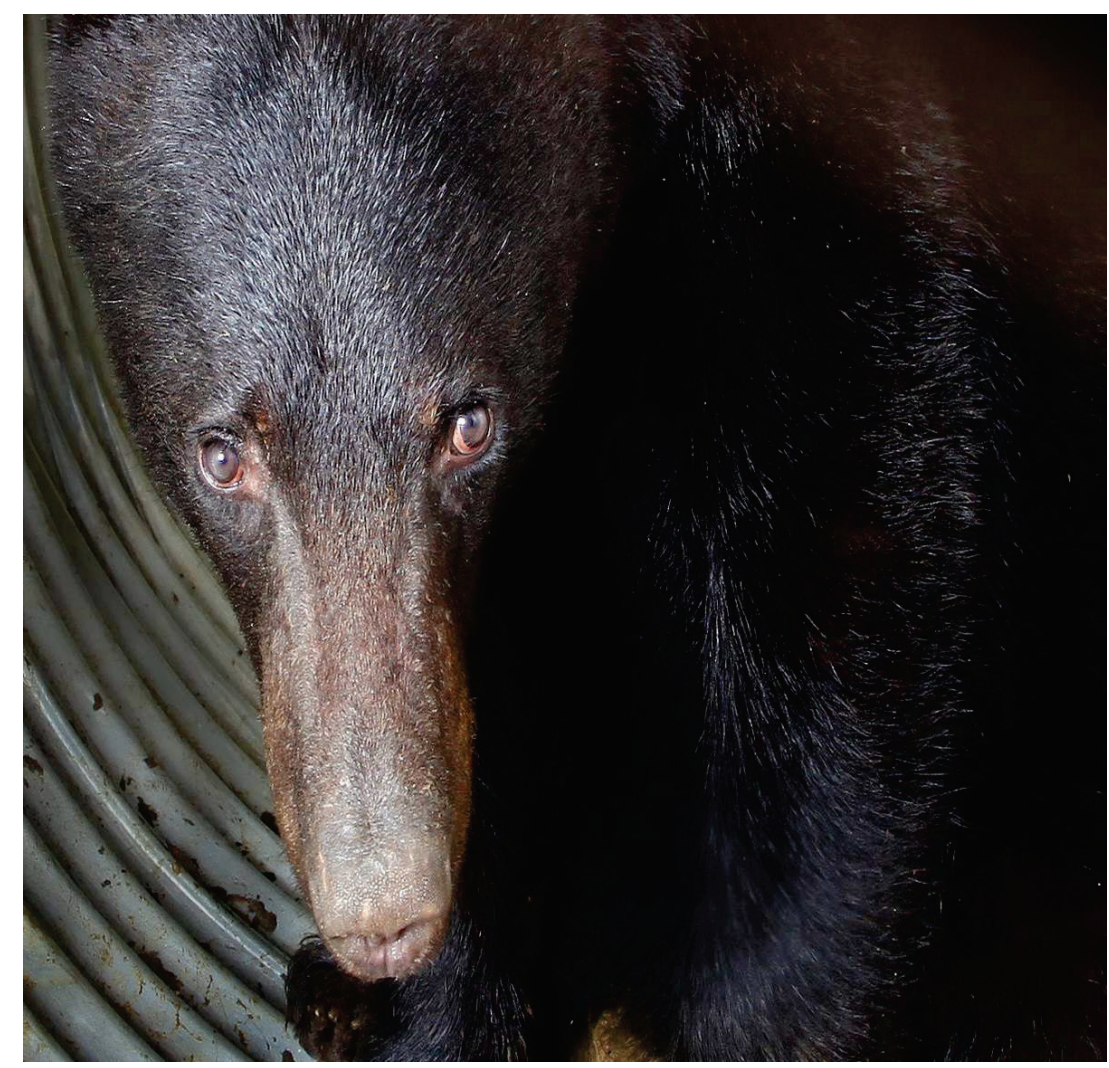

Figure 25. Black bear trapped at the HFIR facility at ORNL (June 2012). (Photo by J. K. Richards.)

\subsubsection{Bat Management}

Occasionally bats can be found roosting on the wall of a building, either inside or outside, on a tree, or lying on the ground. Usually this occurs when a sudden drop in temperature in spring or fall prevents a bat from getting back to its normal roosting site. Bats can carry the rabies virus, and any human contact with bats should be avoided. The TWRA Manager, Wildlife Ecologist, or Wildlife Technician should be 
contacted for removal of bats. These professionals maintain rabies inoculations and are trained in the proper handling of bats.

\subsubsection{Prevention/Minimizing Exposure}

Efforts will be made to discourage use of DOE facilities on the ORR by nuisance wildlife. Further details on the management and prevention of nuisance wildlife problems on the ORR are contained in the Nuisance Wildlife Education and Prevention Plan for the Oak Ridge National Laboratory (Giffen and Darling, in press). The plan outlines certain preventive measures that can be taken to minimize the potential for nuisance wildlife problems on a species-specific basis.

In FY 2007, additional DOE funding was approved to expand nuisance wildlife control efforts on the ORR. A portion of this funding has been used to contract with the USDA, APHIS-Wildlife Services, which has significant experience in this area and holds the federal permits necessary to significantly expand upon the control methods that can be used on the ORR.

\subsubsection{Birds}

\subsubsection{Canada Geese}

Nuisance Canada goose concerns will be handled by the ORR Wildlife Ecologist and/or ORR Wildlife Technician in cooperation with the TWRA Wildlife Manager and USDA, APHIS-Wildlife Services. A multifaceted management approach has been established to address Canada goose nuisance wildlife concerns. The methods include the following:

- Implementation of a no-feeding policy

- Habitat modification to reduce preferred goose habitat

- Landscaping changes to reduce availability of palatable forage plants and create physical barriers.

- Removal

- Egg destruction: Addling of goose eggs was initiated in the spring of 2005 under a USFWS permit and was continued until recently, with a general downward trend in numbers that was reflective of the decrease in the number of nests on the ORR.

- Roundup and relocation: Working through USDA APHIS Wildlife Services under a USFWS permit, TWRA, ORNL Radioactive Materials Analytical Laboratory, ORNL Environmental Protection Services, and the ORR Wildlife Ecologist collect geese in yearly summer roundups. (Yearly roundup and relocation numbers are reflective of the recent decrease in the ORR Canada goose population (Figure 26-27).

- Goose hunt: DOE approved the initiation of a goose hunt (pilot program) in the Three Bend Area in FY 2006. Hunts will be continued based on effectiveness, which is evaluated on a yearly basis.

\subsubsection{Other Birds}

Birds such barn swallows (Hirundo rustica), house sparrows (Passer domesticus, European starlings (Sturnus vulgaris), and rock pigeons (Columba livia) can become a nuisance with their propensity to nest and roost in and around buildings. Most bird nuisance concerns can be handled with modifications in building design and/or additional building maintenance. The ORR Wildlife Ecologist and the TWRA Wildlife Manager will provide advice on potential solutions to these bird nuisance problems. USDA, APHIS-Wildlife Services can be called in if significant problems require euthanasia of unprotected birds (i.e., house sparrows, starlings, and pigeons). Facility Managers are cautioned against disturbing or destroying nests because most birds are protected by the MBTA. 


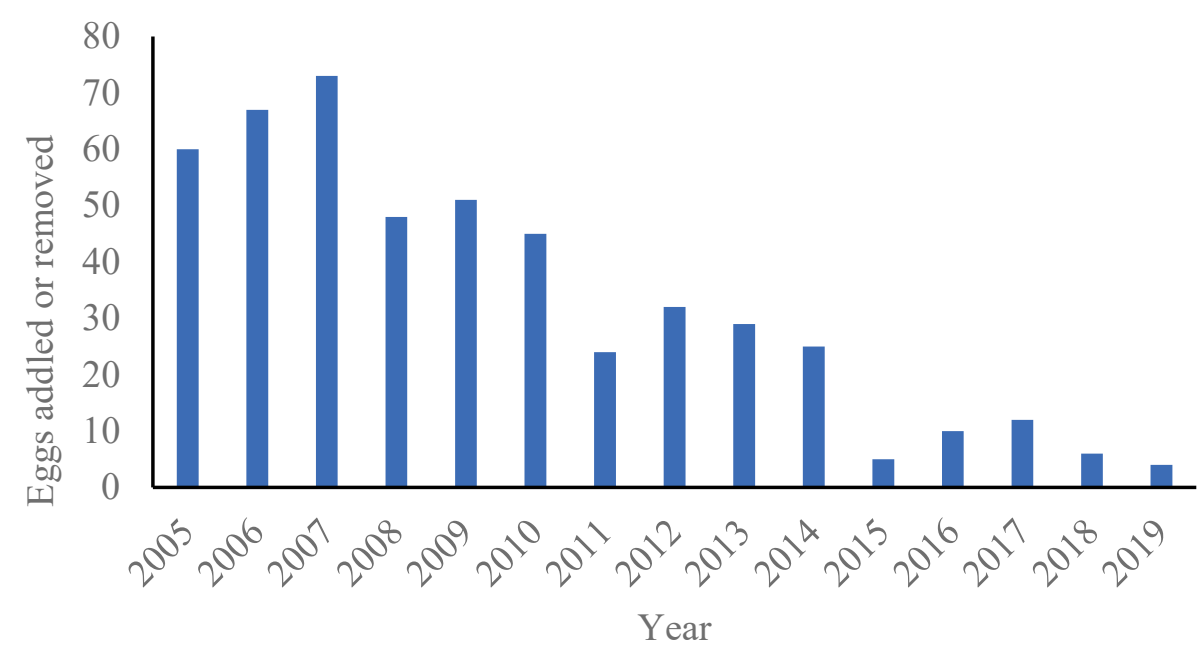

Figure 26. Number of eggs addled/removed during yearly ORR Canada goose nest checks, 2005-2019.

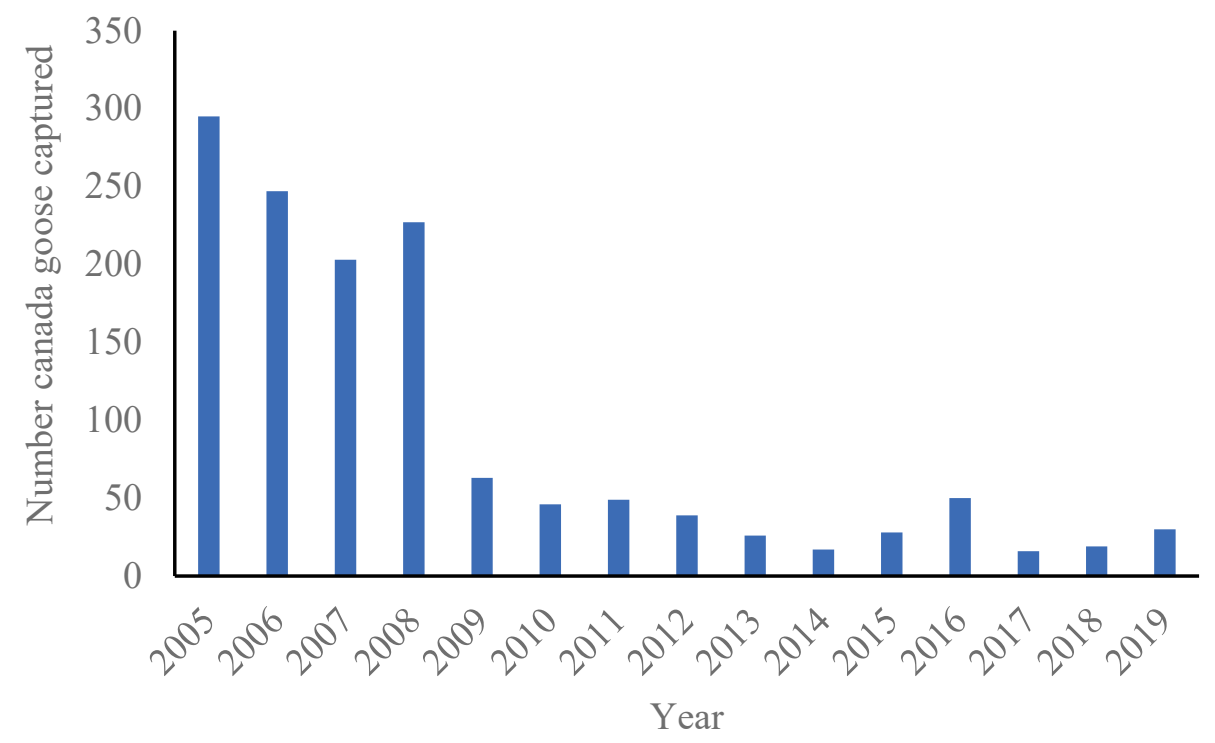

Figure 27. Number of Canada geese captured during yearly summer roundups on the ORR, 2005-2019.

\subsubsection{Snakes}

The copperhead (Agkistrodon contortrix) is the only venomous snake known to reside on the ORR. The copperhead is a pit viper and can be distinguished from nonvenomous snakes by its elliptical pupils and loreal pits (located between and below the eye and nostril). The main nuisance complaints with snakes involve their presence around and in buildings. Landscaping features such as rock slabs and overlapping wooden or stone features in open sunlight, especially near tall herbaceous groundcover, can create attractive habitat for copperheads and other snakes. Note, however, that copperheads rarely inhabit areas that are heavily impacted by humans unless suitable natural habitat has been eliminated nearby, thereby pushing snakes into suboptimal habitat. Even then, copperheads rarely remain in high human-use areas for long. While many nuisance calls claim the presence of copperheads, this is almost never the case as most responses are for watersnakes (Figure 28), ratsnakes, or other nonvenomous colubrids. 
Most medium to larger-bodied snakes are able to access buildings through any gap/hole that is generally $1 / 4$ in. $(0.64 \mathrm{~cm})$ or larger. Control of snakes in buildings first and foremost requires that all gaps of $1 / 4$ in. $(0.64 \mathrm{~cm})$ or larger to the outside be blocked. In general, anything that provides cover close to the ground or provides a stable microclimate can attract snakes. For instance, a snake may seek a dark, cool retreat during warm summer months, or it may seek a warm, damp retreat during colder periods. During summer when snakes are most active, preferred retreat sites are those that provide quick access between sun and shade (e.g., rock slabs used for landscaping, crevices under sidewalks, holes in foundations). Moreover, they can be attracted to the outsides of buildings where there are low bushes and shrubs, rocks, boards, firewood piles, and debris lying on the ground. Such areas can provide both a retreat site and source of food by attracting rodents and various invertebrates. Therefore, if a snake presents a nuisance problem, the aforementioned factors should be thoroughly evaluated by the ORR Wildlife Ecologist and Wildlife Technician, who will provide recommendations for modifying internal and external building features. Importantly, there are no registered toxicants or fumigants for snakes. Several repellents have been promoted, but none is consistently effective, and many can be harmful to humans and nontarget species.

The ORR Wildlife Ecologist/Technician or TWRA Wildlife Manager will respond to emergency snake nuisance concerns.

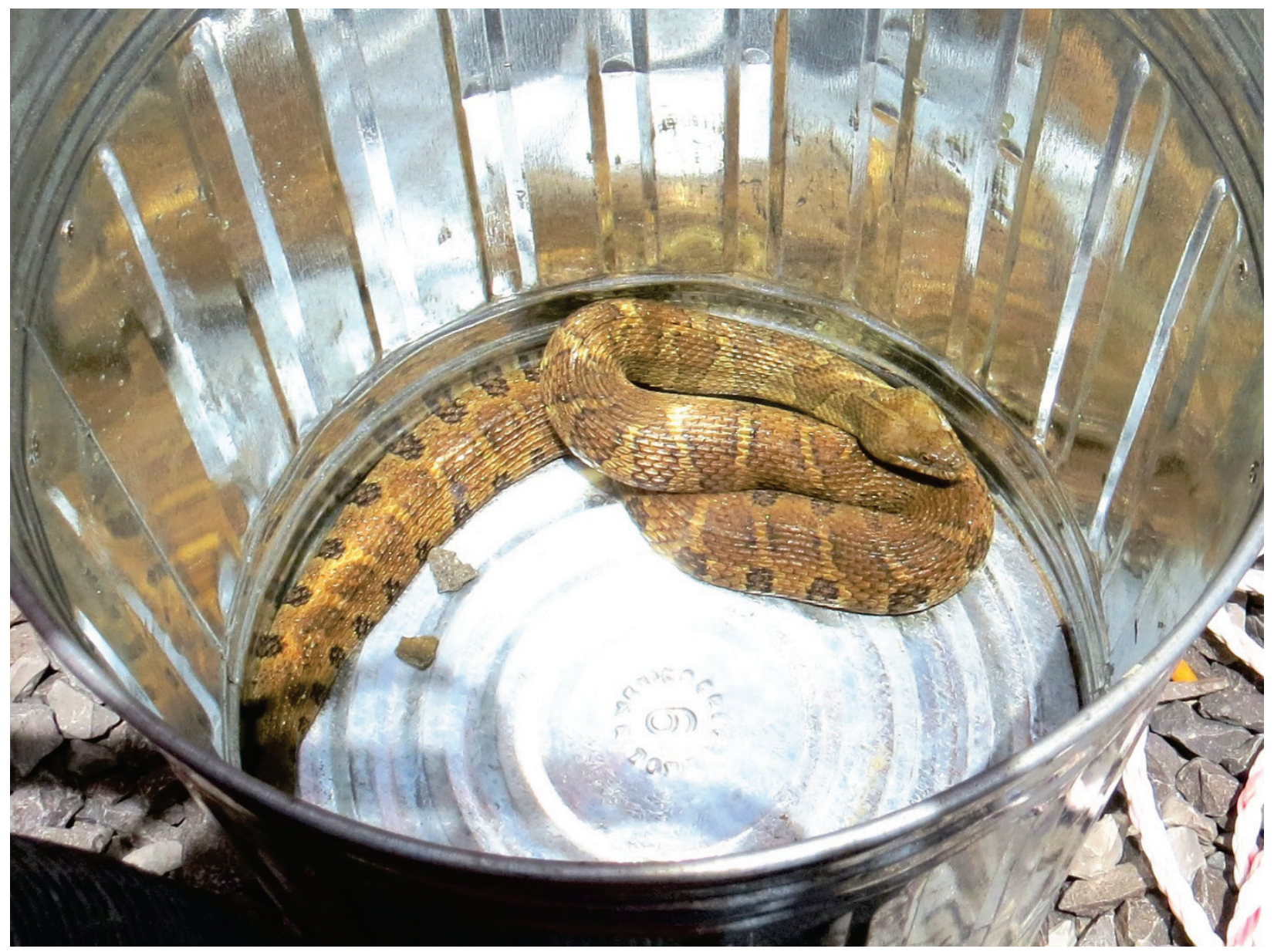

Figure 28. Northern water snake found in a pump house reservoir at ORNL. (Photo by W. K. Roy.) 


\subsubsection{Insects}

\subsubsection{Fire Ants}

The main nuisance insect on the ORR is the fire ant. Imported fire ants are reddish-brown to black and are $1 / 8$ to $1 / 4$ in. $(0.3$ to $0.6 \mathrm{~cm})$ long. They construct nests that are often most visible as dome-shaped mounds of soil, sometimes as large as $3 \mathrm{ft}(0.9 \mathrm{~m})$ in diameter and $11 / 2 \mathrm{ft}(0.5 \mathrm{~m})$ in height. In general, mounds are 12 in. $(30.5 \mathrm{~cm})$ or more in diameter and height. In sandy soils, mounds are flatter and less visible. Fire ants usually build mounds in sunny, open areas such as lawns, pastures, cultivated fields, and meadows, but they are not restricted to these areas. Mounds or nests can also be located in rotting logs, around trees and stumps, under pavement and buildings, and occasionally indoors. Fire ants are most notable at facilities in sparsely vegetated, grassy areas and along sidewalks and curbs. Fire ant mounds are typically treated with chemical pesticides, and each facility is responsible for treatment within its boundaries.

\subsubsection{Other Insects}

The majority of insect pest problems on the ORR are handled by either facility personnel or contracted pest-control companies. In an effort to protect native pollinators, any concerns regarding insects and/or swarms can be directed initially to the ORR Wildlife Ecologist/Technician.

\subsubsection{Bee Swarms}

Occasionally, honey bees will swarm in an area where they could come in contact with employees. When this occurs, the TWRA Manager or Wildlife Ecologist/Technician should be contacted. They will arrange for a trained honey bee specialist to safely remove the swarm.

\subsection{SENSITIVE SPECIES INVENTORY, PROTECTION, AND MANAGEMENT}

Sensitive species are those specifically designated by federal, state, or other government agencies for protection or consideration. Sensitive species in Tennessee include those listed as federally Endangered or Threatened (USFWS 2019), as well as species listed by the state of Tennessee as Endangered, Threatened, In Need of Management or Of Special Concern (TWRA 2018). ORR Wildlife Managers also include those bird species recognized by PIF as being of regional importance in the Appalachian Mountain Region. A list of sensitive species found on the ORR is presented in Table 1. The objective of sensitive-species management is to identify, protect, and preserve individual species and their habitats. The status of the sensitive plant species and the process by which they are identified, and their habitats protected, have been addressed in various ORR reports (Parr 1984; Parr and Pounds 1987; Cunningham et al. 1993). Sensitive avian taxa are discussed by Roger Kroodsma in his article "Edge effect on breeding birds along power-line corridors in east Tennessee" (1987). We have comparatively little information to inform management strategies of most nonavian sensitive wildlife on the ORR. The results of surveys for sensitive species on the ORR are contained in internal reports to Natural Resources Management (Mitchell et al. 1996; Harvey 2006; Giffen, Reasor, and Campbell 2009; Giffen, Reasor, and Campbell 2011; McCracken and Giffen 2015). Continued monitoring of birds (e.g., bald eagle) and mammals (e.g., Indiana bat) is needed. However, additional focus on reptiles and amphibians is particularly important. Short-term objectives for management of sensitive species include continuing to maintain and update lists of all wildlife species on the ORR; identifying, through continued surveys, the rare wildlife that occur on the ORR; determining habitat needs of listed or rare species; providing protection of habitat through special protected area designation (e.g., Research Park Natural Area, State Natural Area); and evaluating the need for initiating (if deemed necessary) active habitat management. 
Current activities to monitor sensitive species include the following:

- TWRA midwinter bald eagles counts and surveys of active nests,

- Partners in Flight surveys,

- acoustical surveys for bats,

- mist-net/harp-trap surveys for bats,

- reptile and amphibian surveys,

- cave surveys, and

- small mammal surveys.

TWRA conducts yearly midwinter bald eagle counts along the Clinch River, which borders the ORR, in accordance with the continuing statewide monitoring program (TWRA 2005). It is part of a count conducted statewide by the agency to monitor population trends for this species, which is increasing in numbers in eastern Tennessee. The ORR supports one or two nests per year, and these are continually monitored.

PIF surveys are conducted yearly on the ORR by ORNL and TWRA personnel and volunteers. A total of 11 PIF routes are present on the ORR and cover a mixture of forest, edge, old field, and grassland habitats. Approximately 6-8 surveys are conducted in May and June during the breeding season for most bird species. 
Table 1. Wildlife species of conservation concern reported for the $\mathrm{ORR}^{a, b}$

\begin{tabular}{|c|c|c|c|c|}
\hline \multirow{2}{*}{ Scientific name } & \multirow{2}{*}{ Common name } & \multicolumn{3}{|c|}{ Status $^{c}$} \\
\hline & & Federal & State & PIF \\
\hline \multicolumn{5}{|c|}{ FISH } \\
\hline Phoxinus tennesseensis & Tennessee dace & & NM & \\
\hline \multicolumn{5}{|c|}{ AMPHIBIANS } \\
\hline Crytobranchus alleganiensis & Hellbender & $\mathrm{MC}$ & $\mathrm{E}$ & \\
\hline Hemidactylium scutatum & Four-toed salamander & & NM & \\
\hline \multicolumn{5}{|c|}{ REPTILES } \\
\hline Pituophis melanoleucus & Northern pinesnake & & $\mathrm{T}$ & \\
\hline \multirow[t]{2}{*}{$\begin{array}{l}\text { Ophisarurus attenuates } \\
\text { longicaudus }\end{array}$} & Eastern slender glass lizard & & NM & \\
\hline & BIRDS & & & \\
\hline \multicolumn{5}{|l|}{ DARTERS } \\
\hline Anhinga anhinga & Anhinga & & NM & \\
\hline \multicolumn{5}{|l|}{ BITTERNS \& HERONS } \\
\hline Egretta caerulea & Little blue heron & & NM & \\
\hline Ixobrychus exilis & Least bittern & & NM & \\
\hline Nycticorax nycticorax & Black-crowned Night-heron & & NM & \\
\hline \multicolumn{5}{|c|}{ KITES, HAWKS, EAGLES, \& ALLIES } \\
\hline Haliaeetus leucocephalus & Bald eagle & $\mathrm{MC}^{d}$ & NM & \\
\hline \multicolumn{5}{|l|}{ FALCONS } \\
\hline Falco peregrinus & Peregrine falcon & $\mathrm{MC}^{e}$ & & \\
\hline Falco sparverius & American kestrel & $\mathrm{MC}$ & & \\
\hline \multicolumn{5}{|c|}{ GROUSE, TURKEY, \& QUAIL } \\
\hline Colinus virginianus & Northern bobwhite & & & CBSD \\
\hline \multicolumn{5}{|c|}{ RAILS, GALLINULES, \& COOTS } \\
\hline Porzana carolina & Sora & $\mathrm{MC}$ & & \\
\hline \multicolumn{5}{|l|}{ SHOREBIRDS } \\
\hline Scolopax minor & American woodcock & $\mathrm{MC}$ & & \\
\hline \multicolumn{5}{|l|}{ CUCKOOS \& ALLIES } \\
\hline Coccyzus americanus & Yellow-billed cuckoo & & & CBSD \\
\hline \multicolumn{5}{|l|}{ OWLS } \\
\hline Aegolius acadicus & Northern saw-whet owl & $\mathrm{MC}$ & & \\
\hline \multicolumn{5}{|l|}{ GOATSUCKERS } \\
\hline Caprimulgus vociferus & Whip-poor-will & & & YWL \\
\hline \multicolumn{5}{|l|}{ SWIFTS } \\
\hline Chaetura pelagica & Chimney swift & & & YWL \\
\hline \multicolumn{5}{|l|}{ WOODPECKERS } \\
\hline Melanerpes erythrocephalus & Red-headed woodpecker & $\mathrm{MC}$ & & YWL \\
\hline Sphyrapicus varius & Yellow-bellied sapsucker & $\mathrm{MC}$ & & \\
\hline
\end{tabular}


Table 1. Wildlife species of conservation concern reported for the $\mathrm{ORR}^{a, b}$ (continued)

\begin{tabular}{|c|c|c|c|c|}
\hline \multirow{2}{*}{ Scientific name } & \multirow{2}{*}{ Common name } & \multicolumn{3}{|c|}{ Status $^{\mathrm{c}}$} \\
\hline & & Federal & State & PIF \\
\hline \multicolumn{5}{|l|}{$\begin{array}{l}\text { TYRANT FLYCATCHERS } \\
\end{array}$} \\
\hline Contopus cooperi & Olive-sided flycatcher & MC & & YWL \\
\hline Contopus virens & Eastern wood-pewee & & & \\
\hline Empidonax trailii & Willow flycatcher & $\mathrm{MC}$ & & \\
\hline \multicolumn{5}{|l|}{ SWALLOWS } \\
\hline Riparia riparia & Bank swallow & & & CBSD \\
\hline \multicolumn{5}{|l|}{ NUTHATCHES } \\
\hline Sitta pusilla & Brown-headed nuthatch & $\mathrm{MC}$ & & \\
\hline \multicolumn{5}{|c|}{ KINGLETS, GNATCATCHERS, \& THRUSHES } \\
\hline Hylocichla mustelina & Wood thrush & $\mathrm{MC}$ & NM & $\mathrm{CI}$ \\
\hline \multicolumn{5}{|l|}{ SHRIKES } \\
\hline Lanius ludovicianus & Loggerhead shrike & $\mathrm{MC}$ & NM & CBSD, FS \\
\hline \multicolumn{5}{|l|}{ WOOD WARBLERS } \\
\hline Vermivora chrysoptera & Golden-winged warbler & $\mathrm{MC}^{f}$ & $\mathrm{~T}$ & CBSD, RWL \\
\hline Vermivora pinus & Blue-winged warbler & $\mathrm{MC}$ & & \\
\hline Setophaga cerulea & Cerulean warbler & MC & NM & RWL \\
\hline Setophaga discolor & Prairie warbler & & & YWL \\
\hline Helmitheros vermivorus & Worm-eating warbler & MC & & \\
\hline Limnothlypis swainsonii & Swainson's warbler & & NM & \\
\hline Protonotaria citrea & Prothonotary warbler & MC & & \\
\hline Geothlypis formosus & Kentucky warbler & MC & & YWL \\
\hline Cardellina canadensis & Canada warbler & & & YWL \\
\hline Parkesia motacilla & Louisiana waterthrush & $\mathrm{MC}$ & & \\
\hline \multicolumn{5}{|c|}{ TOWHEES, SPARROWS, \& ALLIES } \\
\hline Ammodramus savannarum & Grasshopper sparrow & $\mathrm{MC}$ & & CBSD \\
\hline Pooecetes gramineus & Vesper sparrow & & NM & \\
\hline Ammodramus henslowii & Henslow's sparrow & MC & $\mathrm{T}$ & IM, YWL \\
\hline Melospiza georgiana & Swamp sparrow & & & RI \\
\hline \multicolumn{5}{|l|}{ BLACKBIRDS \& allies } \\
\hline Dolichonyx oryzivorus & Bobolink & $\mathrm{MC}$ & & YWL \\
\hline Euphagus carolinus & Rusty Blackbird & & & CBSD \\
\hline Sturnella magna & Eastern meadowlark & & & CBSD \\
\hline \multicolumn{5}{|c|}{ MAMMALS } \\
\hline Zapus hudsonius & Meadow jumping mouse & & NM & \\
\hline Sorex dispar & Long-tailed Shrew & & NM & \\
\hline Synaptomys cooperi & Southern bog lemming & & NM & \\
\hline Myotis sodalis & Indiana bat & $\mathrm{E}$ & NM & \\
\hline Myotis grisescens & Gray bat & $\mathrm{E}$ & & \\
\hline Myotis septentrionalis & Northern long-eared bat & $\mathrm{T}$ & & \\
\hline Myotis lucifugus & Little brown bat & & $\mathrm{T}$ & \\
\hline
\end{tabular}


Table 1. Wildlife species of conservation concern reported for the $\mathrm{ORR}^{a, b}$ (continued)

\begin{tabular}{|c|c|c|c|c|}
\hline \multirow{2}{*}{ Scientific name } & \multirow{2}{*}{ Common name } & \multicolumn{3}{|c|}{ Status $^{c}$} \\
\hline & & Federal & State & PIF \\
\hline Perimyotis subflavus & Tri-colored bat & & $\mathrm{T}$ & \\
\hline Corynorhinus rafinesquii & Rafenisque's big-eared bat & & NM & \\
\hline Myotis leibii & Eastern small-footed bat & & NM & \\
\hline
\end{tabular}

${ }^{a}$ This list identifies sensitive wildlife species found on the ORR. Some of these (e.g., anhinga) have been seen only once or a few times; others, (e.g., American kestrel) are comparatively common and widespread on the Reservation (updated Sept. 2018).

${ }^{b}$ Land and surface waters of the ORR exclusive of the Clinch River, which borders the ORR.

${ }^{c} \mathrm{E}=$ Endangered, $\mathrm{T}=$ Threatened, $\mathrm{MC}=$ Species of Management Concern, $\mathrm{NM}=\mathrm{In}$ Need of Management, $\mathrm{RI}=\mathrm{Regional}$ Importance, $\mathrm{CI}=$ Continental Importance, RWY $=$ Red Watch List, YWL = Yellow Watch List, IM = Immediate

Management, FS = Focal Species, CBSD = Common Bird in Steep Decline.

${ }^{d}$ The bald eagle was federally delisted effective August 8, 2007.

${ }^{e}$ The Peregrine falcon was federally delisted effective August 25, 1999.

${ }^{f}$ The golden-winged warbler is currently under federal review (Sept. 17, 2018).

Efforts to record all avian species surveyed or otherwise encountered continue, and these records are tallied and entered into "ebird," an online database for monitoring bird populations. Recently, the Avian Knowledge Network was examined, with the potential goal of entering all ORR bird data for future reference.

Charles Sturt University and the ORNL Natural Resources Management Team (NRMT) have collaborated in acoustic surveys of bird and anuran species since June 2017. Australian researcher and ornithologist, Liz Znidersic, conducted acoustic and trail camera studies that resulted in discovery of the purple gallinule on the ORR (Figure 29). An article, "First Roane County Record of Purple Gallinule is captured on trail camera," which highlighted the collaboration on the ORR among Liz Znidersic, Kelly Roy, and Sarah Darling, was published in the 2017 issue of The Migrant, a quarterly journal of The Tennessee Ornithological Society describing results of research on Tennessee birds (Roy et al., 2017).

Before 1992, information on the bat species present on the ORR was limited to occasionally finding bats taking refuge in facility structures or bat carcasses in buildings. Scientific advances in acoustic recording equipment since then have made bat population surveys possible. Between 1992 and 2012, most bat surveys were conducted as part of environmental assessments tied to particular projects (Harvey 1992; Harvey 1997; Harvey and Britzke 2004; BHE Environmental, Inc. 2005; BHE Environmental, Inc. 2008; Jackson 2011). Surveys were conducted at several caves and select other areas on the ORR over short periods of time. These involved mist net or harp trap bat capture and identification of bats, or Anabat acoustic surveys (Mitchell et al. 1996; Harvey and Britzke 2003; Giffen and Evans 2011; Giffen and Evans 2012). Acoustical equipment and analytical software are now common practice in bat survey methodology. Beginning in the summer of 2013, acoustic bat population surveys have been carried out annually using Wildlife Acoustics SM3+Bat and SM4Bat FS detectors with high-frequency microphones. Recorded calls were analyzed using Wildlife Acoustics Kaleidoscope Pro Software, Version 1, and Sonabat bat call analytical software from 2013-2015 and using Kaleidoscope Pro Version 4.0.0, both FS and XC, from 2016-2018. Mist net and harp trap surveys were done in 2013 to identify and verify bat species present on the ORR. Acoustic systems, which allow for identification of bats by recording vocalizations, have the advantage over other bat survey techniques (e.g., mist nests, harp traps) in that they do not require the actual handling of the animals. The availability of this technique is important for several reasons:

- Detectors can be deployed passively for a duration of days or weeks and can be programmed to record calls from dusk until dawn without the presence of technical staff. 
- Call identification software has advanced to the point that bats can be identified by species, and call identification accuracy can be statistically determined, thus allowing the presence of sensitive species to be verified at each site.

- More sites can be surveyed concurrently using multiple detectors.

- Identification without contacting bats removes the possibility of spreading diseases, such as Whitenose Syndrome, between animals and limits bat/human interactions.

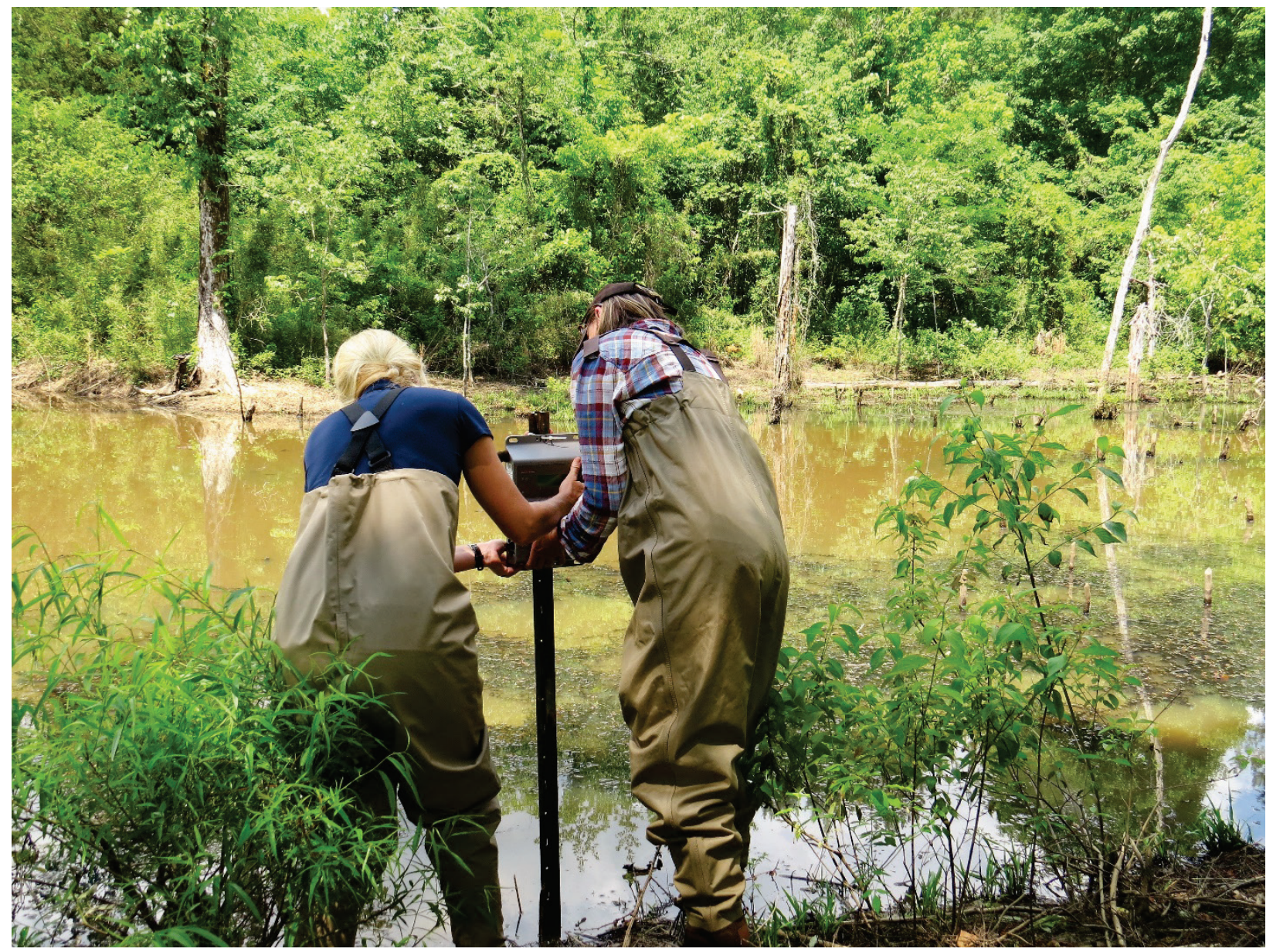

Figure 29. ORR Wildlife Technician Sarah Darling and Researcher Liz Znidersic setting up an Acoustic Recording Device at a beaver pond on the ORR.

Results of surveys from 2013 through 2015 were used to verify that 14 species of bats reside on the ORR. Three state- and federally listed species (Indiana bat, Myotis sodalis-Endangered; gray bat, Myotis grisescens - Endangered, and northern long-eared bat, Myotis septentrionalis - Threatened) are found across the Reservation. An additional four species of state-listed species are found across the ORR (little brown bat, Myotis lucifugus - state threatened; tri-colored bat, Perimyotis subflavus - state threatened; Rafinesque's big-eared bat, Corynorhinus rafinesquii-state in-need-of-management; eastern smallfooted bat, Myotis leibii-state in-need-of-management). The presence of these species means that all projects that could impact these species, whether through incidental take or habitat loss, require consultation with the USFWS before project start-up. Continued monitoring of bat species diversity and population density across the ORR will continue to inform Project Managers and allow TWRA Managers and the ORR Wildlife Ecologist to plan habitat improvement and preservation for these species. 
An extensive reptile and amphibian abundance and distribution survey was conducted on the ORR from 2007 to 2009 (Giffen, Reasor, and Campbell 2009) to update the status of reptile and amphibian populations. It was the first major study conducted on the ORR since 1996. A total of 360 specimens of 35 species were recorded during this survey, including the state-listed in-need-of-management four-toed salamander (Hemidactylum scutatum).

An extensive small mammal abundance and distribution survey was conducted on the ORR from 2009 to 2010 (Giffen, Reasor, and Campbell 2011) to update the status of small mammal populations. It was the first major study conducted on the ORR since 1996. A total of 227 specimens of 9 species were recorded during this survey, including the state-listed in-need-of-management meadow jumping mouse (Zapus hudsonius). Future reptile, amphibian, and small mammal surveys will be conducted in the forthcoming years.

\subsection{WILDLIFE DISEASE MANAGEMENT}

\subsubsection{Rabies}

Potential rabies carriers on the ORR include raccoons, skunks, coyotes, foxes, and bats. There are no current records of rabies cases on the ORR; however, reports of sick animals are closely monitored, and animals are euthanized for testing when necessary. USDA, APHIS-Wildlife Services is the agency responsible for testing the animals, and it has established a mobile laboratory in the vicinity of the deercheck station on Bethel Valley Road. Any sick animals should be reported to either the TWRA Wildlife Manager or the ORR Wildlife Ecologist/Technician.

\subsubsection{Pandemic Flu (Avian Influenza)}

\subsubsection{Monitoring}

Several state and federal agencies are monitoring birds for avian influenza in the United States. Monitoring of the local situation in the bird population is conducted locally (on the ORR and surrounding area) by USDA, APHIS-Wildlife Services and TWRA. The ORR Wildlife Ecologist will maintain regular communication with these agencies. Sampling of a variety of birds began in summer 2006. Samples include throat cultures and cloacal swabs. This enhanced surveillance has included collection along the Mississippi Flyway in western Tennessee (mallard, American wigeon, and other species) and the resident bird collection (mourning dove, black vulture, Canada goose, rock pigeon, European starling, common grackle, wood duck, house sparrow, American crow, American robin, and various raptors).

\subsubsection{Preventing/Minimizing Exposure}

The active Canada goose population control program has been highly successful in reducing the number of geese on the ORR, thus minimizing negative goose-human interactions. Additionally, control of rock pigeons and other nuisance birds on the ORR is actively conducted in cooperation with TWRA and USDA, APHIS-Wildlife Services. The contracting of USDA, APHIS-Wildlife Services allows for the broadening of nuisance-bird population control methods because of the wide scope allowed to them through federal permitting. General control of nesting and roosting nuisance birds through building maintenance and the ORR no-feeding policy will also aid in reducing contact between people and birds around interior campus areas. 


\subsubsection{Education}

TWRA provides hunter information about avian influenza in birds (e.g., precautions, awareness) for the ORR turkey hunts (April) and Canada goose hunts (September), as needed.

The ORR Wildlife Ecologist will continue to educate staff through presentations and informational updates to ORNL Today (http://home.ornl.gov/general/ORNL Today/) and other facility information sites. TWRA has avian influenza information available on its website (https://www.tn.gov/content/tn/twra/wildlife/wildlife-disease.html\#avianInfluenza).

\subsubsection{Handling Sick or Dead Birds}

If sick or dead birds are found on the ORR (particularly if found in groups), the TWRA Wildlife Manager or ORR Wildlife Ecologist should be contacted.

Reports of birds killed for obvious reasons (e.g., roadkills, collisions with windows) should be reported to the Wildlife Ecologist or Wildlife Technician. Of particular interest are groups of sick or dead birds. USDA, APHIS-Wildlife Services, and TWRA provide guidance to their staffs regarding handling of birds (even apparently healthy ones). Birds (dead or alive) should not be handled by untrained persons. TWRA and USDA, APHIS-Wildlife Services are trained to handle these birds and so will dispose of dead and/or infected birds.

\section{PLANNED MANAGEMENT ACTIVITIES: FY 2019 TO FY 2023}

Projected activities for the wildlife management program FY 2019 through FY 2023 are as follows:

- Annual public deer hunts

- Annual public wild turkey hunts

- T\&E and rare taxa surveys (emphasis on amphibians and reptiles)

- Sensitive and understudied habitat inventories (e.g., caves, seeps and springs, forested wetlands and flatwoods, exposed karst, cedar barrens)

- Annual Canada goose hunts

- Other Canada goose population control (e.g., roundup and relocation, egg addling/oiling, nest removal, and deterrent strategies)

- Wood duck census and hunt

- Partners-in-Flight surveys

- Continuation of osprey monitoring program and powerline damage control

- Evaluation and implementation of grassland management approaches, including northern bobwhite habitat enhancement

- Implementation of recommendations from selective forest management study and forest fragmentation study to increase species diversity (formal studies are few, and research is needed)

- Bat surveys using mist nets, harp traps, and Wildlife Acoustics SM4Bat FS detectors and Kaleidoscope Pro software acoustic bat identification system

- Bald eagle surveys and habitat protection (e.g., nests)

- Nuisance wildlife management (selected bird and mammal species)

- Public bird walks and other educational/recreational undertakings 


\section{REFERENCES}

Anderson, R. C., and O. L. Loucks. 1979. "White-tail deer (Odocoileus virginianus) influence on structure and composition of Tsuga canadensis forests." Journal of Applied Ecology 16: 855-861.

BHE Environmental, Inc. 2005. A mist net survey for the Indiana bat at the proposed Oak Ridge Reservation EMWMF Haul Road, Roane County, TN. Prepared for East Tennessee Mechanical Corp., Oak Ridge, TN.

BHE Environmental, Inc. 2008. Mist net survey for the Indiana and the gray bat in selected holdings within the East Tennessee Technology Park, Roane County, TN. Prepared for the US DOE, Oak Ridge, TN.

Brinkley, S. K., and D. A. Buehler. 2012. Monitoring Avian Communities on the Oak Ridge Reservation: Native and Nonnative Grasslands. ORNL/TM-2012/135. Oak Ridge, TN: Oak Ridge National Laboratory.

Buehler, D. A. 1994. Bald Eagle Habitat Suitability on Melton Hill Reservoir and the Clinch River. Environmental Sciences Division Publication No. 4248. ORNL/NERP-9. Oak Ridge, TN: Oak Ridge National Laboratory.

Cunningham, M., L. Pounds, S. Oberholster, P. Parr, L. Edwards, B. Rosensteel, and L. Mann. 1993. Resource Management Plan for the Oak Ridge Reservation, Volume 29: Rare Plants on the Oak Ridge Reservation. ORNL/NERP-7. Oak Ridge, TN: Oak Ridge National Laboratory.

DOE (Department of Energy). 1993. Integrating Natural Resource Damage Assessment and Environmental Restoration Activities at DOE Facilities. Office of Environmental Guidance, US Department of Energy.

DOE (Department of Energy). 2010. Oak Ridge Reservation Annual Site Environmental Report for 2010. DOE/ORO/2379, US Department of Energy.

Fahey, R. T., B. C. Alveshere, J. I. Burton, A. W. D’Amato, Y. L. Dickinson, W. S. Keeton, C. C. Kern, A. J. Larson, B. J. Palik, K. J. Puettmann, and M. R. Saunders. 2018. "Shifting conceptions of complexity in forest management and silviculture." Forest Ecology and Management 421: 59-71.

Gates, J. E., and L. W. Gysel. 1978. "Avian nest dispersion and fledging success in field-forest ecotones." Ecology 59(5): 871-883.

Giffen, N. R., and S. E. Darling. In press. Nuisance Wildlife Education and Prevention Plan for the Oak Ridge National Laboratory. Oak Ridge, TN: Oak Ridge National Laboratory.

Giffen, N. R., J. W. Evans, and P. D. Parr. 2007. Wildlife Management Plan for the Oak Ridge Reservation. ORNL/TM-2006/155. Oak Ridge, TN: Oak Ridge National Laboratory.

Giffen, N. R., J. W. Evans, and P. D. Parr. 2012. Wildlife Management Plan for the Oak Ridge Reservation. ORNL/TM-2012/387. Oak Ridge, TN: Oak Ridge National Laboratory.

Giffen, N. R., R. S. Reasor, and C. A. Campbell. 2009. Reptile and Amphibian Abundance and Distribution Survey. ORNL/TM-2009/296. Oak Ridge, TN: Oak Ridge National Laboratory.

Giffen, N. R., and J. W. Evans. 2011. Bat Monitoring on the Oak Ridge Reservation. Unpublished report for US DOE, Oak Ridge, TN.

Giffen, N. R., and J. W. Evans. 2012. Bat Monitoring on the Oak Ridge Reservation. Unpublished report for US DOE, Oak Ridge, TN.

Giffen, N. R., R. S. Reasor, and C. A. Campbell. 2011. Small Mammal Abundance and Distribution Survey, Oak Ridge Environmental Research Park. ORNL/TM-2011/323. Oak Ridge, TN: Oak Ridge National Laboratory.

Giffen, N. R., D. C. Wade, and M. Mueller. 2012. Interior Forest Areas of the Oak Ridge National Environmental Research Park. ORNL/TM-2012/388. Oak Ridge, TN: Oak Ridge National Laboratory.

Hanberry, B. B., and F. R. Thompson III. 2019. "Open forest management for early successional birds." Wildlife Society Bulletin 43(1): 141-151. 
Harvey, M. J. 1992. Survey for endangered Indiana and gray bats along East Fork Poplar Creek in the Vicinity of Oak Ridge, Tennessee. Unpublished report to Science Applications International Corp.

Harvey, M. J. 1997. Survey for Endangered and Threatened Bats on Parcel ED-1, Oak Ridge Reservation. Unpublished report to the Environmental Sciences Division, Oak Ridge National Laboratory.

Harvey M. J., and E. R. Britzke. 2003. Survey for Bats on the Oak Ridge Reservation. Unpublished report to the Environmental Sciences Division, Oak Ridge National Laboratory.

Harvey, M. J., and E. R. Britzke. 2004. Anabat Survey for Bats at Pond K1007 P1 on the Oak Ridge Reservation. Unpublished report to the Environmental Sciences Division, Oak Ridge National Laboratory.

Harvey, M. J. 2006. Mist Netting Survey of Bats at Caves on the Oak Ridge Reservation. Unpublished report to the Environmental Sciences Division, Oak Ridge National Laboratory.

Hough, A. F. 1965. "A twenty-year record of understory vegetational change in a virgin Pennsylvania forest." Ecology 46: 370-373.

Huges, W. E., A. R. Saremi, and J. F. Paniati. 1996. "Vehicle-animal crashes: an increasing safety problem." ITE Journal 66(8): 24-28.

Jackson, Allyson. 2011. Invertivore (birds and bats) sampling records for Oak Ridge, Tennessee. Biodiversity Research Institute, Portland, ME.

Jones, C., J. McCann, and S, McConville. 2001. A Guide to the Conservation of Forest Interior Dwelling Birds in the Chesapeake Bay Critical Area, June 2000. Critical Area Commission for the Chesapeake and Atlantic Coastal Bays, Annapolis, MD.

Kroodsma, R. L. 1987. "Edge effect on breeding birds along power-line corridors in east Tennessee." American Midland Naturalist 118: 275-283.

Layzer, J. A. 2012. The purpose and politics of ecosystem-based management. In Sustainability science (pp. 177-197). Springer, New York, NY.

Mann, L. K., P. D. Parr, L. R. Pounds, and R. L. Graham. 1996. "Protection of biota on nonpark public lands: examples from the U.S. Department of Energy Oak Ridge Reservation." Environmental Management 20: 207-218.

McCracken, M. K., N. R. Giffen, A. M. Haines, B. J. Guge, and J. W. Evans. 2015. Bat Species Distribution on the Oak Ridge Reservation. ORNL/TM-2015/248. Oak Ridge, TN: Oak Ridge National Laboratory.

McCracken, M. K., and N. R. Giffen. 2017. Invasive Plant Management Plan for the Oak Ridge Reservation. ORNL/TM-2004/98/R2. Oak Ridge, TN: Oak Ridge National Laboratory.

Mitchell, J. M., E. R. Vail, J. W. Webb, and J. W. Evans. 1996. Survey of Terrestrial Vertebrates on the Oak Ridge Reservation. ES/ES/TM-188/R1. Oak Ridge, TN: Oak Ridge National Laboratory.

PIF (Partners in Flight). 2017. Avian Conservation Assessment Database, version 2017. Available at http://pif.birdconservancy.org/ACAD. Accessed on September 18, 2018.

Parr, P. D. 1984. Resource Management Plan for the Oak Ridge Reservation, Volume 4: Endangered and Threatened Plant Species. ORNL-6026/V4. Oak Ridge, TN: Oak Ridge National Laboratory.

Parr, P. D., G. S. Byrd, and J. W. Johnston, Jr. 2012. Integrated Forest Management Plan for the Department of Energy Oak Ridge Reservation. ORNL/TM-2015/389. Oak Ridge, TN: Oak Ridge National Laboratory.

Parr, P. D., G. S. Byrd, J. W. Johnston, Jr., and N. R. Giffen. 2015. Forest Management Plan for the DOE Oak Ridge Reservation: An Interdisciplinary Approach for Managing a Heritage Resource. ORNL/TM-2015/98. Oak Ridge, TN: Oak Ridge National Laboratory.

Parr, P. D., and J. F. Hughes. 2006. Oak Ridge Reservation Physical Characteristics and Natural Resources. ORNL/TM-2006/110. Oak Ridge, TN: Oak Ridge National Laboratory.

Parr, P. D., and J. W. Evans. 1992. Resource Management Plan for the Oak Ridge Reservation, Volume 27: Wildlife Management Plan. ORNL/NERP-6. Oak Ridge, TN: Oak Ridge National Laboratory. 
Parr, P. D., and L. R. Pounds. 1987. Resource Management Plan for the Oak Ridge Reservation, Volume 23: Oak Ridge National Environmental Research Park, Research Sites, and State Natural Areas. ORNUESH-1/V23. Oak Ridge, TN: Oak Ridge National Laboratory.

Parr, P. D., M. G. Ryon, H. D. Quarles, N. R. Giffen, M. S. Salk, and J. W. Webb. 2004. Invasive Plant Management Plan for the Oak Ridge Reservation. ORNL/TM-2004/98. Oak Ridge, TN: Oak Ridge National Laboratory.

Pounds, L. R., P. D. Parr, and M. G. Ryon. 1993. Resource Management Plan for the Oak Ridge Reservation, Volume 30: Oak Ridge National Environmental Research Park Natural Areas and Reference Areas-Oak Ridge Reservation Environmentally Sensitive Sites Containing Special Plants, Animals, and Communities. ORNL/NERP-8. Oak Ridge, TN: Oak Ridge National Laboratory.

Puettmann, K. J., K. D. Coates, and C. C. Messier. 2012. A critique of silviculture: managing for complexity. Island Press: Washington, DC.

Quarles, H. D., M. S. Salk, P. D. Parr, M. G. Ryon, and N. R. Giffen. 2011. Invasive Plant Management Plan for the Oak Ridge Reservation. ORNL/TM 2004/98/R1. Oak Ridge, TN: Oak Ridge National Laboratory.

Robbins, C. S. 1980. "Effect of forest fragmentation on breeding bird populations in the Piedmont of the mid-Atlantic region." Atlantic Naturalist 33:31-36.

Robinson, S. K., F. R. Thompson III, T. M. Donovan, D. R. Whitehead, and J. Faaborg. 1995. "Regional forest fragmentation and the nesting success of migratory birds." Science 267: 1987-1990.

Rosenberg, K. V., A. M. Dokter, P. J. Blancher, J. R. Sauer, A. C. Smith, P. A. Smith, J. C. Stanton, A. Panjabi, L. Helft, M. Parr, P. P. Marra. 2019. "Decline of the North American avifauna." Science, eaaw1313. DOI 10.1126/science.aaw1313.

Ross, B. A., J. R. Bray, and W. H. Marshall. 1970. "Effects of long-term deer exclusion on a Pinus resinosa forest in north-central Minnesota." Ecology 51: 1088-1093.

Roy, W. K., et al. 2017. "First Roane County Record of Purple Gallinule is Captured On Trail Camera," The Migrant 88(4): 137-140.

Ryon, M. G., P. D. Parr and K. Cohen. 2007. Native Grass Community Management Plan for the Oak Ridge Reservation. ORNL/TM-2007/038, Oak Ridge National Laboratory, Oak Ridge, TN.

Seymour, R. S., A. S. White, and G. D. Philip. 2002. "Natural disturbance regimes in northeastern North America- evaluating silvicultural systems using natural scales and frequencies." Forest Ecology and Management 155(1-3): 357-367.

Slocombe, D. S. 1993. Implementing ecosystem-based management. BioScience, 43(9): 612-622.

Slocombe, D. S. 1998. Defining goals and criteria for ecosystem-based management. Environmental management 22(4): 483-493.

Steenberg, J. W., P. N. Duinker, and S. A. Nitoslawski. 2019. Ecosystem-based management revisited: Updating the concepts for urban forests. Landscape and Urban Planning 186: 24-35.

Temple, S. A., and J. R. Cary. 1988. "Modeling dynamics of habitat-interior bird populations in fragmented landscapes." Conservation Biology 2: 340-347.

TWRA (Tennessee Wildlife Resources Agency). 2006. Black Oak Ridge Conservation Easement Final Management Plan. Managing Agency: State of Tennessee, Tennessee Wildlife Resources Agency, in consultation with Department of Environment and Conservation, Division of Natural Heritage, February.

TWRA (Tennessee Wildlife Resources Agency). 2005. Tennessee's Comprehensive Wildlife Conservation Strategy. Available at http://www.wildlifeactionplan.org/pdfs/action_plans/ tn_action_plan.pdf.

TWRA (Tennessee Wildlife Resources Agency). 2018. Tennessee's Watchable Wildlife. Retrieved from http://www.tnwatchablewildlife.org. Accessed on Sept 18, 2018.

TWRA (Tennessee Wildlife Resources Agency). 2016. Threatened and Endangered Species List Rules. pdf. Available at https://www.tn.gov/content/tn/twra/wildlife.html\#endangered. Accessed on September 18, 2018.

TNC (The Nature Conservancy). 1995. The Oak Ridge Reservation, Biodiversity and the Common Ground Process. Final report. Available at http://www.esd.ornl.gov/facilities/nerp/orr_tnc.pdf. 
Washington-Allen, R. A., T. L. Ashwood, S. W. Christensen, H. Offerman, and P. Scarbrough-Luther. 1995. Terrestrial Habitat Mapping of the Oak Ridge Reservation: Phase 1. ES/ER/TM-152. Oak Ridge, TN: Oak Ridge National Laboratory.

Whitney, G. G. 1984. "Fifty years of change in the arboreal vegetation of Heart's Content, an old growth hemlock-white pine-northern hardwood stand." Ecology 65: 403-408.

USFWS (US Fish and Wildlife Service). 2011. "Birds of Management Concern and Focal Species." Available at https://www.fws.gov/migratorybirds/pdf/management/BMCFocalSpecies.pdf. Accessed on September 18, 2018.

USFWS (US Fish and Wildlife Service). 2018. ECOS Environmental Conservation Online System. Retrieved from https://ecos.fws.gov/ecp0/reports/ad-hoc-species-report-input. Accessed on September 18, 2018.

USFWS (US Fish and Wildlife Service). 2019. Endangered Species. Retrieved from https://www.fws.gov/endangered/index.html. Accessed on September 18, 2019. 



\section{APPENDIX A.}

MEMORANDUM OF UNDERSTANDING BETWEEN THE UNITED STATES FISH AND WILDLIFE SERVICE, DEPARTMENT OF THE INTERIOR, AND THE DEPARTMENT OF ENERGY REGARDING IMPLEMENTATION OF EXECUTIVE ORDER 13186, "RESPONSIBILITIES OF FEDERAL AGENCIES TO PROTECT MIGRATORY BIRDS"

$$
\text { AND }
$$

SELECTED PORTIONS OF EXECUTIVE ORDER 13186 



\section{MEMORANDUM OF UNDERSTANDING \\ between \\ THE UNITED STATES DEPARTMENT OF ENERGY \\ and \\ The United States Fish AND WiLdlife SeRvice}

Regarding Implementation of Executive Order 13186, "Responsibilities of Federal Agencies to Protect Migratory Birds"

Prepared by:

United States Department of Energy

and

United States Fish and Wildlife Service

September 12, 2013 


\section{MEMORANDUM OF UNDERSTANDING between \\ The United STATES DEPARTMENT OF ENERGY \\ and \\ The United STATes Fish AND WiLdLIFE SERVICE \\ Regarding Implementation of Executive Order 13186, "Responsibilities of Federal Agencies to Protect Migratory Birds"}

This Memorandum of Understanding (MOU) is entered into by and between the United States

Department of Energy (DOE or the Department) and the United States Department of the Interior, Fish and Wildlife Service (FWS), herein collectively referred to as the Parties.

\section{A. Purpose and Scope}

This MOU meets the requirements under Section 3 of Executive Order 13186, (66 FR 3853, January 17, 2001), concerning the responsibilities of Federal agencies to promote the conservation of migratory bird populations. The purpose of this MOU is to strengthen migratory bird conservation through enhanced collaboration between DOE and the FWS, in coordination with state, tribal, and local governments. This MOU does not remove the Parties' legal requirements under the Migratory Bird Treaty Act (MBTA) and other pertinent statutes; thus it does not authorize the take of migratory birds. This MOU identifies specific areas in which cooperation between the Parties will substantially contribute to the conservation and management of migratory birds and their habitats. This MOU replaces the previous 2006 MOU between DOE and the FWS.

\section{B. Authorities}

This MOU is entered under the provisions of the following laws and other authorities available to the Parties:

- Bald and Golden Eagle Protection Act of 1940, as amended (16 U.S.C. $\$ \S$ 668-668d) (Eagle Act)

- Department of Energy Organization Act of 1977, as amended (42 U.S.C. $§ 7256$ ) 
- Endangered Species Act of 1973, as amended (16 U.S.C. $\$ \S 1531-1544$ ) (ESA)

- Executive Order 13186, Responsibilities of Federal Agencies to Protect Migratory Birds, 2001 (66 FR 3853) (EO 13186)

- Executive Order 13112, Invasive Species, 1999 (64 FR 6183) (EO 13112)

- Fish and Wildlife Coordination Act of 1934, as amended (16 U.S.C. $§ \S 661-666 \mathrm{c}$ ) (FWCA)

- Migratory Bird Conservation Act of 1929 , as amended (16 U.S. C. $\S \S 715-715$ s) (MBCA)

- Migratory Bird Treaty Act of 1918, as amended (16 U.S.C. $\$ \S 703-711$ ) (MBTA)

- National Environmental Policy Act of 1969 , as amended (42 U.S.C. $\$ \S 4321-4347$ ) (NEPA)

\section{Missions of Both Parties}

\section{$\underline{\text { DOE }}$}

The mission of DOE is to ensure America's security and prosperity by addressing its energy, environmental, and nuclear challenges through transformative science and technology solutions. DOE contributes to the future of the Nation by fostering energy efficiency and the development of clean and renewable energy technologies; enhancing nuclear security through defense and nonproliferation efforts; and advancing innovation and discovery in science and technology. The Department, including the National Nuclear Security Administration (NNSA), operates 24 preeminent research laboratories and sites (collectively DOE Sites or sites), four power marketing administrations (Bonneville Power Administration (BPA), Southeastern Power Administration (SEPA), Southwestern Power Administration (SWPA), and Western Area Power Administration (WAPA)), as well as undertakes remediation of the environmental legacy of Cold War activities at DOE sites across the country. All components of DOE - including NNSA and the four power marketing administrations - are covered by this MOU.

- The NNSA is responsible for the management and security of the nation's nuclear weapons, 
nuclear nonproliferation, and naval reactor programs. It also responds to nuclear and radiological emergencies in the United States and abroad. Additionally, NNSA Federal agents provide safe and secure transportation of nuclear weapons and components and special nuclear materials, and carry out other missions supporting the national security.

- The BPA mission is to create and deliver the best value for customers and constituents in concert with others to assure the Pacific Northwest has an adequate, efficient, economical and reliable power supply; a transmission system that is adequate to the task of integrating and transmitting power from Federal and non-Federal generating units; and mitigation of the Federal Columbia River Power System's impacts on fish and wildlife.

- The SEPA is responsible for marketing electric power and energy generated at reservoirs operated by the U.S. Army Corps of Engineers. Southeastern does not own transmission facilities and must contract with other utilities to provide transmission, or "wheeling" services, for the Federal power.

- The SWPA markets hydroelectric power from U.S. Army Corps of Engineers multipurpose dams. Southwestern operates and maintains 1,380 miles of high-voltage transmission lines, substations, and a communications system.

- WAPA markets and delivers reliable, renewable, cost-based hydroelectric power and related services from 56 power plants operated mainly by the Bureau of Reclamation and U.S. Army Corps of Engineers. Western operates and maintains the transmission system from its four regional offices.

\section{FWS}

As a Federal agency within the U.S. Department of the Interior, the mission of the FWS is to work with others to conserve, protect, manage, and enhance fish, wildlife, plants, and their habitats for the continuing benefit of the American people. The FWS Division of Migratory Bird Management serves as a focal point in the United States for policy development and strategic planning, program implementation, and evaluation of actions designed to conserve migratory birds and their habitats. 
The FWS is legally mandated to implement the conservation provisions of the MBTA, which includes responsibilities for managing migratory bird populations, domestic and international coordination, and the development and enforcement of regulations that govern the take of migratory birds. The MBCA and the FWCA mandate migratory bird habitat conservation, including protection through acquisition, enhancement, and/or management to avoid and minimize adverse impacts.

FWS programs that involve bird conservation activities include:

1. The Division of Migratory Bird Management and the Migratory Bird Programs in the FWS Regional Offices serve as focal points for policy development and strategic planning. These offices develop and implement monitoring and management initiatives that help maintain healthy populations of migratory birds and their habitats and provide continued opportunities for citizens to enjoy bird-related recreation.

2. The Division of Bird Habitat Conservation is instrumental in supporting habitat conservation partnerships through the administration of bird conservation grant programs and development of Joint Ventures that serve as major vehicles for implementing the various bird conservation plans across the country.

3. Ecological Services Field Offices across the country serve as the primary contacts for technical assistance and environmental reviews involving migratory bird issues. The Field Offices coordinate with the Regional Migratory Bird Offices, as necessary, regarding MBTA and Eagle Act permits and overall migratory bird conservation.

4. The Office of Law Enforcement is the principal FWS program that enforces the legal provisions of the MBTA, Eagle Act, ESA, and other laws pertaining to migratory bird conservation.

5. The National Wildlife Refuge System manages National Wildlife Refuges (NWRs) and Waterfowl Production Areas across the country, many of which were established to protect and conserve migratory birds. NWRs not only protect important bird habitat, but also focus on monitoring migratory bird populations and restoring and maintaining native habitats. 
6. The Science Applications program works with other Service programs and partners to ensure that the necessary science and tools are available for planning and implementing the most efficient and effective conservation actions to protect fish and wildlife including migratory birds. They facilitate regional self-directed science management partnerships called Landscape Conservation Cooperatives to develop and apply shared science capacity to conservation.

\section{Statement of Mutual Interest and Benefit}

DOE manages approximately 2.28 million acres of land, of which a substantial amount is undeveloped and includes wetlands, shrub-steppe, shortgrass prairie, desert, and forested areas. Much of these lands provide habitat for a variety of wildlife, including many species of migratory birds. DOE takes its environmental stewardship role seriously and advocates an environmental management system (EMS) approach, conforming to the ISO 14001:2004 (E) International Standard, towards compliance with applicable environmental laws and regulations and preservation of natural and cultural resources. Migratory birds are a part of the natural and human-made environment at DOE sites, and proper management of migratory birds and their habitats on DOE lands fosters vigorous and diverse species groupings. DOE recognizes that some of its activities have the potential to affect migratory birds (e.g., transmission lines, power poles, invasive weed-control, and various construction and deconstruction activities). To lessen the adverse effects on migratory birds, whenever appropriate and feasible, DOE components currently:

1. Use bird-friendly transmission lines, insulators, and power poles designed to minimize bird collisions and electrocutions, as suggested by the Avian Power Line Interaction Committee (APLIC).

2. Sponsor workshops with Federal and private entities on minimizing electrocutions of birds and bird collisions with electric utility structures.

3. Collaborate with public and private entities on research related to the conservation of migratory birds and their habitats.

4. Monitor environmental cleanups and construction and deconstruction activities, and, 
when necessary and feasible, use conservation measures such as netting or noise devices to discourage migratory bird nesting or schedule such activities to avoid nesting seasons;

5. Use invasive weed management practices that pose minimal risks to migratory birds; reseed areas with appropriate native plant species to encourage migratory bird use.

6. Operate according to habitat management plans developed by DOE for various bird species such as the bald eagle, Mexican spotted owl, wood stork and southwestern willow flycatcher, and other FWS Birds of Conservation Concern.

7. Restore and enhance the habitat of migratory birds, as practicable.

Pursuant to E.O. 13423, Strengthening Federal Environmental, Energy, and Transportation Management, and E.O. 13514, Federal Leadership in Environmental, Energy, and Economic Performance, DOE components will continue to use EMSs at all DOE sites as a systematic and structured approach to identify and address the environmental consequences of operations and mission activities. In addition, DOE routinely uses the NEPA process to evaluate the potential environmental effects of proposed Federal actions such as those carried out by the renewable energy financial assistance and loan guarantee programs, including potentially significant effects to migratory birds, and to consider reasonable alternatives to those actions. Environmental Impact Statements will consider the means to mitigate adverse environmental impacts from those actions as required by $40 \mathrm{CFR} \S 1502.16$. Federal environmental laws such as the ESA, Eagle Act, and the MBTA also apply to DOE, including DOE activities involving funding of third parties. In cooperation with applicants, DOE prepares environmental review documents, consults with relevant Federal, State, local, and Tribal agencies, and oversees public involvement in the environmental review of DOE's proposed actions.

DOE has a long history of collaboration on issues related to migratory birds. For example, DOE has for many years sought to address adverse environmental effects of energy technologies through interagency collaboration and research and development activities, such as serving on the FWS's Wind Turbine Siting Guidelines Federal Advisory Committee, 
co-leading the Solar Energy Development Programmatic Environmental Impact Statement with the U.S. Department of the Interior, Bureau of Land Management, and developing monitoring, avoidance and minimization technologies through partnerships such as the Bats and Wind Energy Cooperative.

Both Parties have interests and responsibilities in the conservation and management of America's natural heritage and natural resources. The Parties agree that migratory birds are important components of biological diversity, and that their conservation and management will help to sustain ecological integrity and will serve the growing public demand for outdoor recreation, conservation education, wildlife viewing, and hunting opportunities. Further, the Parties mutually agree that it is important to: 1) conserve migratory birds and their habitats; 2) recognize that actions that may provide long-term benefits to migratory bird populations may have short-term effects on individual birds or local populations; and 3) recognize that restoration of migratory bird populations and habitats can be a long-term endeavor. It is in the interests of both Parties that potential adverse effects, direct and indirect, are assessed, and then avoided or minimized, to the extent practicable and within each Agency's authority to do so. In consideration of these premises, the Parties agree as follows.

\section{E. Responsibilities of Both Parties}

To the extent allowed by law, subject to the availability of appropriations and within Administration budgetary limits, and in accord with DOE and the FWS missions and capabilities, both Parties shall:

1. Protect, enhance, and manage habitats of migratory birds, to the extent practicable. This includes:

a. Implementing management practices that avoid or minimize adverse effects on migratory bird populations and their nesting, foraging, migration, staging or wintering habitats. Examples include:

(1)When designing new projects, ensuring that they avoid important migratory bird habitats and otherwise avoid or minimize direct and indirect effects of new projects on migratory birds and their habitats, and when practicable and appropriate, restore and 
enhance bird habitat.

(2) Instituting management practices for controlling non-native plants and animals to protect migratory birds and their habitats.

(3) Using effective techniques to minimize the risk of collisions with structures including power lines, buildings, and communication devices.

(4) Shielding night lights at facilities that might attract night-flying migrant.

(5) Constructing or utilizing engineered constraint systems to prevent migratory birds from nesting or roosting in areas of recognized hazard.

b. Working collaboratively with Federal and State agencies, Tribal Nations and other interested non-governmental entities to identify, protect, restore, enhance, monitor and manage important migratory bird areas.

c. Preventing or abating the pollution detrimental to migratory birds and their habitats.

2. Promote monitoring, research, and information exchange related to migratory bird conservation and program actions that may affect migratory birds, and provide access to information on environmental contaminants and other avian stressors that are relevant to the conservation of migratory birds. This includes:

a. As practicable and compatible with other study needs and program mandates, collaborating on warranted studies: (1) on migratory bird species that may be affected by agency actions, infrastructure, or facilities; and (2) to identify habitat conditions essential to sustain migratory bird populations.

b. Sharing inventory, monitoring, and research results with other Federal and State agencies and Tribal Nations, as appropriate, and among DOE elements, as practicable, and with national repositories such as the Avian Knowledge Network.

c. Developing partnerships with other agencies and non-Federal entities to further bird conservation, as practicable.

3. Identify and pursue training opportunities for appropriate DOE and DOE contractor employees in appropriate methods and techniques to: 1) inventory and monitor migratory 
birds; 2) assess population status of migratory birds; 3 ) assess temporal and spatial bird use within project areas; 4) evaluate effects of projects on migratory birds; and 5) develop management practices that avoid or minimize adverse effects and promote beneficial proactive approaches to migratory bird conservation.

4. Participate annually, or as appropriate, in the interagency Council for the Conservation of Migratory Birds. As identified in its charter, the duties of the Council include the following:

a. Sharing the latest resource information to assist in the conservation and management of migratory birds.

b. Developing an annual report of accomplishments and recommendations related to E.O. 13186.

c. Fostering partnerships to further the goals of E.O. 13186.

d. Selecting an annual recipient of a Presidential Migratory Bird Federal Stewardship Award for contributions to the protection of migratory birds.

5. Periodically evaluate the measures taken under this MOU, which may include those measures listed in sec. E.1.a, to protect, restore and enhance migratory birds, including avoiding or minimizing the take of migratory birds, to determine whether the most effective conservation measures are employed. These efforts will be coordinated through the FWS's Division of Migratory Birds.

6. Support efforts to promote the ecological, economic, and recreational values of migratory birds by supporting outreach and educational activities and materials, as appropriate.

\section{F. Responsibilities of the DOE}

To the extent allowed by law, subject to the availability of appropriations and within Administration budgetary limits, and in accord with the Department's missions and capabilities, the DOE shall:

1. In keeping with the MBTA and Eagle Act, and other applicable laws, engage the FWS for coordination regarding proposed actions that may have direct and indirect adverse effects 
on migratory birds or their habitats. This will typically be accomplished through DOE's continued use of the NEPA process to analyze the potential environmental effects of proposed actions, including potentially significant effects to migratory birds, and to consider reasonable alternatives to those actions including potential means to address adverse environmental effects. Environmental Impact Statements will consider the means to mitigate adverse environmental effects from those actions as required by $40 \mathrm{CFR}$ 1502.16. DOE will evaluate information provided by the FWS on specific and programmatic actions, including Federally funded energy projects, concerning the presence, effects on, and conservation of migratory birds, and consider recommendations provided by the FWS with regard to those birds in departmental decision-making. When appropriate, recipients of financial assistance will be notified to contact the FWS to discuss compliance with appropriate laws protecting migratory birds, independent of DOE's funding decision. In such instances, DOE will direct the recipients to the appropriate FWS Regional Migratory Bird Permit Office.

2. Engage the FWS for coordination prior to DOE operations and activities with significant adverse effects on migratory birds and their habitats, to initiate appropriate actions to avoid or minimize the take of migratory birds. Identification of potential impacts will be accomplished through DOE's continued use of EMS as the management framework that DOE components use at DOE sites for compliance with applicable environmental laws and regulations. This may include the establishment of programs with objectives and targets to improve the conservation of migratory birds and, where appropriate, restore and/or enhance bird habitats at each DOE site. This may also result in the development of site-specific, species-specific conservation plans that describe conservation opportunities to avoid or minimize facility- and project-related effects for migratory birds and their habitat.

3. Engage the FWS on the development and implementation of strategies to continually improve the conservation of migratory birds and their habitats in the conduct of environmental cleanup activities at DOE sites. Statutory authorities on the protection of 
migratory birds and their habitats are recognized as potential ARARs ${ }^{1}$ in project plans, developed by DOE and approved by the U.S. Environmental Protection Agency, for environmental legacy cleanup being conducted at DOE sites under the Comprehensive Environmental Response, Compensation, and Liability Act. For example, the environmental cleanup of the DOE Hanford site in Richland, Washington, includes monitoring of bird populations and habitats, as appropriate and feasible, to facilitate decisions about the need for, and effectiveness of, conservation efforts. DOE will continue to make information relevant to migratory bird conservation at its environmental cleanup sites available to the FWS.

4. Engage the FWS on the development and implementation of strategies to improve or enhance the conservation of migratory birds and their habitats at the following National Environmental Research Parks and other ecological resource preservation areas established across the DOE Complex:

- Hanford Site, Richland, WA

- Idaho National Laboratory, Idaho Falls, ID

- Fermilab, Batavia, IL

- Nevada National Security Site, near Las Vegas, NV

- Los Alamos National Laboratory, Los Alamos, NM

- Savannah River Site, Aiken, SC

- Oak Ridge Site, Oak Ridge, TN

Ecological Resource Preservation Areas have been established at:

- Brookhaven National Laboratory, Upton, NY

- Lawrence Livermore National Laboratory, Livermore, CA

- Sandia National Laboratories, Albuquerque, NM

- Sandia National Laboratories, Livermore, CA (wildlife reserve)

At these parks and preservation areas, DOE evaluates the environmental consequences of energy use and development as well as strategies to mitigate these effects. DOE may conduct research, among other activities at these DOE sites, to develop strategies for the

${ }^{1}$ Applicable or Relevant and Appropriate Requirements (ARARs) 
preservation and enhancement of habitat for migratory birds; maintenance of bird populations; restoration of populations that have been reduced or extirpated by human activities; and minimization of human impacts on native species.

5. Engage the FWS on the development and implementation of strategies to improve or enhance the conservation of migratory birds and their habitats at water impoundment structures (e.g., dams and retention ponds) at the following DOE sites:

- Savannah River Site, Aiken, SC

- Oak Ridge Site, Oak Ridge, TN

- Fermilab, Batavia, IL

6. Engage the FWS on the exchange of best available scientific information regarding current and emerging technological measures and practices to avoid or minimize adverse effects of energy technologies on migratory birds through such forums as the National Wind Coordinating Collaborative biennial Wind-Wildlife Research Meeting. Another mechanism for information sharing is the National Renewable Energy Laboratory (NREL)-administered Wind-Wildlife Impacts Literature Database (WILD), which can be found at http://www.nrel.gov/wind/wild/. WILD is a publicly available, online, searchable bibliographic database of documents, including journal articles, conference proceedings, government publications, books, utility company reports, etc., that focuses on the effects of wind energy development on wildlife. NREL also maintains an online listing of NREL-published documents and reports on avian issues available at http://www.nrel.gov/wind/avian reports.html.

7. Consider FWS recommendations and suggested practices regarding energy development to avoid or minimize direct and indirect effects on migratory birds and their habitats.

8. Advise private parties and landowners seeking to interconnect electricity generating sources to DOE owned power transmission grids, to coordinate with the servicing FWS Regional Office to determine applicable conservation requirements under the MBTA.

9. Advise the public of this MOU through a notice published in the Federal Register.

\section{G. Responsibilities of the FWS}


Unless otherwise specified, the following activities will be coordinated through the appropriate Regional Migratory Bird Programs. To the extent permitted by law and subject to the availability of appropriations and Administration budgetary limits, and to the extent that the following obligations are in accord with agency missions and capabilities, the FWS shall:

1. Work to identify special migratory bird habitats (e.g., migration corridors, stopover habitats, nesting habitats) under the stewardship of DOE.

2. Provide assistance to identify particular species and habitats that would benefit most from agency land management decisions.

3. Initiate new or provide greater support for long-term research and monitoring programs for birds on DOE and adjacent lands, as funding and appropriate opportunities allow.

4. Through the FWS Division of Migratory Birds, keep DOE informed of the latest directions in bird conservation that might affect DOE activities, lands or policies by providing information on:

a. Changes to the MBTA and its regulations and procedures, or other acts and their regulations affecting migratory birds;

b. Population trends of species that might be affected by activities on DOE lands;

c. Changes to the list of Birds of Conservation Concern;

d. Changes in, updates to, or additions to national and regional bird conservation plans (e.g., Partners in Flight bird conservation plans, United States Shorebird Conservation Plan, North American Waterbird Conservation Plan, and the North American Waterfowl Management Plan); and

e. Updated protection measures for reducing human-caused bird mortality as new information becomes available.

\section{H. Definitions}

Action - a program, activity, project, official policy (such as a rule or regulation), or formal plan directly carried out by a Federal agency. 


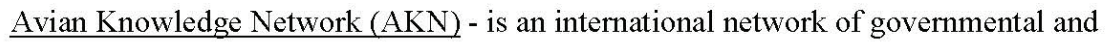
non-governmental institutions and individuals linking avian conservation, monitoring and science through efficient data management and coordinated development of useful solutions using best-science practices based on the data. With data collections covering North, Central and South America and all migratory bird flyways, AKNs collective knowledge and best practices to answer conservation information needs are growing through common data structure and collaborative problem-solving. http://www.avianknowledge.net/

Birds of Conservation Concern - published by the Fish and Wildlife Services' Division of Migratory Bird Management, refers to the list of migratory and non-migratory birds of the United States and its Territories that are of conservation concern. The most current version of the list, Birds of Conservation Concern 2008, is available at: (http://www.fws.gov/migratorybirds).

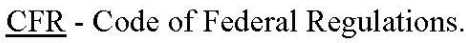

Effects - a change or changes to natural resources and the components, structures, and functioning of affected ecosystems.

Energy facilities - power generation or energy transmission infrastructure.

Incidental take - see Take.

Intentional take - see Take.

Migratory bird - an individual of any species protected by the Migratory Bird Treaty Act. A list of migratory birds can be found in $50 \mathrm{CFR} \S$

10.13: http://www.gpo.gov/fdsys/pkg/CFR-2002-title50-vol1/pdf/CFR-2002-title50-vol1-se c10-13.pdf.

North American Waterbird Conservation Plan (NAWCP) - a coalition of Federal and State government agencies, non-governmental organizations, and private interests focusing on the conservation of waterbirds, primarily marsh birds and colonial waterbirds: http://www.waterbirdconservation.org/nawcp.html.

North American Waterfowl Management Plan (NAWMP) - a coalition of Federal and State 
government agencies, non-governmental organizations, and private interests focusing on the conservation of waterfowl:

(http://www.fws.gov/birdhabitat/NAWMP/files/ImplementationFramework.pdf).

National Environmental Policy Act (NEPA) - requires Federal agencies to prepare a detailed analysis of the environmental impacts of their proposal and alternatives and to include public involvement in the decision making process for actions significantly affecting the quality of the human environment.

Partners in Flight (PIF) - a cooperative effort involving partnerships among Federal and State government agencies, non-governmental organizations, conservation groups, foundations, universities, and industry focusing on the conservation of land birds (www.partnersinflight.org).

DOE site - refers to the location where DOE or related contractors, organizations or other entities conduct operations. These include contractor-operated DOE owned or leased facilities at discrete locations across the U.S. In the case of Government Owned Government Operated (GOGO) facilities (including Power Administrations), it refers to the DOE operating organization. See site descriptions at DOE National Laboratories and Technology Centers at http://energy.gov/organization/labs-techcenters.htm and at NNSA at http:/www.nnsa.energy.gov/aboutus/ourlocations.

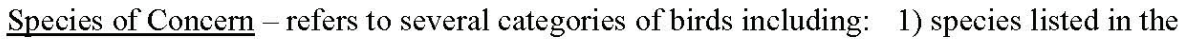
periodic report, Birds of Conservation Concern, published by the FWS Division of Migratory Bird Management (http://www.fws.gov/migratorybirds); 2) priority migratory bird species documented in the comprehensive bird conservation plans (North American Waterbird Conservation Plan, U.S. Shorebird Conservation Plan, Partners in Flight Bird Conservation Plans); 3) species or populations of waterfowl identified as high, or moderately high, continental priority in the North American Waterfowl Management Plan; 4) listed threatened and endangered bird species in $50 \mathrm{CFR} \S 17.11$; and 5) MBTA-listed gamebirds of management concern (as listed in the Birds of Management Concern list (http://www.fws.gov/migratorybirds). 
Take - to pursue, hunt, shoot, wound, kill, trap, capture or collect or attempt to pursue, hunt, wound, kill, trap, capture or collect (50 CFR $\S 10.12$ ). The Executive Order further defines "take" to include intentional take, meaning take that is the purpose of the activity in question, and unintentional (incidental) take, meaning take that results from, but is not the purpose of, the activity in question. Intentional and unintentional take constitute take as defined by the MBTA. The regulations implementing the Eagle Act define take to mean pursue, shoot, shoot at, poison, wound, kill, capture, trap, collect, destroy, molest, or disturb bald and golden eagles (50 CFR § 22.3).

$\underline{\text { Unintentional take }- \text { See Take. }}$

United States Shorebird Conservation Plan (USSCP) - an effort undertaken by a partnership of Federal and State government agencies, non-governmental organizations, and private entities to ensure stable and self-sustaining populations of all shorebird species are restored and protected (http://www.fws.gov/shorebirdplan/USShorebird.htm).

\section{Dispute Resolution}

Prevention of potential conflicts or resolutions of disagreements between the Parties will be attempted first at staff levels and elevated through the respective organizational levels if necessary. Conflict prevention or traditional Alternative Dispute Resolution processes will be used to attempt to achieve consensus.

Collaborative processes, including informal meetings or negotiations, will be used to avoid or minimize a dispute. If the dispute already has developed, more traditional processes may be appropriate, such as mediation or a negotiation assisted by a neutral third party. Notification of potential conflict or a dispute by either Party must be put in writing and attempts to resolve the matter at the Field level should occur within 30 days of the date of written notification. If there is no resolution at this level within 30 days, either Party may elevate the issue to the appropriate officials.

\section{J. Agreement}

It is mutually agreed and understood that: 
1. This MOU in no way alters or diminishes any Party's responsibilities under any statute or other legal authority.

2. Either Party may terminate this MOU, in whole or in part, at any time before the date of expiration by providing the other Party 30 day's written notice to that effect.

3. Changes to this MOU shall be made by means of written modification(s) bilaterally executed by the Parties. This instrument in no way alters a Party's obligations to conduct environmental analyses, including compliance with NEPA requirements. Modification of this MOU may be made by the issuance of a written amendment(s) signed and dated by the signatories.

4. This MOU in no way restricts either Party from participating in similar activities with other public or private agencies, governments, organizations, or individuals.

5. Documents furnished to a Party under this MOU may be subject to the Freedom of Information Act (FOIA, 5 U.S.C. § 552). A Party shall not release documents originating in the other Party to a FOIA requester. Rather, the Party shall forward such document(s) to the originating Party for review, determination, and response directly to the requester.

6. This is not a binding contract but is an MOU, which broadly states basic understandings between the Parties hereto of the tasks and methods for performing the tasks, described herein. The details of the levels of support to be furnished one organization by the other with respect to funding shall be developed in specific interagency agreements or other agreements, subject to the availability of funds. This MOU shall not be used to obligate or commit funds or as the basis for the transfer of funds. This instrument does not establish authority for noncompetitive award of any contract or other agreement. Any contract or agreement for training or other service must fully comply with all applicable requirements for competition.

7. Any press releases that reference this MOU, or the relationship established between the Parties of this MOU, shall have prior approval of both Parties.

8. Periodic meetings of the Parties shall be scheduled to review progress and identify 
opportunities for advancing the understandings in this MOU. Collaboration under this MOU shall be in accordance with the applicable statutes and regulations governing the respective Parties.

9. This MOU does not require changes to current contracts, permits or other third-party agreements. The MOU recognizes that DOE may not be able to implement some elements of the MOU until such time as DOE has successfully included them in formal planning processes.

10. This MOU is intended only to improve the internal management of the Executive Branch of the Federal Government and does not create any right or benefit, substantive or procedural, separately enforceable at law or equity by a party against the United States, its agencies or instrumentalities, its officers or employees, or any other person.

11. This MOU takes effect upon the signature of DOE and FWS and shall remain in effect for five years from the date of execution. This MOU may be extended or amended upon written request of either DOE or FWS and the subsequent written concurrence of the other Party.

12. The principal contacts for this MOU are as follows:

Josh Silverman

Director, Office of Sustainability Support Office of Health, Safety, and Security U.S. Department of Energy 1000 Independence Avenue, SW

Washington, DC 20585

Signatories:

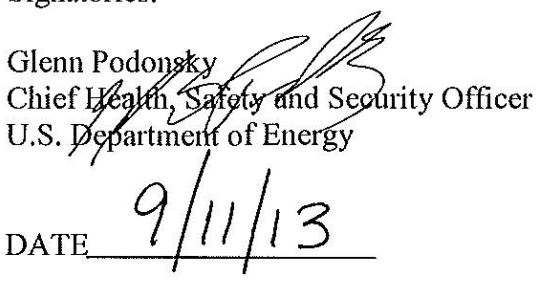

Brad Bortner

Chief, Division of Migratory Bird Management U.S. Fish and Wildlife Service U.S. Department of the Interior 4401 N. Fairfax Drive, MS 4107 Arlington, VA 22203

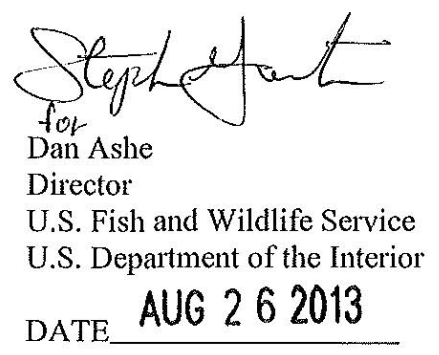


Bruce Held

Acting Administrator

National Nuclear Security Administration

U.S. Department of Energy

DATE QD WWW SEP 122013 


\section{SELECTED PORTIONS OF EXECUTIVE ORDER 13186}

Sec. 3. Federal Agency Responsibilities. (a) Each Federal agency taking actions that have, or are likely to have, a measurable negative effect on migratory bird populations is directed to develop and implement, within 2 years, a Memorandum of Understanding (MOU) with the Fish and Wildlife Service (Service) that shall promote the conservation of migratory bird populations.

(b) In coordination with affected Federal agencies, the Service shall develop a schedule for completion of the MOUs within 180 days of the date of this order. The schedule shall give priority to completing the MOUs with agencies having the most substantive impacts on migratory birds.

(c) Each MOU shall establish protocols for implementation of the MOU and for reporting accomplishments. These protocols may be incorporated into existing actions; however, the MOU shall recognize that the agency may not be able to implement some elements of the MOU until such time as the agency has successfully included them in each agency's formal planning processes (such as revision of agency land management plans, land use compatibility guidelines, integrated resource management plans, and fishery management plans), including public participation and NEPA analysis, as appropriate. This order and the MOUs to be developed by the agencies are intended to be implemented when new actions or renewal of contracts, permits, delegations, or other third party agreements are initiated as well as during the initiation of new, or revisions to, land management plans.

(d) Each MOU shall include an elevation process to resolve any dispute between the signatory agencies regarding a particular practice or activity.

(e) Pursuant to its MOU, each agency shall, to the extent permitted by law and subject to the availability of appropriations and within Administration budgetary limits, and in harmony with agency missions:

(1) support the conservation intent of the migratory bird conventions by integrating bird conservation principles, measures, and practices into agency activities and by avoiding or minimizing, to the extent practicable, adverse impacts on migratory bird resources when conducting agency actions;

(2) restore and enhance the habitat of migratory birds, as practicable;

(3) prevent or abate the pollution or detrimental alteration of the environment for the benefit of migratory birds, as practicable;

(4) design migratory bird habitat and population conservation principles, measures, and practices, into agency plans and planning processes (natural resource, land management, and environmental quality planning, including, but not limited to, forest and rangeland planning, coastal management planning, watershed planning, etc.) as practicable, and coordinate with other agencies and nonfederal partners in planning efforts;

(5) within established authorities and in conjunction with the adoption, amendment, or revision of agency management plans and guidance, ensure that agency plans and actions promote programs and recommendations of comprehensive migratory bird planning efforts such as Partners-in-Flight, U.S. National Shorebird Plan, North American Waterfowl Management Plan, North American Colonial Waterbird Plan, and other planning efforts, as well as guidance from other sources, including the Food and Agricultural Organization's International Plan of Action for Reducing Incidental Catch of Seabirds in Longline Fisheries;

(6) ensure that environmental analyses of Federal actions required by the NEPA or other established environmental review processes evaluate the effects of actions and agency plans on migratory birds, with emphasis on species of conservation/management concern;

(7) provide notice to the Service in advance of conducting an action that is intended to take migratory birds, or annually report to the Service on the number of individuals of each species of migratory birds intentionally taken during the conduct of any agency action, including but not limited to banding or marking, scientific collecting, taxidermy, and depredation control;

(8) minimize the intentional take of species of concern by: (i) delineating standards and procedures for such take; and (ii) developing procedures for the review and evaluation of take actions. With respect 
to intentional take, the MOU shall be consistent with the appropriate sections of 50 CFR. parts 10, 21, and 22;

(9) identify where unintentional take reasonably attributable to agency actions is having, or is likely to have, a measurable negative effect on migratory bird populations, focusing first on species of concern, priority habitats, and key risk factors. With respect to those actions so identified, the agency shall develop and use principles, standards, and practices that will lessen the amount of unintentional take, developing any such conservation efforts in cooperation with the Service. These principles, standards, and practices shall be regularly evaluated and revised to ensure that they are effective in lessening the detrimental effect of agency actions on migratory bird populations. The agency also shall inventory and monitor bird habitat and populations within the agency's capabilities and authorities to the extent feasible to facilitate decisions about the need for, and effectiveness of, conservation efforts;

(10) within the scope of its statutorily-designated authorities, control the import, export, and establishment in the wild of live exotic animals and plants that may be harmful to migratory bird resources;

(11) promote research and information exchange related to the conservation of migratory bird resources, including coordinated inventorying and monitoring and the collection and assessment of information on environmental contaminants and other physical or biological stressors having potential relevance to migratory bird conservation. Where such information is collected in the course of agency actions or supported through Federal financial assistance, reasonable efforts shall be made to share such information with the Service, the Biological Resources Division of the U.S. Geological Survey, and other appropriate repositories of such data (e.g., the Cornell Laboratory of Ornithology);

(12) provide training and information to appropriate employees on methods and means of avoiding or minimizing the take of migratory birds and conserving and restoring migratory bird habitat;

(13) promote migratory bird conservation in international activities and with other countries and international partners, in consultation with the Department of State, as appropriate or relevant to the agency's authorities;

(14) recognize and promote economic and recreational values of birds, as appropriate; and

(15) develop partnerships with non-Federal entities to further bird conservation.

(f) Notwithstanding the requirement to finalize an MOU within 2 years, each agency is encouraged to immediately begin implementing the conservation measures set forth above in subparagraphs (1) through (15) of this section, as appropriate and practicable. 
APPENDIX B.

SELECTED PORTIONS OF DOE ORDER 450.1, ENVIRONMENTAL PROTECTION PROGRAM, CHANGE 2 (DECEMBER 7, 2005) 



\section{SELECTED PORTIONS OF DOE ORDER 450.1, ENVIRONMENTAL PROTECTION PROGRAM, CHANGE 2 (DECEMBER 7, 2005)}

1. OBJECTIVES. To implement sound stewardship practices that are protective of the air, water, land, and other natural ... resources impacted by ... DOE operations and by which DOE cost effectively meets or exceeds compliance with applicable environmental; public health; and resource protection laws, regulations, and DOE requirements. This objective must be accomplished by implementing Environmental Management Systems (EMSs) at DOE sites. An EMS is a continuing cycle of planning, implementing, evaluating, and improving processes and actions undertaken to achieve environmental goals. These EMSs must be part of Integrated Safety Management Systems (ISMSs)....

3. APPLICABILITY.

a. DOE Elements.

(1) ..., this Order applies to all DOE elements ... that are responsible for the management and operation of the Department's facilities, including elements of the National Nuclear Security Administration and power administrations.

b. DOE Contractors.

The Contractor Requirements Document (CRD), Attachment 2, sets forth requirements of this Order that will apply to contractors responsible for the management and operation of the Department-owned facilities whose contracts include the CRD.

(1) This CRD must be included, as appropriate, in all site/facility management contracts involving activities associated with the use, storage, disposal and transportation of waste; emissions to air; discharges to water; and management of ... other natural resources.

4. REQUIREMENTS.

a. General Requirements. All DOE elements must ensure that site ISMSs include an EMS that does the following.

(1) Provides for the systematic planning, integrated execution, and evaluation of programs for-

(c) compliance with applicable environmental protection requirements.

(2) Includes policies, procedures, and training to identify activities with significant environmental impacts, to manage, control, and mitigate the impacts of these activities, and to assess performance and implement corrective actions where needed.

(3) Includes measurable environmental goals, objectives, and targets that are reviewed annually and updated when appropriate.

b. Integration of an EMS into ISMS. As part of integrating EMSs into site ISMSs, DOE elements must do the following.

(1) Consider the following for inclusion as applicable:

(d) protection of other natural resources including biota,

(e) protection of site resources from wildland and operational fires,....

(2) Promote the long-term stewardship of a site's natural ... resources throughout its operational, closure, and post-closure life cycle. 
5. RESPONSIBILITIES. All DOE elements ... are responsible for implementing the requirements specified in paragraph 4.... Specific responsibilities for implementing this Order are set forth below.

d. DOE Operations/Field/Site Office Managers, ... in coordination with their reporting sites and PSOs, must do the following.

(4) Incorporate, where appropriate, environmentally and economically beneficial landscape practices into all new landscaping programs, policies, and practices for facilities under their purview, in furtherance of compliance with Executive Order 13148.

(7) Ensure site annual budgetary processes include the funding and resources needed to implement this Order, ...

(14) Conduct environmental monitoring, as appropriate, to support the site's ISMS, to detect, characterize, and respond to releases from DOE activities; assess impacts; estimate dispersal patterns in the environment; characterize the pathways of exposure to members of the public; characterize the exposures and doses to individuals, to the population; and to evaluate the potential impacts to the biota in the vicinity of the DOE activity.

(15) Ensure the analytical work supporting environmental monitoring is implemented using-

(a) a consistent system for collecting, assessing, and documenting environmental data of known and documented quality. 


\section{SELECTED PORTIONS OF ATTACHMENT 2: CONTRACTOR REQUIREMENTS DOCUMENT TO DOE O 450.1, ENVIRONMENTAL PROTECTION PROGRAM}

Regardless of the performer of the work, contractors with this Contractor Requirements Document (CRD) incorporated into their contracts are responsible for (1) compliance with the requirements of the $\mathrm{CRD}$ and (2) flowing down the requirements of the CRD to subcontracts at any tier to the extent necessary to ensure the contractors' compliance with the requirements.

This CRD requires contractors to integrate numerous environmentally related requirements already placed on it by existing statutes, regulations, and policies through the use of an Environmental Management System (EMS) incorporated into an Integrated Safety Management System (ISMS). EMS requirements must be addressed in the contractor's ISMS ....

Contractors must:

1. General Requirements. Ensure their integrated safety management systems (ISMSs) include environmental management systems (EMSs) that do the following.

(a) Provide for the systematic planning, integrated execution, and evaluation of programs for-

(1) public health and environmental protection, ... and

(3) compliance with applicable environmental protection requirements.

(b) Include policies, procedures, and training to identify activities with significant environmental impacts, to manage, control, and mitigate the impacts of these activities, and to assess performance and implement corrective actions where needed.

(c) Include measurable environmental goals, objectives, and targets that are reviewed annually and updated when appropriate.

2. Integration of an EMS into ISMS. As part of integrating EMSs into their ISMSs, do the following.

(a) Consider the following for inclusion as applicable:

(4) protection of other natural resources including biota,

(5) protection of site resources from wildland and operational fires ...

(b) promote the long-term stewardship of a site's natural ... resources throughout its operational, closure, and post-closure life cycle; ....

(c) ensure the early identification of, and appropriate response to, potential adverse environmental impacts associated with DOE operations, including as appropriate, preoperational characterization and assessment; and effluent and surveillance monitoring.

6. Incorporate, where appropriate, environmentally and economically beneficial landscape practices into all new landscaping programs, policies, and practices for facilities. [See requirements placed on Federal agencies in Executive Order 13148, Greening the Government Through Leadership in Environmental Management.]

10. Conduct environmental monitoring, as appropriate, to support the site's ISMSs, to detect and characterize releases from DOE activities; assess impacts; estimate the dispersal patterns in the environment; characterize the pathways of exposure to members of the public; and characterize the exposures and doses to individuals, and to the population; and to evaluate the potential impacts to the biota in the vicinity of the DOE activity. 


\section{SELECTED PORTIONS OF ATTACHMENT 3: POLLUTION PREVENTION [P2] AND SUSTAINABLE ENVIRONMENTAL STEWARDSHIP GOALS TO DOE O 450.1, ENVIRONMENTAL PROTECTION PROGRAM}

1. PURPOSE.

c. To integrate pollution prevention and sustainable environmental stewardship into DOE operations as a cost-effective business practice that will:

(2) protect environmental resources,....

2. GOALS, OBJECTIVES AND STRATEGIES.

The Department herein establishes five performance-based P2 and Sustainable Environmental Stewardship goals that are to be achieved by DOE sites through the integration of P2 into environmental management systems pursuant to DOE 450.1 and its Contractor Requirements Document (CRD). The accompanying strategies for achieving the P2 and Sustainable Environmental Stewardship goals are to be considered for inclusion in sites' environmental management systems, as applicable or otherwise appropriate. DOE sites are also to consider mission performance and lifecycle costs when selecting specific strategies for achieving the P2 and Sustainable Environmental Stewardship goals.

\section{GOAL - PROTECT THE ENVIRONMENT AND ENHANCE MISSION ACCOMPLISHMENT} THROUGH REDUCTION OF ENVIRONMENTAL RELEASES

OBJECTIVE - Reduce environmental hazards, protect environmental resources, $\ldots$ by eliminating or minimizing the use of toxic chemicals and associated releases of pollutants to the environment that would otherwise require control, treatment, monitoring, and reporting.

\section{STRATEGIES-}

- $\quad$ Based on OAs, establish objectives and measurable targets in site EMSs for minimizing the use of toxic chemicals, and reducing associated releases of pollutants to the environment (air, water, soil, biota).

GOAL - PROTECT THE ENVIRONMENT AND ENHANCE MISSION ACCOMPLISHMENT THROUGH INCORPORATION OF ENVIRONMENTAL STEWARDSHIP IN PROGRAM PLANNING AND OPERATIONAL DESIGN

OBJECTIVE — Reduce environmental hazards, conserve environmental ... resources, ... by incorporating sustainable environmental stewardship in the commissioning of site operations and facilities.

\section{STRATEGIES-}

- Establish sustainable environmental stewardship objectives and measurable targets in site environmental management systems (EMSs).

- Green Landscaping

- Implement cost-effective, sustainable landscape design and management practices to reduce adverse impact to the natural environment and native ecological systems.

- Identify resources needed to implement this sustainable environmental stewardship goal and site-specific objectives and targets in site annual budgetary processes. 
APPENDIX C.

OUTLINE OF SELECTED PARTS OF THE TENNESSEE

LAWS RELATED TO WILDLIFE 



\section{TENNESSEE CODE ANNOTATED}

Title 70, Wildlife Resources

Chapter 4, "Miscellaneous Regulations"

Part 1-Hunting and Fishing

70-4-101. Ownership and title to wildlife vested in the state.

70-4-102. Illegal taking, possession or destruction of wildlife-Penalty for violations.

70-4-103. Fox hunting-Training of hunting dogs-Penalty.

70-4-104. Catching or killing fish-Fishing regulations.

70-4-105. Lawful possession of wildlife by legal license holders.

70-4-106. Permission of owner of land to take wildlife or big game required-Penalty for violations.

70-4-107. Hunting and fishing seasons-Bag and creel limits-Nonprotected wildlife.

70-4-108. Hunting from or across public road or near dwelling-Penalty.

70-4-109. Hunting from aircraft, watercraft or motor vehicles unlawful-Penalty-Exception for persons confined to wheelchairs.

70-4-110. Spotlighting deer-Penalty.

70-4-111. Hunting or killing any big game during closed season-Penalty.

70-4-112. Hunting and chasing coons regulated-Training season-Violations-Penalties.

70-4-113. Use of bait, pitfalls and certain other devices in taking birds and animals prohibitedPenalty-Exceptions.

70-4-114. Destruction of dens or nests-Spotlighting-Use of spears, explosives, chemicals or other devices unlawful-Penalty.

70-4-115. Destruction and disposal of wildlife-Permit-Penalty.

70-4-116. Hunting, killing and possession of deer, bear, wild elk, wild boar and wild turkeyTransporting-Tagging-Penalties.

70-4-117. Possession of weapons in areas inhabited by big game-Penalty.

70-4-118. Unlawful to hunt deer being chased by dogs or to permit dogs to hunt or chase deerConfiscation of dogs-Penalties.

70-4-119. Taking of aquatic animal life other than game fish-Possession of commercial fishing gear on contaminated waters-Use of explosives, electrical devices or poisons in taking fish-Penalties.

70-4-120. Trapping, snaring or baiting regulations-Penalties for violations-Snare traps-Use of tamed quail to train bird dogs.

70-4-121. United States fish and wildlife service exempt from game laws.

70-4-122. Coon dog training.

70-4-123. Hunting with bow and arrow while in possession of firearms or accompanied by a person in possession of firearms-Penalty. 
70-4-124. Wearing daylight fluorescent orange color while hunting big game required-Penalty.

70-4-125. Causing death to wildlife, hunting dog or domestic animal by poisonous substance prohibited.

70-4-126. Use of electronic or battery operated device to lure or kill a fox prohibited-Penalty.

70-4-127. Dove-baiting prohibited.

70-4-128. Posting notice of dove-baiting.

70-4-129. Sale of fish and wildlife by charitable organizations.

70-4-130. Albino deer.

Part 2-Wildlife Regulation and Protection.

70-4-201. Possession of or traffic in protected wildlife illegal-Exception-Penalty.

70-4-202. Use or possession of wildlife, hides or parts thereof illegally taken unlawful.

70-4-203. Transportation of protected game or fish out of the state-Duty of transporters-Penalty.

70-4-204. Cold storage of wildlife-Penalty for violations.

70-4-205. Use of state-controlled water areas and land bordering thereon.

70-4-206. Pollution of waters-Penalty for violations-Nuisance.

70-4-207. Defacing and destroying notice of commission or agency-Penalty.

70-4-208. Unlawful importation of skunks-Penalty.

70-4-209. Purchase or sale of red fox hides, furs or pelts.

70-4-210. Deer hides-Squirrel pelts and tails.

70-4-211. Nets and other fishing equipment near mouth of watercourse-Penalty.

Chapter 8, "Species Protection and Conservation"

Part 1-Nongame and Endangered Species.

70-8-101. Short title.

70-8-102. Declaration of policy.

70-8-103. Part definitions.

70-8-104. Nongame species-Promulgation of regulations-Prohibited acts.

70-8-105. Endangered or threatened species list.

70-8-106. Management programs-Exceptions to regulations.

70-8-107. Rulemaking authority.

70-8-108. Penalties for violations-Searches and seizures-Forfeitures.

70-8-109. Construction of provisions-Importation from other states.

70-8-110. Funding-Donations.

70-8-111. Authorization to enter agreements.

70-8-112. Species similar to endangered species. 
Part 3-Rare Plant Protection and Conservation.

70-8-301. Short title.

70-8-302. Legislative findings.

70-8-303. Part definitions.

70-8-304. Powers of commissioner.

70-8-305. List of endangered species.

70-8-306. Licensing and regulation of nursery farmers.

70-8-307. Right of access for inspections.

70-8-308. Public works projects.

70-8-309. Violations.

70-8-310. Penalties.

70-8-311. Enforcement of provisions-Injunctions.

70-8-312. Powers of commissioner.

70-8-313. Rules and regulations.

70-8-314. Limitations on implementing provisions. 

APPENDIX D.

VERTEBRATE WILDLIFE SPECIES OF THE OAK RIDGE RESERVATION 

Amphibians of the Oak Ridge Reservation ${ }^{a, b}$

\begin{tabular}{|c|c|c|}
\hline Family & Scientific name & Common name \\
\hline \multicolumn{3}{|c|}{ ORDER: Caudata } \\
\hline \multirow[t]{3}{*}{ Ambystomatidae } & Ambystoma maculatum & Spotted salamander \\
\hline & Ambystoma opacum & Marbled salamander \\
\hline & Ambystoma tigrinum tigrinum & Eastern tiger salamander \\
\hline Cryptobranchidae & Cryptobranchus alleganiensis & Hellbender \\
\hline \multirow[t]{12}{*}{ Plethodontidae } & Aneides aeneus & Green salamander \\
\hline & Desmognathus conanti/fuscus & dusky salamander \\
\hline & Eurycea cirrigera & Southern two-lined salamander \\
\hline & Eurycea longicauda & Long-tailed salamander \\
\hline & Eurycea lucifuga & Cave salamander \\
\hline & Gyrinophilus porphyriticus & Spring salamander \\
\hline & Hemidactylium scutatum & Four-toed salamander ${ }^{c}$ \\
\hline & Plethodon cinereus & Eastern red-backed salamander \\
\hline & Plethodon glutinosus & Northern slimy salamander \\
\hline & Plethodon ventralis & Southern zigzag salamander \\
\hline & Pseudotriton montanus & Mud salamander \\
\hline & Pseudotriton ruber ruber & Northern red salamander \\
\hline Salamandridae & Notophthalmus viridescens & Eastern newt \\
\hline
\end{tabular}

ORDER: Anura

\begin{tabular}{lll}
\hline Bufonidae & Bufo americanus americanus & Eastern American toad \\
& Bufo fowleri & Fowler's toad \\
Hylidae & Acris crepitans crepitans & Eastern cricket frog, northern cricket frog \\
& Hyla versicolor & Gray treefrog \\
& Hyla chrysoscelis & Cope's gray treefrog \\
& Pseudacris crucifer crucifer & Northern spring peeper \\
& Pseudacris feriarum feriarum & Upland chorus frog \\
Microhylidae & Gastrophryne carolinensis & Eastern narrow-mouthed toad \\
Ranidae & Lithobates catesbeiana & American bullfrog, bullfrog \\
& Lithobates clamitans melanota & Green frog, northern green frog \\
& Lithobates palustris & Pickerel frog \\
& Lithobates pipiens & Northern leopard frog \\
& Lithobates sphenocephalus & Southern leopard frog \\
Lithobates sylvaticus & Wood frog \\
Scaphiopodidae & Scaphiopus holbrookii & Eastern spadefoot \\
\hline
\end{tabular}

${ }^{a}$ Updated November 2011.

${ }^{b}$ Taxonomic source: Integrated Taxonomic Information System, http://www.itis.gov.

${ }^{c}$ Deemed by the state of Tennessee as In Need of Management. 
Reptiles of the Oak Ridge Reservation ${ }^{a, b}$

\begin{tabular}{|c|c|c|}
\hline Family & Scientific name & Common name \\
\hline \multicolumn{3}{|c|}{ ORDER: Testudines } \\
\hline Chelydridae & Chelydra serpentina serpentina & Common snapping turtle \\
\hline \multirow[t]{8}{*}{ Emydidae } & Chrysemys picta & Painted turtle \\
\hline & Graptemys geographica & Common map turtle \\
\hline & Graptemys ouachitensis & Ouachita map turtle \\
\hline & Graptemys pseudogeographica & False map turtle \\
\hline & Pseudemys concinna concinna & Eastern river cooter \\
\hline & Terrapene carolina carolina & Eastern box turtle \\
\hline & Trachemys scripta elegans & Red-eared slider \\
\hline & Trachemys scripta troostii & Cumberland slider \\
\hline \multirow[t]{2}{*}{ Kinosternidae } & Sternotherus minor minor & Loggerhead musk turtle \\
\hline & Sternotherus odoratus & Common musk turtle \\
\hline Trionychidae & Apalone spinifera spinifera & Eastern spiny softshell turtle \\
\hline \multicolumn{3}{|c|}{ ORDER: Squamata } \\
\hline Anguidae & Ophisaurus attenuatus longicaudus & Eastern slender glass lizard \\
\hline \multirow[t]{18}{*}{ Colubridae } & Carphophis amoenus amoenus & Eastern worm snake \\
\hline & Cemophora coccinea copei & Northern scarletsnake \\
\hline & Coluber constrictor & Racer \\
\hline & Diadophis punctatus edwardsii & Northern ring-necked snake \\
\hline & Heterodon platirhinos & Eastern hog-nosed snake \\
\hline & Lampropeltis calligaster rhombomaculata & Mole kingsnake \\
\hline & Lampropeltis getula nigra & Black kingsnake \\
\hline & Lampropeltis triangulum triangulum & Eastern milksnake \\
\hline & Nerodia sipedon & Northern watersnake \\
\hline & Opheodrys aestivus & Rough greensnake \\
\hline & Pituophis melanoleucus melanoleucus & Northern pinesnake \\
\hline & Pantherophis guttatus guttatus & Cornsnake \\
\hline & Pantherophis spiloides & Eastern ratsnake \\
\hline & Regina septemvittata & Queensnake \\
\hline & Storeria dekayi & Dekay's brownsnake \\
\hline & Storeria occipitomaculata & Red-bellied snake \\
\hline & Thamnophis sirtalis sirtalis & Common garter snake \\
\hline & Virginia valeriae valeriae & Eastern smooth earth snake \\
\hline Phrynosomatidae & Sceloporus undulatus & Eastern fence lizard \\
\hline \multirow[t]{4}{*}{ Scincidae } & Plestiodon fasciatus & Five-lined skink \\
\hline & Plestiodon inexpectatus & Southeastern five-lined skink \\
\hline & Plestiodon laticeps & Broadhead skink \\
\hline & Scincella lateralis & Ground skink, little brown skink \\
\hline Teiidae & Aspidoscelis sexlineatus & Six-lined racerunner \\
\hline Viperidae & Agkistrodon contortrix & Eastern copperhead \\
\hline
\end{tabular}

${ }^{a}$ Updated October 2019.

${ }^{b}$ Taxonomic source: Integrated Taxonomic Information System, http://www.itis.gov. 
Mammals of the Oak Ridge Reservation (revised October 2019)

\begin{tabular}{|c|c|c|c|}
\hline Family & Common name & Scientific name & Status \\
\hline \multicolumn{4}{|c|}{ ORDER: Artiodactyla } \\
\hline \multirow[t]{2}{*}{ Cervidae } & Elk & Cervus canadensis & Transient \\
\hline & White-tailed deer & Odocoileus virginianus & Resident \\
\hline Suidae & Feral hog & Sus scrofa & Introduced \\
\hline \multicolumn{4}{|c|}{ ORDER: Carnivora } \\
\hline \multirow[t]{6}{*}{ Canidae } & Coyote & Canis latrans & Resident \\
\hline & Red fox & Vulpes vulpes & Resident \\
\hline & Gray fox & Urocyon cinereoargenteus & Resident \\
\hline & Mink & Mustela vison & Resident \\
\hline & Northern river otter & Lontra canadensis & Resident \\
\hline & Opossum & Didelphis virginiana & Resident \\
\hline Felidae & Bobcat & Lynx rufus & Resident \\
\hline Mephitidae & Striped skunk & Mephitis mephitis & Resident \\
\hline Mustelidae & Long-tailed weasel & Mustela frenata & Resident \\
\hline Procyonidae & Raccoon & Procyon lotor & Resident \\
\hline Ursidae & Black bear & Ursus americana & Transient \\
\hline \multicolumn{4}{|c|}{ ORDER: Chiroptera } \\
\hline Molossidae & Brazilian free-tailed bat & Tadarida aegyptiaca & Acoustic records \\
\hline \multirow[t]{12}{*}{ Vespertilionidae } & Rafinesque's big-eared bat ${ }^{a}$ & Corynorhinus rafinesquii & Acoustic records \\
\hline & Big brown bat & Eptesicus fuscus & Resident \\
\hline & Silver-haired bat & Lasionycteris noctivagans & Resident \\
\hline & Eastern red bat & Lasiurus borealis & Resident \\
\hline & Seminole bat & Lasiurus seminolus & Transient \\
\hline & Gray bat ${ }^{b}$ & Myotis grisescens & Resident \\
\hline & Eastern small-footed bat ${ }^{a}$ & Myotis leibii & Acoustic records \\
\hline & Little brown bat ${ }^{c}$ & Myotis lucifugus & Resident \\
\hline & Northern long-eared bat ${ }^{d}$ & Myotis septentrionalis & Resident \\
\hline & Indiana $\mathrm{bat}^{b}$ & Myotis sodalis & Resident \\
\hline & Evening bat & Nycticeius humeralis & Resident \\
\hline & Tri-colored bat ${ }^{c}$ & Perimyotis subflavus & Resident \\
\hline \multicolumn{4}{|c|}{ ORDER: Cingulata } \\
\hline Dasypodidae & Nine-banded armadillo & Dasypus novemcinctus & Possible resident $^{e}$ \\
\hline \multicolumn{4}{|c|}{ ORDER: Eulipotyphla } \\
\hline \multirow[t]{6}{*}{ Soricidae } & Northern short-tailed shrew & Blarina brevicauda & Resident \\
\hline & Least shrew & Cryptotis parva & Resident \\
\hline & Southeastern shrew ${ }^{a}$ & Sorex longirostris & Resident \\
\hline & Smoky shrew ${ }^{a}$ & Sorex fumeus & Historical records ${ }^{f}$ \\
\hline & Rock (long-tailed) shrew ${ }^{a}$ & Sorex dispar & Historical records ${ }^{f}$ \\
\hline & Masked shrew & Sorex cinereus & Resident \\
\hline Talpidae & Eastern mole & Scalopus aquaticus & Resident \\
\hline \multicolumn{4}{|c|}{ ORDER: Lagomorpha } \\
\hline Leporidae & Eastern cottontail & Sylvilagus floridanus & Resident \\
\hline \multicolumn{4}{|c|}{ ORDER: Rodentia } \\
\hline Castoridae & Beaver & Castor canadensis & Resident \\
\hline Cricetidae & Eastern harvest mouse & Reithrodontomys humulis & Resident \\
\hline & White-footed mouse & Peromyscus leucopus & Resident \\
\hline
\end{tabular}


Mammals of the Oak Ridge Reservation (revised October 2019) (continued)

\begin{tabular}{|c|c|c|c|}
\hline Family & Common name & Scientific name & Status \\
\hline \multicolumn{4}{|c|}{ ORDER: Rodentia (continued) } \\
\hline & Golden mouse & Peromyscus nuttalli & Resident \\
\hline & Deer mouse & Peromyscus maniculatus & Resident \\
\hline & Southern bog lemming ${ }^{a}$ & Synaptomys cooperi & Historical records ${ }^{f}$ \\
\hline & Marsh rice rat & Oryzomys palustris & Resident \\
\hline & Hispid cotton rat & Sigmodon hispidus & Resident \\
\hline & Woodland vole & Pitymys pinetorum & Resident \\
\hline & Meadow vole & Microtus pennsylvanicus & Resident \\
\hline & Muskrat & Ondatra zibethicus & Resident \\
\hline Dipodidae & Meadow jumping mouse & Zapus hudsonius & Resident \\
\hline \multirow[t]{2}{*}{ Muridae } & Norway rat & Rattus norvegicus & Resident \\
\hline & House mouse & Mus musculus & Resident \\
\hline \multirow[t]{4}{*}{ Sciuridae } & Eastern chipmunk & Tamias striatus & Resident \\
\hline & Groundhog & Marmota monax & Resident \\
\hline & Eastern gray squirrel & Sciurus carolinensis & Resident \\
\hline & Southern flying squirrel & Glaucomys volans & Resident \\
\hline Zapodinae & Woodland jumping mouse & Napaeozapus insignis & Historical records $f$ \\
\hline
\end{tabular}

${ }^{a}$ State-deemed In Need of Management.

${ }^{b}$ Federally Endangered.

${ }^{c}$ State-deemed Threatened.

${ }^{d}$ Federally Threatened.

${ }^{e}$ First recorded in 2019.

$f_{\text {Last recorded in } 1958 .}$ 
Birds of the Oak Ridge Reservation ${ }^{a}$

\begin{tabular}{|c|c|c|c|}
\hline Common name & Scientific name & Presence & Status $^{b}$ \\
\hline \multicolumn{4}{|l|}{ Loons } \\
\hline Common loon & Gavia immer & Winter & \\
\hline \multicolumn{4}{|l|}{ Grebes } \\
\hline Pied-billed grebe & Podilymbus podiceps & Casual visitor & \\
\hline Horned grebe & Podiceps auritus & Winter & \\
\hline Eared grebe & Podiceps nigricollis & Transient & \\
\hline \multicolumn{4}{|l|}{ Pelicans } \\
\hline American white pelican & Pelecanus erythrorhynchos & Transient & \\
\hline \multicolumn{4}{|l|}{ Cormorants } \\
\hline Double-crested cormorant & Phalacrocorax auritus & Casual visitor & \\
\hline \multicolumn{4}{|l|}{ Darters } \\
\hline Anhinga & Anhinga anhinga & Transient & NM \\
\hline \multicolumn{4}{|l|}{ Bitterns \& herons } \\
\hline Great blue heron & Ardea herodias & Breeder & \\
\hline Great egret & Ardea alba & Casual visitor & NM \\
\hline Snowy egret & Egretta thula & Migrant & NM \\
\hline Little blue heron & Egretta caerulea & Casual visitor & NM \\
\hline Green heron & Butorides virescens & Breeder & \\
\hline Black-crowned night-heron & Nycticorax nycticorax & Breeder & NM \\
\hline Least bittern & Ixobrychus exilis & Casual visitor & NM \\
\hline White ibis & Eudocemus albus & Casual visitor & \\
\hline \multicolumn{4}{|l|}{ Swans, geese, \& ducks } \\
\hline Mute swan & Cygnus olor & Casual visitor & \\
\hline Canada goose & Branta canadensis & Breeder & $\mathrm{MC}, \mathrm{OA}$ \\
\hline Cackling goose & & & $\mathrm{MC}$ \\
\hline Ross's goose & Chen rossii & Migrant & $\mathrm{MC}$ \\
\hline Snow goose & Chen caerulescens & Migrant & $\mathrm{MC}$ \\
\hline Greater white-fronted goose & Anser albifrons & Migrant & $\mathrm{MC}$ \\
\hline Wood duck & Aix sponsa & Breeder & $\mathrm{MC}$ \\
\hline Green-winged teal & Anas crecca & Winter & $\mathrm{MC}$ \\
\hline American black duck & Anas rubripes & Winter & $\mathrm{MC}$ \\
\hline Mallard & Anas platyrhynchos & Breeder & $\mathrm{MC}$ \\
\hline Northern pintail & Anas acuta & Winter & $\mathrm{MC}$ \\
\hline Blue-winged teal & Anas discors & Winter & $\mathrm{MC}$ \\
\hline Gadwall & Anas strepera & Winter & \\
\hline American wigeon & Anas americana & Winter & $\mathrm{MC}$ \\
\hline Northern shoveler & Anas clypeata & Winter & $\mathrm{MC}$ \\
\hline Canvasback & Aythya valisineria & Winter & $\mathrm{MC}$ \\
\hline Redhead & Aythya americana & Winter & $\mathrm{MC}$ \\
\hline Ring-necked duck & Aythya collaris & Winter & $\mathrm{MC}$ \\
\hline Greater scaup & Aythya marila & Winter & $\mathrm{MC}$ \\
\hline Lesser scaup & Aythya affinis & Winter & $\mathrm{MC}$ \\
\hline Bufflehead & Bucephala clangula & Winter & \\
\hline Hooded merganser & Lophodytes cucullatus & Winter & \\
\hline Red-breasted merganser & Mergus serrator & Winter & \\
\hline
\end{tabular}


Birds of the Oak Ridge Reservation ${ }^{a}$ (continued)

\begin{tabular}{|c|c|c|c|}
\hline Common name & Scientific name & Presence & Status $^{b}$ \\
\hline Common merganser & Mergus merganser & Winter & \\
\hline Ruddy duck & Oxyura jamaicensus & Winter & \\
\hline \multicolumn{4}{|l|}{ Vultures } \\
\hline Black vulture & Coragyps atratus & Breeder & \\
\hline Turkey vulture & Cathartes aura & Breeder & \\
\hline \multicolumn{4}{|l|}{ Kites, hawks, eagles, \& allies } \\
\hline Osprey & Pandion haliaetus & Breeder & \\
\hline Bald eagle & Haliaeetus leucocephalus & Breeder & \\
\hline Northern harrier & Circus cyaneus & Winter & \\
\hline Sharp-shinned hawk & Accipiter striatus & Possible breeder & \\
\hline Cooper's hawk & Accipiter cooperii & Possible breeder & \\
\hline Red-shouldered hawk & Buteo lineatus & Breeder & \\
\hline Red-tailed hawk & Buteo jamaicensis & Breeder & \\
\hline Broad-winged hawk & Buteo platypterus & Breeder & RI \\
\hline \multicolumn{4}{|l|}{ Falcons } \\
\hline American kestrel & Falco sparverius & Breeder & $\mathrm{MC}$ \\
\hline Peregrine falcon & Falco peregrinus & Migrant & SE, RI \\
\hline \multicolumn{4}{|l|}{ Grouse, turkey \& quail } \\
\hline Ruffed grouse & Bonasa umbellus & Casual visitor & RI \\
\hline Wild turkey & Meleagris gallopavo & Breeder & \\
\hline Northern bobwhite & Colinus virginianus & Breeder & RI \\
\hline \multicolumn{4}{|l|}{ Rails, gallinules, \& coots } \\
\hline Sora & Porzana carolina & Migrant & $\mathrm{MC}$ \\
\hline American coot & Fulica americana & Casual visitor & \\
\hline Common moorhen & Gallinula chloropus & Migrant & \\
\hline Purple Gallinule & Porphyrio martinica & Casual visitor & \\
\hline \multicolumn{4}{|l|}{ Cranes } \\
\hline Sandhill crane & Grus canadensis & Migrant & \\
\hline \multicolumn{4}{|l|}{ Storks } \\
\hline Woodstork & Mycteria americana & Casual visitor & $\mathrm{MC}, \mathrm{ST}$ \\
\hline \multicolumn{4}{|l|}{ Plovers } \\
\hline Killdeer & Charadrius vociferus & Breeder & \\
\hline Semipalmated plover & Charadrius semipalmatus & Migrant & \\
\hline \multicolumn{4}{|l|}{ Sandpipers \& allies } \\
\hline Greater yellowlegs & Tringa melanoleuca & Migrant & \\
\hline Lesser yellowlegs & Tringa flavipes & Migrant & \\
\hline Solitary sandpiper & Tringa solitaria & Migrant & \\
\hline Spotted sandpiper & Actitus macularius & Casual visitor & \\
\hline Pectoral sandpiper & Calidris melanotos & Migrant & \\
\hline White-rumped sandpiper & Calidris fuscicollis & Migrant & \\
\hline Least sandpiper & Calidris minutilla & Migrant & \\
\hline Wilson's snipe & Gallinago delicata & Winter & $\mathrm{MC}$ \\
\hline American woodcock & Scolopax minor & Breeder & $\mathrm{MC}$ \\
\hline \multicolumn{4}{|l|}{ Gulls \& terns } \\
\hline Bonaparte's gull & Larus philadelphia & Winter & \\
\hline Ring-billed gull & Larus delawarensis & Winter & \\
\hline
\end{tabular}


Birds of the Oak Ridge Reservation ${ }^{a}$ (continued)

\begin{tabular}{|c|c|c|c|}
\hline Common name & Scientific name & Presence & Status $^{b}$ \\
\hline Caspian tern & Sterna caspia & Transient & \\
\hline Forster's tern & Sterna forsteri & Transient & \\
\hline \multicolumn{4}{|l|}{ Pigeons \& doves } \\
\hline Rock pigeon & Columba livia & Breeder & \\
\hline Mourning dove & Zenaida macroura & Breeder & $\mathrm{MC}$ \\
\hline \multicolumn{4}{|l|}{ Cuckoos } \\
\hline Yellow-billed cuckoo & Coccyzus americanus & Breeder & \\
\hline \multicolumn{4}{|l|}{ Owls } \\
\hline Northern saw-whet owl & Aegolius acadicus & Transient & MC, ST, RI \\
\hline Eastern screech-owl & Megascops asio & Breeder & \\
\hline Great horned owl & Bubo virginianus & Breeder & \\
\hline Barred owl & Strix varia & Breeder & \\
\hline Barn owl & Tyto alba & Breeder & \\
\hline \multicolumn{4}{|l|}{ Goatsuckers } \\
\hline Common nighthawk & Chordeiles minor & Breeder & \\
\hline Chuck-will's-widow & Caprimulgus carolinensis & Breeder & RI \\
\hline Whip-poor-will & Caprimulgus vociferus & Breeder & RI \\
\hline \multicolumn{4}{|l|}{ Swifts } \\
\hline Chimney swift & Chaetura pelagica & Breeder & RI \\
\hline \multicolumn{4}{|l|}{ Hummingbirds } \\
\hline Ruby-throated hummingbird & Archilochus colubris & Breeder & \\
\hline \multicolumn{4}{|l|}{ Kingfishers } \\
\hline Belted kingfisher & Megaceryle alcyon & Breeder & RI \\
\hline \multicolumn{4}{|l|}{ Woodpeckers } \\
\hline Red-bellied woodpecker & Melanerpes carolinus & Breeder & \\
\hline Red-headed woodpecker & Melanerpes erythrocephalus & Breeder & MC, RI \\
\hline Yellow-bellied sapsucker & Sphyrapicus varius & Winter & MC \\
\hline Downy woodpecker & Picoides pubescens & Breeder & RI \\
\hline Hairy woodpecker & Picoides vollosus & Breeder & \\
\hline Northern flicker & Colaptes auratus & Breeder & RI \\
\hline Pileated woodpecker & Dryocopus pileatus & Breeder & \\
\hline \multicolumn{4}{|l|}{ Tyrant flycatchers } \\
\hline Olive-sided flycatcher & Contopus cooperi & Migrant & MC, RI \\
\hline Eastern wood-pewee & Contopus virens & Breeder & RI \\
\hline Acadian flycatcher & Empidonax virescens & Breeder & RI \\
\hline Willow flycatcher & Empidonax trailii & Breeder & MC, RI \\
\hline Eastern phoebe & Sayornis phoebe & Breeder & \\
\hline Great crested flycatcher & Myiarchus crinitus & Breeder & \\
\hline Eastern kingbird & Tyrannus tyrannus & Breeder & \\
\hline Western kingbird & Tyrannus verticalis & Transient & \\
\hline \multicolumn{4}{|l|}{ Larks } \\
\hline Horned lark & Eremophila alpestris & Casua & \\
\hline
\end{tabular}


Birds of the Oak Ridge Reservation ${ }^{a}$ (continued)

\begin{tabular}{|c|c|c|c|}
\hline Common name & Scientific name & Presence & Status $^{b}$ \\
\hline \multicolumn{4}{|l|}{ Swallows } \\
\hline Purple martin & Progne subis & Breeder & \multirow[t]{6}{*}{ RI } \\
\hline Tree swallow & Tachycineta bicolor & Breeder & \\
\hline Northern rough-winged swallow & Stelgidopteryx serripennis & Breeder & \\
\hline Cliff swallow & Petrochelidon fulva & Breeder & \\
\hline Barn swallow & Hirundo rustica & Breeder & \\
\hline Bank swallow & Petrochelidon pyrrhonota & Migrant & \\
\hline \multicolumn{4}{|l|}{ Jays \& crows } \\
\hline Blue jay & Cyannocitta cristata & Breeder & \\
\hline American crow & Corvus brachyrhynchos & Breeder & \\
\hline \multicolumn{4}{|l|}{ Titmice \& chickadees } \\
\hline Carolina chickadee & Poecile carolinensis & Breeder & \multirow[t]{2}{*}{ RI } \\
\hline Tufted titmouse & Baeolophus bicolor & Breeder & \\
\hline \multicolumn{4}{|l|}{ Nuthatches } \\
\hline Red-breasted nuthatch & Sitta canadensis & Winter & \multirow[b]{3}{*}{$\mathrm{MC}, \mathrm{RI}$} \\
\hline White-breasted nuthatch & Sitta carolinensis & Breeder & \\
\hline Brown-headed nuthatch & Sitta pusilla & Breeder & \\
\hline \multicolumn{4}{|l|}{ Creepers } \\
\hline Brown creeper & Certhia americana & Winter & \\
\hline \multicolumn{4}{|l|}{ Wrens } \\
\hline Carolina wren & Thryothorus ludovicianus & Breeder & \\
\hline House wren & Troglodytes aedon & Breeder & \\
\hline Winter wren & Troglodytes troglodytes & Winter & \\
\hline Sedge wren & Cistothorus platensis & Migrant & \\
\hline Marsh wren & Cistothorus palustris & Migrant & \\
\hline \multicolumn{4}{|l|}{ Kinglets, gnatcatchers, \& thrushes } \\
\hline Golden-crowned kinglet & Regulus satrapa & Winter & \multirow{10}{*}{$\begin{array}{l}\mathrm{FS}, \mathrm{MC}, \mathrm{RI}, \\
\mathrm{NM}\end{array}$} \\
\hline Ruby-crowned kinglet & Regulus calendula & Winter & \\
\hline Blue-gray gnatcatcher & Polioptila caerulea & Breeder & \\
\hline Eastern bluebird & Siala sialis & Breeder & \\
\hline Veery & Catharus fuscescens & Migrant & \\
\hline Swainson's thrush & Catharus ustulatus & Migrant & \\
\hline Hermit thrush & Catharus guttatus & Winter & \\
\hline Wood thrush & Hylocichla mustelina & Breeder & \\
\hline American robin & Turdus migratorius & Breeder & \\
\hline Varied thrush & Ixoreus naevius & Transient & \\
\hline \multicolumn{4}{|l|}{ Pipits \& wagtails } \\
\hline American pipit & Anthus rubescens & Migrant & \\
\hline \multicolumn{4}{|l|}{ Thrashers \& mockingbirds } \\
\hline Gray catbird & Dumetella carolinensis & Breeder & \\
\hline Northern mockingbird & Mimus polyglottos & Breeder & \\
\hline Brown thrasher & Toxostoma rufum & Breeder & RI \\
\hline
\end{tabular}


Birds of the Oak Ridge Reservation ${ }^{a}$ (continued)

\begin{tabular}{|c|c|c|c|}
\hline Common name & Scientific name & Presence & Status $^{b}$ \\
\hline \multicolumn{4}{|l|}{ Waxwings } \\
\hline Cedar waxwing & Bombycilla cedrorum & Breeder & \\
\hline \multicolumn{4}{|l|}{ Shrikes } \\
\hline Loggerhead shrike & Lanius ludovicianus & Transient & $\begin{array}{l}\mathrm{FS}, \mathrm{MC}, \mathrm{NM} \text {, } \\
\text { RI }\end{array}$ \\
\hline \multicolumn{4}{|l|}{ Starlings } \\
\hline European starling & Sturnus vulgaris & Breeder & \\
\hline \multicolumn{4}{|l|}{ Vireos } \\
\hline White-eyed vireo & Vireo griseus & Breeder & \\
\hline Blue-headed vireo & Vireo solitarius & Migrant & \\
\hline Yellow-throated vireo & Vireo flavifrons & Breeder & RI \\
\hline Red-eyed vireo & Vireo olivaceus & Breeder & \\
\hline Warbling vireo & Vireo gilvus & Casual visitor & \\
\hline \multicolumn{4}{|l|}{ Wood warblers } \\
\hline Blue-winged warbler & Vermivora pinus & Breeder & MC, RI \\
\hline Golden-winged warbler & Vermivora chrysotera & Migrant & $\mathrm{MC}, \mathrm{ST}, \mathrm{RI}$ \\
\hline Tennessee warbler & Oreothlypis peregrina & Migrant & \\
\hline Nashville warbler & Oreothlypis ruficapilla & Migrant & \\
\hline Northern parula & Setophaga americana & Breeder & \\
\hline Yellow warbler & Setophaga petechia & Breeder & \\
\hline Chestnut-sided warbler & Setophaga pensylvanica & Migrant & \\
\hline Magnolia warbler & Setophaga magnolia & Migrant & \\
\hline Cape may warbler & Setophaga tigrina & Migrant & \\
\hline Black-throated blue warbler & Setophaga caerulescens & Migrant & \\
\hline Yellow-rumped warbler & Setophaga coronata & Winter & \\
\hline Black-throated green warbler & Setophaga virens & Possible breeder & \\
\hline Blackburnian warbler & Setophaga fusca & Migrant & RI \\
\hline Yellow-throated warbler & Setophaga dominica & Breeder & RI \\
\hline Pine warbler & Setophaga pinus & Breeder & \\
\hline Prairie warbler & Setophaga discolor & Breeder & MC, RI \\
\hline Palm warbler & Setophaga palmarum & Migrant & \\
\hline Bay-breasted warbler & Setophaga castanea & Migrant & \\
\hline Blackpoll warbler & Setophaga striata & Migrant & \\
\hline Cerulean warbler & Setophaga cerulea & Possible breeder & $\begin{array}{l}\mathrm{FS}, \mathrm{MC}, \mathrm{NM} \text {, } \\
\text { RI }\end{array}$ \\
\hline Black-and-white warbler & Mniotilta varia & Possible breeder & RI \\
\hline American redstart & Setophaga ruticilla & Possible breeder & \\
\hline Prothonotary warbler & Protonotaria citrea & Breeder & MC \\
\hline Worm-eating warbler & Helmitheros vermivorus & Breeder & MC, RI \\
\hline Ovenbird & Seiurus aurocapillus & Breeder & \\
\hline Swainson's warbler & Limnothlypis swainsonii & Casual visitor & $\mathrm{MC}, \mathrm{NM}, \mathrm{RI}$ \\
\hline Northern waterthrush & Parkesia novaboracensus & Migrant & \\
\hline Louisiana waterthrush & Parkesia motacilla & Possible breeder & $\mathrm{MC}, \mathrm{RI}$ \\
\hline Kentucky warbler & Geothlypis formosus & Breeder & MC, RI \\
\hline Common yellowthroat & Geothlypis trichas & Breeder & \\
\hline
\end{tabular}


Birds of the Oak Ridge Reservation ${ }^{a}$ (continued)

\begin{tabular}{|c|c|c|c|}
\hline Common name & Scientific name & Presence & Status $^{b}$ \\
\hline Hooded warbler & Setophaga citrina & Breeder & RI \\
\hline Wilson's warbler & Cardellina pusilla & Migrant & \\
\hline Canada warbler & Cardellina canadensis & Migrant & RI \\
\hline Yellow-breasted chat & Icteria virens & Breeder & RI \\
\hline \multicolumn{4}{|l|}{ Tanagers } \\
\hline Summer tanager & Piranga rubra & Breeder & RI \\
\hline Scarlet tanager & Piranga olivacea & Breeder & RI \\
\hline \multicolumn{4}{|l|}{ Cardinals, grosbeaks, $\&$ allies } \\
\hline Northern cardinal & Cardinalis cardinalis & Breeder & \\
\hline Rose-breasted grosbeak & Pheucticus ludovicianus & Migrant & \\
\hline Blue grosbeak & Passerina caerulea & Breeder & \\
\hline Indigo bunting & Passerina cyanea & Breeder & RI \\
\hline Dickcissel & Spiza americana & Casual visitor & $\mathrm{MC}$ \\
\hline \multicolumn{4}{|l|}{ Towhees, sparrows, \& allies } \\
\hline Eastern towhee & Pipilo erythrophthalmus & Breeder & RI \\
\hline American tree sparrow & Spizella arborea & Winter & \\
\hline Chipping sparrow & Spizella passerina & Breeder & \\
\hline Field sparrow & Spizella pusilla & Breeder & RI \\
\hline Savannah sparrow & Passerculus sandwichensis & Migrant + winter & \\
\hline Grasshopper sparrow & Ammodramus savannarum & Breeder & RI \\
\hline Henslow's sparrow & Ammodramus henslowii & Casual visitor & FS, MC, ST, RI \\
\hline Fox sparrow & Passerella iliaca & Winter & \\
\hline Song sparrow & Melospiza melodia & Breeder & \\
\hline Swamp sparrow & Melospiza georgiana & Winter & \\
\hline White-throated sparrow & Zonotrichia albicollis & Winter & \\
\hline White-crowned sparrow & Zonotrichia leucophrys & Migrant & \\
\hline Vesper sparrow & Pooecetes gramineus & Migrant & \\
\hline Dark-eyed junco & Junco hyemalis & Winter & \\
\hline \multicolumn{4}{|l|}{ Blackbirds \& allies } \\
\hline Bobolink & Dolichonyx oryzivorus & Migrant & \\
\hline Red-winged blackbird & Agelaius phoeniceus & Breeder & \\
\hline Rusty blackbird & Euphagus carolinus & Winter & FS, MC \\
\hline Eastern meadowlark & Sturnella magna & Breeder & RI \\
\hline Common grackle & Quiscalus quiscula & Breeder & \\
\hline Brown-headed cowbird & Molothrus ater & Breeder & \\
\hline Orchard oriole & Icterus spurius & Breeder & \\
\hline Baltimore oriole & Icterus galbula & Breeder & \\
\hline \multicolumn{4}{|l|}{ Finches } \\
\hline Purple finch & Carpodacus purpureus & Winter & \\
\hline House finch & Carpodacus mexicanus & Breeder & \\
\hline Pine siskin & Carduelis pinus & Migrant & \\
\hline American goldfinch & Carduelis tristis & Breeder & \\
\hline Evening grosbeak & Coccothraustes vespertinus & Migrant & \\
\hline
\end{tabular}


Birds of the Oak Ridge Reservation ${ }^{a}$ (continued)

\begin{tabular}{|c|c|c|c|}
\hline Common name & Scientific name & Presence & Status $^{b}$ \\
\hline Old World sparrows & & & \\
\hline House sparrow & Passer domesticus & Breeder & \\
\hline
\end{tabular}

${ }^{a}$ Updated September 2018.

${ }^{b}$ Status:

$\mathrm{MC}=$ Federally listed as Of Management Concern

$\mathrm{NM}=$ Deemed by the state of Tennessee as In Need of Management

$\mathrm{RI}=$ Partners-in-Flight-designated birds of Regional Importance

$\mathrm{SE}=$ State Endangered

$\mathrm{ST}=$ State Threatened

FT $=$ Federally Threatened

$\mathrm{OA}=$ Federally listed as overly abundant

$\mathrm{FS}=$ Federally listed as a focal species 

APPENDIX E.

DEFINITION OF WILDLIFE MANAGEMENT 

The "Tennessee Nongame and Endangered or Threatened Wildlife Species Conservation Act of 1974" (Title 70, Wildlife Resources, Chap. 8, "Species Protection and Conservation, Part 1-Nongame and Endangered Species," Tennessee Code Annotated) defines "management" as "the collection and application of biological information for the purposes of increasing the number of individuals within species and populations of wildlife up to the optimum carrying capacity of their habitat and maintaining such levels. The term includes the entire range of activities that constitute a modern scientific resource program including, but not limited to, research, census, law enforcement, habitat acquisition and improvement, and education. Also included within the term, when and where appropriate, is the periodic or total protection of species or populations as well as regulated taking."

Historically, at least through the 1960s, wildlife management was production oriented. That is, land management was directed toward a goal of producing the highest yield of game species for recreational harvesting. In the southeastern United States, these species were usually northern bobwhite, wild turkey, and white-tailed deer. Wildlife management and research in the 1970s grew rapidly and diversified. The Endangered Species Act of 1973 was indicative of public concern and an appreciation for nongame animals in general, and as a result, most state wildlife agencies embarked on nongame research programs that supplemented more traditional efforts toward the maintenance and expansion of game species.

Songbird and small mammal species were studied in a variety of forest types, and the community became the unit of study, with diversity being the major indicator of habitat quality (Landers and Johnson 1980). Habitat analysis was conducted at all levels of resolution. Microscale habitat data were used to determine the physical characteristics of forests that influenced the structure of avian communities, and the same techniques were applied to small mammal communities.

Wildlife management in its present form ranges from single-species management to management of communities consisting of many species to management of ecoregions, each consisting of many different communities distributed over a region. In state wildlife agencies, there is a trend to expend more effort on nongame species, mostly in response to public demands for greater equity of management for game and nongame species on public lands. The demand for greater nongame research has also resulted in a tendency to depart from single-species management. The large number of nongame species has caused nongame management to focus on the community and bioregion levels. Responsible agencies are searching for management techniques that will maximize the diversity of nongame communities and benefit as many game species as possible. Nevertheless, single-species management remains important to game species and to those species that are rare and/or endangered.

\section{REFERENCES}

Landers, J. L., and A. S. Johnson. 1980. “Trends in wildlife habitat research.” In Proceedings, Annual Conference of the Southeastern Association of Fish \& Wildlife Agencies. Wildlife Resources Agency, Nashville, TN. 



\section{APPENDIX F.}

WILDLIFE MANAGEMENT ACTIVITIES FISCAL YEAR 1983 THROUGH FISCAL YEAR 2019 

Wildlife studies on the Oak Ridge Reservation (ORR) have been aimed toward a better understanding of the ecological relationships of a species with habitat, information on population sizes and health, baseline data, and impacts of various activities. These studies have been done through the Facilities and Operations Directorate and the Environmental Sciences Division (ESD) in coordination with the Tennessee Wildlife Resources Agency (TWRA). Wildlife-related projects over the last three decades have included those related to the following:

- White-tailed deer

- Statistics on deer/vehicle collisions (Muller et al. 2014)

- Aging techniques to determine the structure of the population (Tennessee Tech graduate student project) (Mitchell 1989)

- Hunt data for sex, age, location killed, liver, bone, radioactivity levels, chronic wasting disease, Lyme disease (ticks), and abosomal parasite counts

- Wild turkey

- Reintroduction of turkeys to ORR

- Radio-tracking to determine habitat preferences (with University of Tennessee researcher)

- Recording of poult sightings and deaths

- Trapping and removal for reintroduction at other Tennessee sites

- Nongame species

- Radio-tracking of coyote

- Coyote history, abundance, and distribution

- Comparison of songbirds in different pine plantations (Hardy 1991)

- Ecology of gray foxes (Greenberg, Pelton, and Parr 1988)

- Bat surveys (Harvey 1997; Harvey and Britzke 2003; Harvey and Britzke 2004; Harvey 2006)

- Partners-in-Flight bird surveys

- Small mammal surveys (Giffen, Reasor, and Campbell 2011)

- Reptile and amphibian surveys (Giffen, Reasor, and Campbell 2009)

- Remediation-effects-related research

- Turtles, fish, and benthos invertebrates

- Contaminant-transport-related research

- Deer (Garten and Lomax 1987)

- Waterfowl

\section{SUMMARY OF MANAGEMENT ACTIVITIES: FY 1983 TO FY 2019}

Specific projects to be implemented during the period from fiscal year (FY) 1983 to FY 1987 were summarized in the 1984 Wildlife Management Plan (Kitchings and Story 1984). Many of these activities were initiated, but others were not because of changes in program priorities. The following summary highlights the activities and notable accomplishments of the wildlife program from FY 1983 to FY 2019. (The FY begins October 1st and continues through September 30th.)

\section{FY 1983}

- Evaluation of wildlife management needs and development of plan for ORR

\section{FY 1984}

- Publication of original wildlife management plan for ORR 


\section{FY 1985}

- Cooperative agreement between US Department of Energy (DOE) and TWRA designating ORR as a Wildlife Management Area (WMA) (November 30, 1984)

- Location of TWRA Wildlife Manager on-site

- Mast surveys done for ORR (data used in regional statistics)

- Removal of geese from contaminated ponds

FY 1986

- Initiation of public deer hunting (winter 1985)

- Release of first wild turkeys on ORR

- Study of deer-age structure on ORR from hunt data by Tennessee Tech student

- Mast surveys on ORR

FY 1987

- Second release of wild turkeys on ORR

- Initiation of turkey radio-tracking for habitat-preference information

- Placement of wood-duck nesting boxes on ORR

- Work with ESD on study identifying sources of contamination for deer

- Continuation of mast surveys

- Continuation of study on deer-age structure from hunt data

- Annual public deer hunt (first effect of hunts reflected in lower deer/vehicle collision data for year)

FY 1988

- $\quad$ Radio-tracking of turkeys released in 1987

- Placement of wood-duck nesting boxes on ORR

- Establishment of osprey nesting platforms

- Studies of waterfowl contamination/transport

- Canada goose roundup and banding for identification

- Annual mast survey on ORR

- Annual public deer hunt

- Trapping and removal of wild turkeys to stock other eastern Tennessee areas

FY 1989

- Establishment of additional osprey nesting platforms

- Placement of wood-duck nesting boxes on ORR

- Continuation of waterfowl contamination study

- Canada goose roundup with banding and collaring

- Annual mast survey

- Annual public deer hunt

- Implementation of plans to keep waterfowl off contaminated ponds

- Trapping and removal of wild turkeys to stock other areas in eastern Tennessee

FY 1990

- Extension of cooperative agreement between DOE and TWRA for wildlife management on ORR

- Reevaluation from safety standpoint of areas on ORR open to hunters

- Banding of first osprey young on ORR

- Placement of wood-duck boxes on ORR

- Continuation of osprey restoration program

- Canada goose roundup

- Annual mast survey

- Annual public deer hunt

- Trapping and removal of wild turkeys to stock other areas in eastern Tennessee 


\section{FY 1991}

- Update of wildlife management plan

- Computerization of historical white-tailed deer information on database (20 years of data)

- Preparation of updated document on ORR deer statistics

- Annual public deer hunt

- Feasibility study for reintroduction of bald eagles on ORR

- Canada goose roundup

- Annual mast survey

- Continuation of osprey restoration program

- Trapping and removal of wild turkeys to stock other areas in East Tennessee

- Placement of additional wood-duck boxes

FY 1992

- Initiation of discussions regarding possible eagle hacking program for restoration of species on ORR

- Annual public deer hunts

- Canada goose roundup

- Annual mast survey

- Continuation of osprey restoration program

- Trapping and removal of wild turkeys to stock other areas in eastern Tennessee

- Continuation of wood-duck-habitat establishment program

- Evaluation of impacts of discontinuation of forest management program on species and habitat diversity

- Great blue heron contamination studies

FY 1993

- Continuation of bald eagle research and consideration of hacking program

- Annual public deer hunts

- Canada goose roundup

- Annual mast survey

- Continuation of osprey restoration program

- Trapping and removal of wild turkeys to stock other areas in eastern Tennessee

- Continuation of wood-duck establishment program

- Evaluation of need for selective forest management and recommendations

- Evaluation of impact of forest fragmentation on wildlife species

FY 1994

- Continuation of bald eagle research and consideration of hacking program

- Annual public deer hunts

- Canada goose roundup

- Annual mast survey

- Continuation of osprey restoration program

- Removal of wild turkeys to stock other areas in East Tennessee

- Continuation of wood-duck establishment program

- Implementation of recommendations from selective forest management study and forest fragmentation study to increase species diversity

FY 1995

- Continuation of bald eagle research and consideration of hacking program

- Annual public deer hunts

- Canada goose roundup

- Annual mast survey

- Continuation of osprey restoration program 
- Continuation of wood-duck establishment program

- Selective forest management for species diversity

FY 1996

- Annual public deer hunts

- Annual public turkey hunts

- Annual goose roundup

FY 1997

- Annual public deer hunts

- Annual public turkey hunts

- Annual goose roundup

- Surveys of bat populations using mist nets

FY 1998

- Annual public deer hunts

- Annual public turkey hunts

- Annual goose roundup

FY 1999

- Annual public deer hunts

- Annual public turkey hunts

- Annual goose roundup

FY 2000

- Annual public deer hunts

- Annual public turkey hunts

- Annual goose roundup

FY 2001

- Annual public turkey hunts

- Annual goose roundup

FY 2002

- Annual public deer hunts

- Annual goose roundup

FY 2003

- Annual public deer hunts

- Annual public turkey hunts

- Annual goose roundup

- Surveys of bat populations using mist nets and Anabat acoustical identification system

FY 2004

- Annual public deer hunts

- Annual public turkey hunts

- Annual goose roundup

- Surveys of bat populations using Anabat acoustical identification system

FY 2005

- Annual public deer hunts

- Annual public turkey hunts

- Annual goose roundup

- Relocation of 117 ORR Canada geese to Hiwassee Wildlife Refuge and Chota WMA, Tennessee

- Initiation of Canada goose egg addling/nest destruction program (60 eggs addled/oiled)

FY 2006

- Annual public deer hunts

- Annual public turkey hunts 
- Public goose hunts at Three Bend Scenic and Wildlife Management Refuge Area

- Annual goose roundup

- Relocation of 200 ORR Canada geese to Hiwassee Wildlife Refuge and Chota WMA, Tennessee

- Continuation of Canada goose egg addling/nest destruction program (67 eggs addled/oiled)

- Surveys of bat populations using Anabat acoustical identification system and mist nets

FY 2007

- Annual public deer hunts

- Annual public turkey hunts

- Public goose hunts at Three Bend Scenic and Wildlife Management Refuge Area

- Annual goose roundup

- Relocation of 203 ORR Canada geese to Hiwassee Wildlife Refuge, Kyles Ford WMA, and private land, Tennessee

- Continuation of Canada goose egg addling/nest destruction program (73 eggs addled/oiled)

- Initiation of 3-year reservation-wide reptile and amphibian study

FY 2008

- Annual public deer hunts

- Annual public turkey hunts

- Public goose hunts at Three Bend Scenic and Wildlife Management Refuge Area

- Annual goose roundup

- Relocation of 227 ORR Canada geese to Hiwassee Wildlife Refuge, Kyles Ford WMA, and private land (one hybrid), Tennessee

- Continuation of Canada goose egg addling/nest destruction program (48 eggs addled/oiled)

- Completion of second year of 3-year reservation-wide reptile and amphibian study

FY 2009

- Annual public deer hunts

- Annual public turkey hunts

- Public goose hunts at Three Bend Scenic and Wildlife Management Refuge Area

- Annual goose roundup

- Relocation of 63 ORR Canada geese to Chota WMA and private land (one hybrid), Tennessee

- Continuation of Canada goose egg addling/nest destruction program (51 eggs addled/oiled)

- Completion of third year of 3-year reservation-wide reptile and amphibian study

- Initiation of 2-year reservation-wide small mammal study

FY 2010

- Annual public deer hunts

- Annual public turkey hunts

- Public goose hunts at Three Bend Scenic and Wildlife Management Refuge Area

- Annual goose roundup

- Relocation of 46 ORR Canada geese to Nolichucky WMA, Tennessee

- Continuation of Canada goose egg addling/nest destruction program (45 eggs addled/oiled)

- Completion of second year of 2-year reservation-wide small mammal study

FY 2011

- Annual public deer hunts

- Annual public turkey hunts

- Public goose hunts at Three Bend Scenic and Wildlife Management Refuge Area

- Annual goose roundup

- Relocation of 49 ORR Canada geese to Kyles Ford WMA, Tennessee

- Continuation of Canada goose egg addling/nest destruction program (24 eggs addled/oiled)

- Anabat surveys at various locations on ORR 
- Study of grassland birds in native and nonnative grasslands

- Mapping of ORR interior forests

FY 2012

- Annual public deer hunts

- Annual public turkey hunts

- Public goose hunts at Three Bend Scenic and Wildlife Management Refuge Area

- Annual goose roundup

- Relocation of 39 ORR Canada geese to Rankin WMA, Tennessee (27 geese from Solway boat ramp area, a nearby off-site location)

- Continuation of Canada goose egg addling/nest destruction program (32 eggs addled/oiled)

- Anabat surveys at various locations on ORR

- Study of grassland birds in native and nonnative grasslands

- Mapping of ORR interior forests

FY 2013

- Annual public deer hunts

- Annual public turkey hunts

- Public goose hunts at Three Bend Scenic and Wildlife Management Refuge Area

- Annual goose roundup

- Continuation of Canada goose egg addling/nest destruction program (29 eggs addled/oiled)

- SM2BAT FS surveys of bats at various locations on ORR

- Bat mist net surveys at Freels Bend Causeway - three survey nights during summer season

\section{FY 2014}

- Annual public deer hunts

- Annual public turkey hunts

- Public goose hunts at Three Bend Scenic and Wildlife Management Refuge Area

- Annual goose roundup

- Continuation of Canada goose egg addling/nest destruction program (25 eggs addled/oiled)

- SM2BAT FS surveys of bats at various locations on ORR

FY 2015

- Annual public deer hunts

- Annual public turkey hunts

- Public goose hunts at Three Bend Scenic and Wildlife Management Refuge Area

- Annual goose roundup

- Continuation of Canada goose egg addling/nest destruction program (25 eggs addled/oiled)

- SM2BAT FS surveys of bats at various locations on ORR

FY 2016

- Annual public deer hunts

- Annual public turkey hunts

- Public goose hunts at Three Bend Scenic and Wildlife Management Refuge Area

- Annual goose roundup

- Continuation of Canada goose egg addling/nest destruction program (10 eggs removed)

- SM4BAT FS surveys of bats at various locations on ORR

FY 2017

- Annual public deer hunts

- Annual public turkey hunts

- Public goose hunts at Three Bend Scenic and Wildlife Management Refuge Area

- Annual goose roundup

- Continuation of Canada goose egg addling/nest destruction program (12 eggs removed) 
- SM4BAT FS surveys of bats at various locations on ORR

- Intensive groundhog trapping/removal on ORR (38 groundhogs removed)

- Startup of enlisting University of Tennessee wildlife students to do TWRA volunteer work at the Three Bend Scenic and Wildlife Management Refuge Area

\section{FY2018}

- Annual public deer hunts

- Annual public turkey hunts

- Public goose hunts at Three Bend Scenic and Wildlife Management Refuge Area

- Annual goose roundup

- Continuation of Canada goose egg addling/nest destruction program (6 eggs removed)

- SM4BAT FS surveys of bats at various locations on ORR

- Intensive beaver trapping/removal on the ORR (57 beavers removed)

- Continuation of University of Tennessee wildlife students doing volunteer work at the Three Bend Scenic and Wildlife Management Refuge Area

FY2019

- Annual public deer hunts

- Annual public turkey hunts

- Public goose hunts at Three Bend Scenic and Wildlife Management Refuge Area

- Annual goose roundup

- Continuation of Canada goose egg addling/nest destruction program (4 eggs removed)

- SM4BAT FS surveys of bats at various locations on ORR

- Continued beaver trapping/removal on the ORR (14 beavers removed)

- Transition to passive beaver management in select areas

- Continuation of University of Tennessee wildlife student volunteer work at the Three Bend Scenic and Wildlife Management Refuge Area

- Identification of wildlife corridors on/through the ORR via computer simulation (see cover image, by CR DeRolph)

- Amphibian and reptile surveys identified several new locations for sensitive taxa and documented one new species for the ORR (southern zigzag salamander, Plethodon ventralis)

- Cave surveys identified five sensitive taxa considered new on the ORR

- Snail surveys documented nearly 50 taxa, several new to Anderson and Roane County, and several considered rare by TDEC (e.g., Anguispira jessica)

\section{REFERENCES}

Garten, C. T., Jr., and R. D. Lomax. 1987. Strontium-90 Contamination in Vegetation from Radioactive Waste Seepage Areas at ORNL, and Theoretical Calculations of SR-90 Accumulation by Deer. ORNL/TM-10453. Oak Ridge, TN: Oak Ridge National Laboratory.

Giffen, N. R., R. S. Reasor, and C. A. Campbell. 2009. Reptile and Amphibian Abundance and Distribution Survey. ORNL/TM-2009/296. Oak Ridge, TN: Oak Ridge National Laboratory.

Giffen, N. R., R. S. Reasor, and C. A. Campbell. 2011. Small Mammal Abundance and Distribution Survey, Oak Ridge Environmental Research Park. ORNL/TM-2011/323. Oak Ridge, TN: Oak Ridge National Laboratory.

Greenberg, C. H., M. R. Pelton, and P. D. Parr. 1988. Gray Fox Ecology in the Oak Ridge National Environmental Research Park: Food Habits, Home Range and Habitat Use. ORNL/NERP-3. Oak Ridge, TN: Oak Ridge National Laboratory. 
Hardy, C. 1991. "A Comparison of Bird Communities in Loblolly vs. White Pine Plantations on the Oak Ridge National Environmental Research Park.” Thesis, University of Tennessee, Knoxville.

Harvey, M. J. 1997. Survey for Endangered and Threatened Bats on Parcel ED-1, Oak Ridge Reservation. Unpublished report to the Environmental Sciences Division, Oak Ridge National Laboratory.

Harvey M. J., and E. R. Britzke. 2003. Survey for Bats on the Oak Ridge Reservation. Unpublished report to the Environmental Sciences Division, Oak Ridge National Laboratory.

Harvey, M. J., and E. R. Britzke. 2004. Anabat Survey for Bats at Pond K1007 P1 on the Oak Ridge Reservation. Unpublished report to the Environmental Sciences Division, Oak Ridge National Laboratory.

Harvey, M. J. 2006. Mist Netting Survey of Bats at Caves on the Oak Ridge Reservation. Unpublished report to the Environmental Sciences Division, Oak Ridge National Laboratory.

Kitchings, J. T., and J. D. Story. 1984. Resource Management Plan for the Oak Ridge Reservation, Volume 16: Wildlife Management. ORNL/TM-6026. Oak Ridge, TN: Oak Ridge National Laboratory.

Mitchell, C. M. 1989. "Influence of Either-Sex Harvest on the Age and Sex Structure of White-Tailed Deer on Oak Ridge Wildlife Management Area, Tennessee.” Thesis, Tennessee Technological University, Cookeville, TN.

Muller, L. I., A. M. Hackworth, N. R. Giffen, J. W. Evans, J. Henning, G. J. Hickling, and P. Allen. 2014. "Spatial and Temporal Relationships Between Deer Harvest and Deer-Vehicle Collisions at Oak Ridge Reservation, Tennessee." Wildlife Society Bulletin 38(4): 812-820. 